\title{
MARCELA MORELLI
}

Impacto do Tipo de Dieta no Valor de Pegada Hídrica, na Eficiência de Uso de Nutrientes e no Custo de Produção de Bovinos em Confinamento

Pirassununga

2018 


\section{MARCELA MORELLI}

\section{Impacto do Tipo de Dieta no Valor de Pegada Hídrica, na Eficiência de Uso de Nutrientes e no Custo de Produção de Bovinos em Confinamento}

Tese apresentada ao Programa de Pós-Graduação em Nutrição e Produção Animal da Faculdade de Medicina Veterinária e Zootecnia da Universidade de São Paulo como pré-requisito para obtenção do Título de Doutor em Ciências.

\section{Departamento:}

Nutrição e Produção animal

Área de concentração:

Nutrição e Produção animal

Orientador:

Prof. Dr. Julio Cesar Pascale Palhares

Coorientador:

Prof. Dr. Augusto Hauber Gameiro

\section{Pirassununga}


ERRATA

MORELLI, M. Impacto do tipo de dieta no valor de pegada hídrica, na eficiência de uso de nutrientes e no custo de produção de bovinos em confinamento.

2018. 88 f. Tese (Doutorado em Ciências) - Faculdade de Medicina Veterinária e Zootecnia, Universidade de São Paulo, Pirassununga , 2018.

\section{Página}

$$
\text { Ficha }
$$

Catalográfica

RESUMO

ABSTRACT

\section{Onde se lê}

$110 \mathrm{p}$

$110 \mathrm{p}$.

$110 p$
Leia-se

$88 p$

$88 p$

$88 p$ 
Autorizo a reprodução parcial ou total desta obra, para fins acadêmicos, desde que citada a fonte.

\section{DADOS INTERNACIONAIS DE CATALOGAÇÃO NA PUBLICAÇÃO}

(Biblioteca Virginie Buff D’Ápice da Faculdade de Medicina Veterinária e Zootecnia da Universidade de São Paulo)

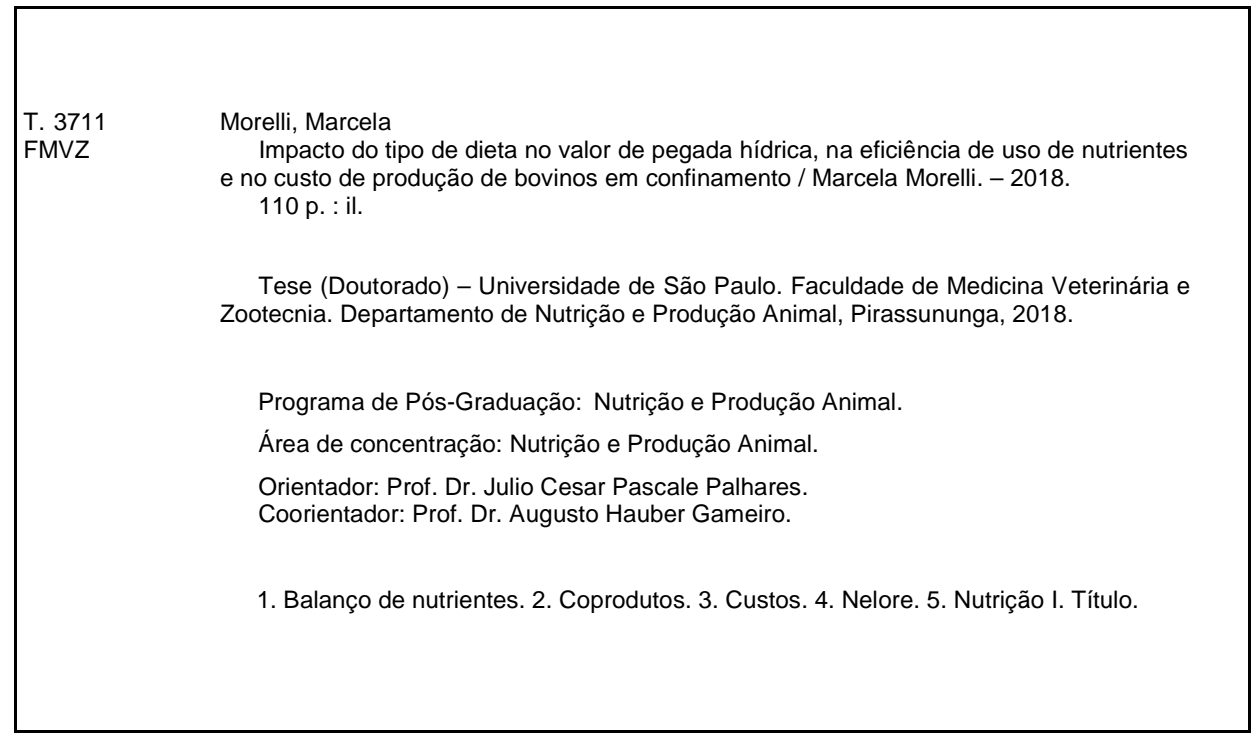

Ficha catalográfica elaborada pela bibliotecária Maria Aparecida Laet, CRB 5673-8, da FMVZ/USP. 


\section{CERTIFICADO}

Certificamos que a proposta intitulada "IMPACTO DO TIPO DE DIETA NO VALOR DA PEGADA HÍDRICA DE BOVINOS EM CONFINAMENTO", protocolada sob o CEUA no 8510190118 (ID 004451), sob a responsabilidade de Julio Cesar Pascale Palhares e equipe; Marcela Morelli - que envolve a produção, manutenção e/ou utilização de animais pertencentes ao filo Chordata, subfilo Vertebrata (exceto o homem), para fins de pesquisa científica ou ensino - está de acordo com os preceitos da Lei 11.794 de 8 de outubro de 2008, com o Decreto 6.899 de 15 de julho de 2009, bem como com as normas editadas pelo Conselho Nacional de Controle da Experimentação Animal (CONCEA), e foi aprovada pela Comissão de Ética no Uso de Animais da Faculdade de Medicina Veterinária e Zootecnia da Universidade de São Paulo (CEUA/FMVZ) na reunião de 23/01/2018.

We certify that the proposal "IMPACT OF THE TYPE OF DIET ON THE VALUE OF THE WATER FOOTPRINT OF CATTLE IN FEEDLOT", utilizing 104 Bovines (104 males), protocol number CEUA 8510190118 (ID 004451), under the responsibility of Julio Cesar Pascale Palhares and team; Marcela Morelli - which involves the production, maintenance and/or use of animals belonging to the phylum Chordata, subphylum Vertebrata (except human beings), for scientific research purposes or teaching - is in accordance with Law 11.794 of October 8, 2008, Decree 6899 of July 15, 2009, as well as with the rules issued by the National Council for Control of Animal Experimentation (CONCEA), and was approved by the Ethic Committee on Animal Use of the School of Veterinary Medicine and Animal Science (University of São Paulo) (CEUA/FMVZ) in the meeting of 01/23/2018.

Finalidade da Proposta: Pesquisa

Vigência da Proposta: de 07/2016 a 11/2016

Área: Nutrição E Produção Animal

Origem: $\quad$ Animais provenientes de outros projetos

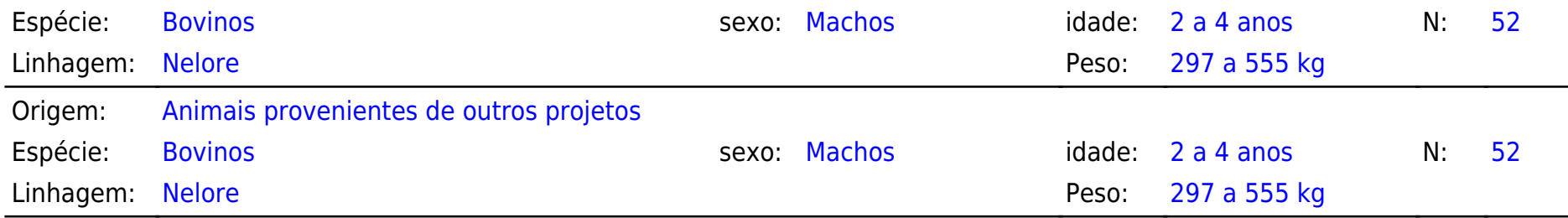

Local do experimento: A parte experimental do estudo foi conduzida no Sistema de Confinamento da Embrapa Pecuária Sudeste, localizada no município de São Carlos, Estado de São Paulo, distante 8 km do centro da cidade e 234 km da Capital do Estado, a 21 $57 \square 33.32 \square$ S $4750 \square 33,28 \square$ W, a altitude de 856 metros. O confinamento era provido de 4 baias coletivas parcialmente cobertas de $400 \mathrm{~m} 2$, equipados com dois cochos automatizados GrowSafe ${ }^{\circledR}$.

São Paulo, 10 de julho de 2018

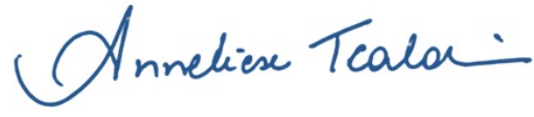

Profa. Dra. Anneliese de Souza Traldi

Presidente da Comissão de Ética no Uso de Animais

Faculdade de Medicina Veterinária e Zootecnia da Universidade de São Paulo

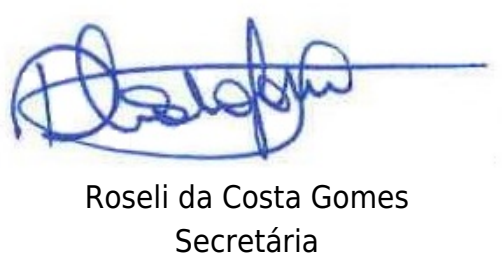

Faculdade de Medicina Veterinária e Zootecnia da Universidade de São Paulo 


\section{FOLHA DE AVALIAÇÃO}

Autor: MORELLI, Marcela

Título: Impacto do tipo de dieta no valor de pegada hídrica, na eficiência de uso de nutrientes e no custo de produção de bovinos em confinamento

Tese apresentada ao Programa de Pós-

Graduação em Nutrição e Produção Animal da Faculdade de Medicina Veterinária e Zootecnia da Universidade de São Paulo para obtenção do título de Doutor em Ciências.

Data:

1

\section{Banca Examinadora}

Prof. Dr.

Instituição: Julgamento:

Prof. Dr. Instituição: Julgamento:

Prof. Dr. Instituição: Julgamento:

Prof. Dr. Instituição: Julgamento:

Prof. Dr. Instituição: Julgamento: 
"Que comece agora e que seja permanente essa vontade de ir além daquilo que me espera."

Caio Fernando Abreu

"Quando acreditamos apaixonadamente em algo que não existe, o criamos. $O$ inexistente é algo que não desejamos suficiente".

Franz Kafka

Dedicatória

Primeiramente a Deus, aos meus pais, minha família e a todos que me apoiaram. 


\section{AGRADECIMENTOS}

Primeiramente à Deus, por permitir a realização do meu sonho.

A Faculdade de Medicina Veterinária e Zootecnia e a Embrapa Pecuária Sudeste, por fornecer suporte e infraestrutura para a realização deste trabalho.

Ao CNPq pela concessão da bolsa e recursos para este experimento (Pegada Hídrica Produtos Carne e Leite/Processo CNPq 404243/2014-3).

Ao meu orientador Dr. Julio C. Pascale Palhares, pela orientação, ensinamentos, conversas e confiança em mim depositada. Ao meu coorientador Dr. Augusto Hauber Gameiro, pela coorientação e por toda ajuda no desenvolvimento do projeto.

Aos pesquisadores da Embrapa Pecuária Sudeste, Dr. Alexandre Berndt, Dr. Waldomiro Barioni Junior, Dra. Teresa Cristina Alves, Dr. Rymer Ramiz Tullio por toda a atenção, presteza, carinho e exemplo de profissionalismo.

A todos os funcionários da Embrapa Pecuária Sudeste, em especial, ao Carlão, Egleu, Gilberto e os funcionários do setor de leite, Cidinho, Dona Leni, Juarez, Seu Paulo, Verônica e Seu Cosme por toda ajuda, amizade e dedicação. Vocês fizeram que eu me sentisse em casa.

A minha amiga/irmã do doutorado pra vida: Táisla I. Novelli (Maria) pela imensa colaboração no desenvolvimento desta pesquisa e por todos os momentos de trabalho e descontração, mesmo aos feriados, finais de semana ás 6 horas da manhã, pelos vários dias sem almoço, pelas correrias atrás de boi, pelos entendimentos dos mapas e por todo o cuidado com nosso cantinho (confinamento), sem você nada disso teria sido possível. Também pela amizade e companhia para todos os momentos.

Aos amigos da Embrapa: Paulo De Meo Filho, Leandro Sakamoto (Lê), Rafaela Vincenzi (Rafa), e todos estagiários que por ali passaram, por toda a amizade e companheirismo durante essa jornada.

Aos meus pais, Vania e José Luis e meu irmão Ariel, por abraçarem e acreditarem no meu sonho. Por me proporcionarem todo o suporte e incentivo para a realização do mesmo. Além de toda a paciência e compreensão dos momentos de ausência para os estudos. Também pelo amor incondicional, sem vocês eu jamais chegaria tão longe.

Ao meu tio Márcio, por todo apoio, atenção. Meu grande incentivador a seguir a carreira acadêmica desde meu início da graduação.

Ao meu namorado Bruno Mochiutti, pelo companheirismo e compreensão, dos finais de semana de trabalho, do cansaço de todos os dias e pelo "cheiro de boi" (haha).

E, por fim, a todos que de alguma forma ajudaram direta ou indiretamente no desenvolvimento deste trabalho. 


\section{RESUMO}

MORELLI, M. Impacto do Tipo de Dieta no Valor de Pegada Hídrica, na Eficiência de Uso de Nutrientes e no Custo de Produção de Bovinos em Confinamento. [Impact of Diet Type on Water Footprint Value, Nutrient Use Efficiency and Production Costs of Feedlot Cattle]. 2018. 110p. Tese (Doutorado em Ciências) - Faculdade de Medicina Veterinária e Zootecnia, Universidade de São Paulo, Pirassununga, 2018.

A quantidade de água consumida na produção de carne bovina influencia a visão da sociedade sobre a sustentabilidade desta produção em comparação com as outras fontes de proteína. O objetivo geral do estudo é avaliar como o tipo de dieta impacta a eficiência de uso da água e de nutrientes de bovinos em sistema de confinamento. O cálculo da pegada hídrica considerou as águas azul, verde e cinza consumidas no sistema de produção e no abate dos animais. Foram avaliados dois tipos de dietas, uma com o concentrado composto de milho e farelo de soja, e outra com a substituição total destes ingredientes por coprodutos (gérmen de milho gordo, polpa cítrica e farelo de amendoim). Não houve diferenças nas características de desempenho dos animais entre as dietas. A substituição promoveu a redução do consumo de água verde e redução nos valores de pegada hídrica total, porém aumentou os valores de água azul. A pegada hídrica total da dieta convencional foi de $2.125,54 \mathrm{~L} \mathrm{~kg}^{-1}$ carne e a da dieta com uso de coprodutos foi de $2.042,56 \mathrm{~L} \mathrm{~kg}^{-}$

${ }^{1}$ carne. A pegada hídrica verde representou $88,45 \%$ e $88,52 \%$ para a dieta convencional e com uso de coprodutos, respectivamente. $\mathrm{O}$ balanço de nutrientes da dieta convencional foi de $115,13 \mathrm{~kg}$ de $\mathrm{N}, 13,90 \mathrm{~kg}$ de $\mathrm{P}$ e 73,69 $\mathrm{kg}$ de $\mathrm{K}$ e na dieta de coprodutos foi de 234,63 $\mathrm{kg}$ de N, 29,76 kg de P e $58,62 \mathrm{~kg}$ de $\mathrm{K}$. Do ponto de vista ambiental o uso de coprodutos foi positivo, mas a análise econômica dessa intervenção nutricional se mostrou inviável aumentando os custos em 9,25\%. A utilização de alimentos alternativos na dieta de bovinos de corte confinados manteve o desempenho animal e promoveu uma melhor eficiência hídrica. Estudos que relacionam a pegada hídrica com o manejo nutricional na produção animal são importantes para gestão hídrica da produção, promovendo impactos positivos na conservação dos recursos hídricos.

Palavras-chave: Balanço de nutrientes. Coprodutos. Custos. Nelore. Nutrição 


\begin{abstract}
MORELLI, M. Impact of Diet Type on Water Footprint Value, Nutrient Use Efficiency and Production Costs of Feedlot Cattle. [Impacto do Tipo de Dieta no Valor de Pegada Hídrica, na Eficiência de Uso de Nutrientes e no Custo de Produção de Bovinos em Confinamento]. 2018. 110p. Tese (Doutorado em Ciências) - Faculdade de Medicina Veterinária e Zootecnia, Universidade de São Paulo, Pirassununga, 2018.

The amount of water consumed in beef production influences society's view on the sustainability of this production compared to other sources of protein. The overall objective of the study is to evaluate how the type of diet impacts the efficiency of water and nutrient use of cattle in a feedlot system. The calculation of the water footprint considered the blue, green and gray waters consumed in the system of production and the slaughter of the animals. Two types of diets were evaluated, one with corn and soybean meal concentrate, and the other with total substitution of these ingredients by co-products (corn germ, citrus pulp and peanut meal). There were no differences in the performance characteristics of the animals between the diets. The substitution promoted the reduction of green water consumption and reduction in the total water footprint values but increased the values of blue water. The total water footprint of the conventional diet was $2,125.54 \mathrm{~L} \mathrm{~kg}-1$ meat and that of the diet with use of co-products was $2,042.56 \mathrm{~L} \mathrm{~kg}-1$ meat. The green water footprint represented $88.45 \%$ and $88.52 \%$ for the conventional diet and with co-products, respectively. The nutrient balance of the conventional diet was $115.13 \mathrm{~kg} \mathrm{~N}, 13.90 \mathrm{~kg} \mathrm{P}$ and 73.69 $\mathrm{kg} \mathrm{K}$ and in the co-products, diet was $234.63 \mathrm{~kg} \mathrm{~N}, 29.76 \mathrm{~kg} \mathrm{P}$ and $58.62 \mathrm{~kg}$ of $\mathrm{K}$. From the environmental point of view, the use of co-products was positive, but the economic analysis of this nutritional intervention was not feasible, increasing expenses by $9.25 \%$. The use of alternative foods in the diet of confined beef cattle-maintained animal performance and promoted better water efficiency. Studies that relate the water footprint to nutritional management in animal production are important for water production management, promoting positive impacts on the conservation of water resources.
\end{abstract}

Keywords: Nutrient balance. Coproducts. Costs. Nellore. Nutrition 


\section{Lista de Figuras}

Figura 1. Representação esquemática dos componentes diretos e indiretos em cada estágio da cadeia de suprimentos de um produto de origem animal.............................. 7

Figura 2. Fases da avaliação da pegada hídrica ............................................................ 8

Figura 3. Linha do tempo dos eventos ocorridos durante o período experimental......... 21

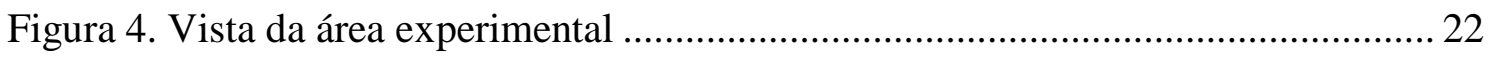




\section{Lista de Gráficos}

Gráfico 1. Rebanho bovino nos principais países em porcentagem de animais 3

Gráfico 2. Produção de carne bovina em milhões de toneladas

Gráfico 3. Temperaturas médias, máximas, mínimas $\left({ }^{0} \mathrm{C}\right)$ e precipitação $(\mathrm{mm})$ para o período experimental

Gráfico 4. Valores de pegada hídrica azul $\left(\mathrm{L} \mathrm{kg}^{-1}\right.$ carne $)$ no abatedouro de Tangará da Serra/MT nos anos de 2012,2013,2014 e 2015.... 46

Gráfico 5. Valores de pegada hídrica azul ( $\mathrm{L} \mathrm{kg}^{-1}$ carne) no abatedouro de Promissão/SP nos anos de 202,2013,2014 e 2015

Gráfico 6. Valores de pegada hídrica cinza ( $\mathrm{L} \mathrm{kg}^{-1}$ carne) nos anos de 2012,2013 e 2014 em Tangará da Serra. 


\section{Lista de Tabelas}

Tabela 1. Pegada hídrica de alguns tipos de alimentos

Tabela 2. Valores de demanda hídrica do produto carne bovina

Tabela 3. Composição bromatológica de diferentes coprodutos utilizados na alimentação de ruminantes.

Tabela 4. Impacto da cobrança pelo uso da água no setor agrícola da bacia do rio Paraíba do Sul

Tabela 5. Características produtivas e ambientais dos nove confinamentos comerciais 26

Tabela 6. Caracterização dos grupos experimentais

Tabela 7. Composição das dietas experimentais.

Tabela 8. Médias de desempenho dos animais de cada grupo experimental

Tabela 9. Ingestão de matéria seca total por tipo de ingredientes durante o período de confinamento.

Tabela 10. Valores de pegada hídrica total e por tipo de água dos grupos experimentais

Tabela 11. Consumos de água verde, teor de água nos produtos e pegada hídrica verde por tipo de dieta.

Tabela 12. Consumos de água verde total e alocada ee os fatores de alocação de coproduto utilizado FAO (2013).

Tabela 13. Consumo total de água por tipo de dieta

Tabela 14. Consumos médios de água de dessedentação de acordo com o tipo de dieta45 
Sumário

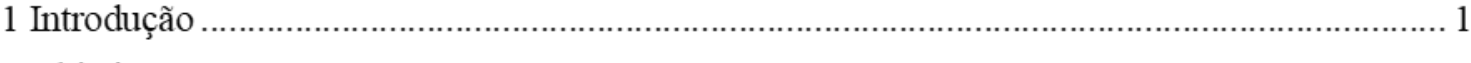

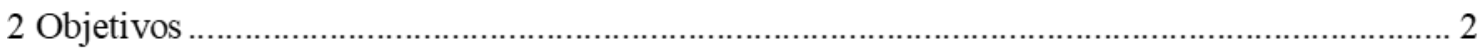

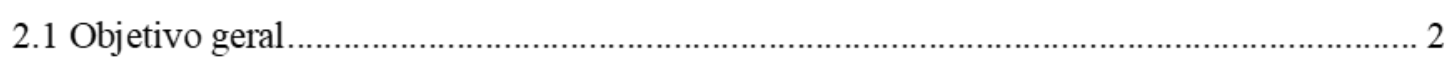

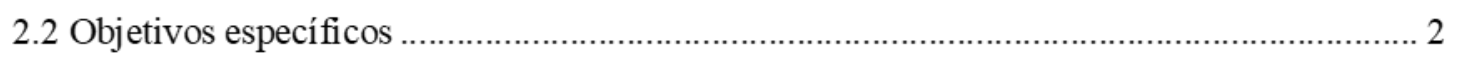

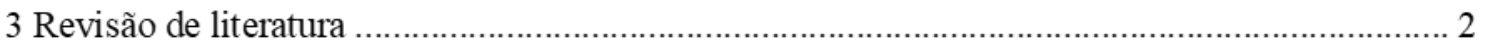

3.1 Produção de bovinos e sistemas confinados no brasil ........................................................ 3

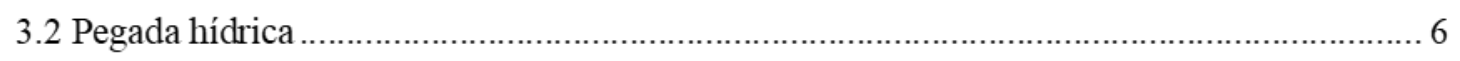

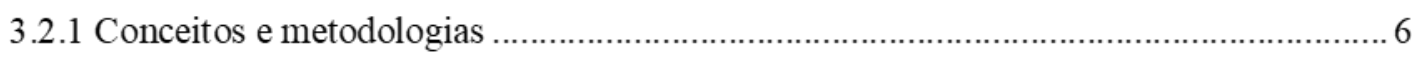

3.2.2 Cálculo da pegada hídrica na produção animal ...................................................... 8

3.3 Manejo nutricional e o uso de coprodutos .................................................................. 12

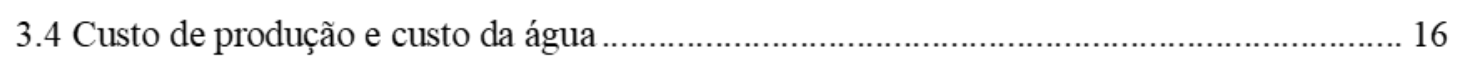

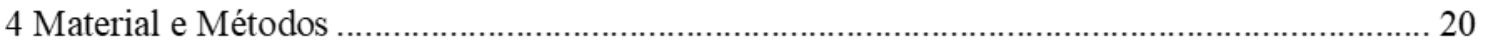

4.1 Condição experimental e caracterização dos confinamentos comerciais de gado de corte 20

4.2 Intervenções nutricionais avaliadas na fase experimental ................................................ 27

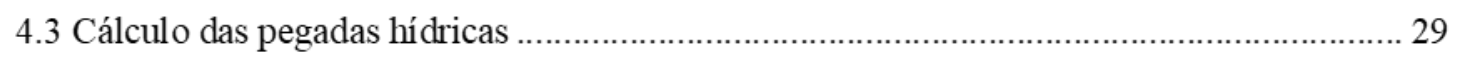

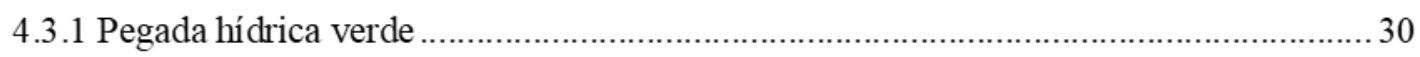

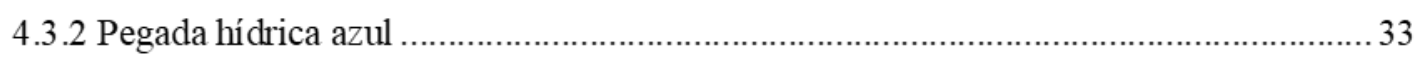

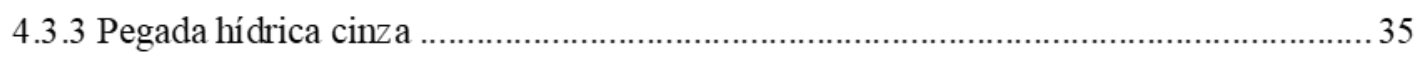

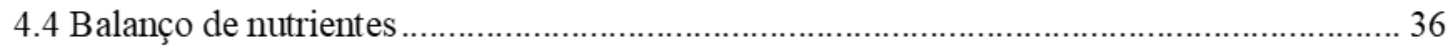

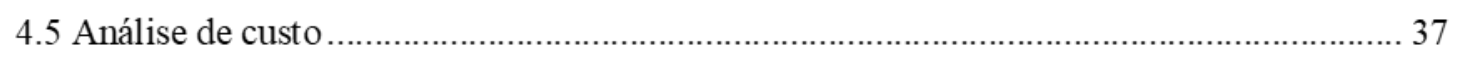

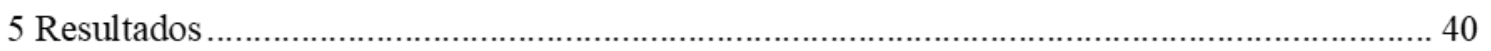

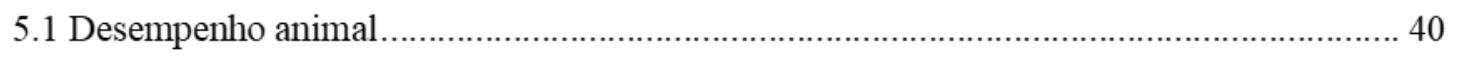

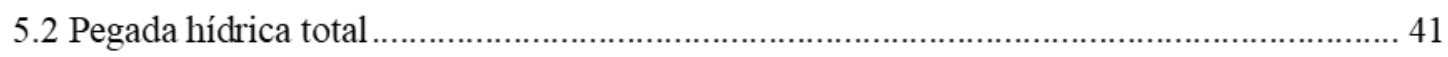

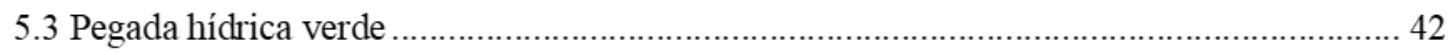

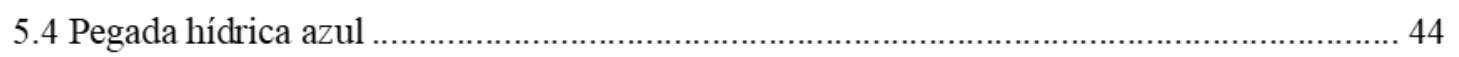

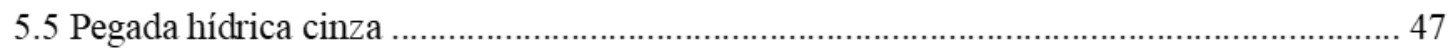

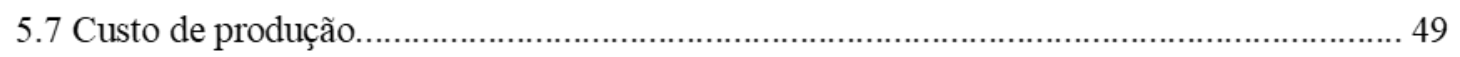

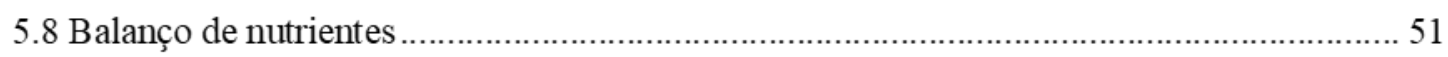

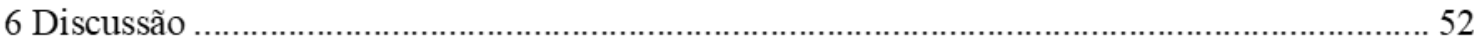

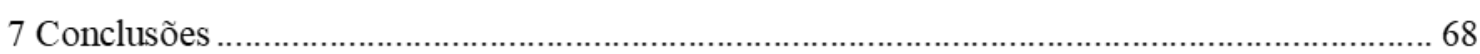

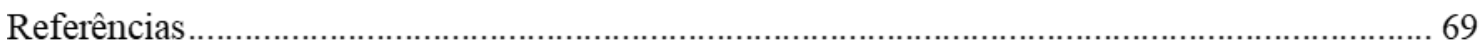

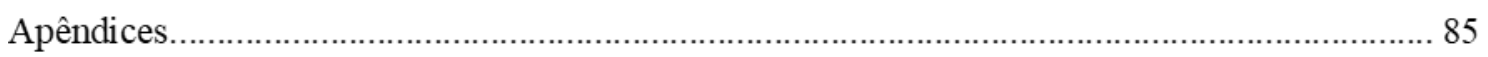




\section{INTRODUÇÃO}

Nos últimos anos, a sociedade tem considera outros requisitos além dos relacionados a qualidade, na compra dos alimentos. Produtos certificados como orgânicos, "verdes" ou produzidos considerando o bem-estar dos animais e menor impacto ambiental têm representado um mercado em expansão. A discussão sobre alimentação e sustentabilidade teve início com a questão de como será possível alimentar nove bilhões de habitantes, previstos para viver no planeta em 2050 (CONTE; BOFF, 2013) sem degradar o meio ambiente de forma irreversível. Segundo Morin (2013), o "problema da agricultura é de âmbito planetário, indissociável do problema da água, da demografia, da urbanização, de ecologia (mudanças climáticas), bem como, da alimentação".

Crises hídricas e situações de escassez de água tendem a ser cada vez mais recorrentes em diversas regiões do planeta. Nestes momentos, a produção animal é, muitas vezes, contestada pelo uso que faz da água e apontada como a grande vilã. É notório que a competição por água entre os diferentes usos e usuários será crescente. A produção de alimentos consome 86\% da água doce do planeta (GERBENS-LEENES; NOBHEBEL; KROL, 2010). A grande diversidade dos sistemas de produção animal e suas interações faz com que a análise do consumo da água pela agropecuária seja complexa e muitas vezes, contraditória (FAO, 2006). Nesse cenário, a atividade da bovinocultura de corte tem sofrido questionamentos pela sociedade devido à quantidade de água consumida na produção de carne, comparando-se essa quantidade com a consumida na produção de outras carnes e alimentos (PETERS et al., 2010).

Métodos e métricas que possuam uma visão multidisciplinar e que avaliem as demandas hídricas tornam-se alternativas para a tomada de decisão ambiental. A avaliação ambiental das atividades humanas pela abordagem metodológica de "pegadas" é crescente, sendo as pegadas ecológica, de carbono e hídrica as mais presentes nas iniciativas científicas e sociais. O cálculo da pegada hídrica pode ser visto como uma ferramenta de gestão da água dentro do sistema de produção, fornecendo informações quantitativas que possibilitam ações mitigatórias e de melhoria da eficiência de uso do recurso, além de possibilitar subsidiar o impacto socioeconômico dos mesmos na atividade e/ou na sociedade. Promover o conhecimento da utilização da água pela pecuária e desenvolver métodos padronizados para quantificação desta utilização é a melhor forma senão a única, para atingir o equilíbrio hídrico (GIRARD, 2012). 
Os resultados propostos neste estudo contribuirão para preencher uma lacuna nas ciências zootécnicas e ambientais nacional e internacional. Pois estas não dispõem de significativa quantidade de informações e conhecimentos sobre o consumo de água na produção de bovinos confinados em condições tropicais. Aliado a mensuração do consumo de água, avaliar o uso de coprodutos na alimentação animal é uma prática que contribui para conferir um uso nobre a esses coprodutos, bem como reduzir o passivo ambiental das atividades agropecuárias.

\section{OBJETIVOS}

\subsection{OBJETIVO GERAL}

O objetivo geral do estudo é avaliar como o tipo de dieta impacta a eficiência de uso da água e de nutrientes de bovinos em sistema de confinamento.

\subsection{OBJETIVOS ESPECÍFICOS}

i) Avaliar duas intervenções nutricionais quanto aos seus impactos nos valores das pegadas hídricas verde e azul;

ii) Monitorar duas unidades industriais de referência para avaliação do uso da água no processamento e beneficiamento do produto carne bovina;

iii) Calcular a pegada hídrica de nove sistemas confinados comerciais;

iv) Mensurar o custo da água no custo de produção do produto e o impacto econômico das intervenções nutricionais;

v) Avaliar a eficiência de uso pelos animais dos elementos nitrogênio, fósforo e potássio por tipo de dieta.

\section{REVISÃO DE LITERATURA}

Nesta revisão serão abordados os temas: produção de bovinos e sistemas confinados no Brasil, pegada hídrica na produção animal, relação do manejo nutricional e manejo ambiental, e custo de produção e custo da água. 


\subsection{PRODUÇÃO DE BOVINOS E SISTEMAS CONFINADOS NO BRASIL}

O rebanho mundial de bovinos de corte tem demostrado significativo crescimento, chegando ao final do ano de 2016 com 998 milhões de cabeças. Segundo o Departamento de Agricultura dos Estados Unidos (USDA/FAO, 2016) cinco países detêm mais de 80\% dos animais (Gráfico 1).

Gráfico 1. Rebanho bovino nos principais países em porcentagem de animais

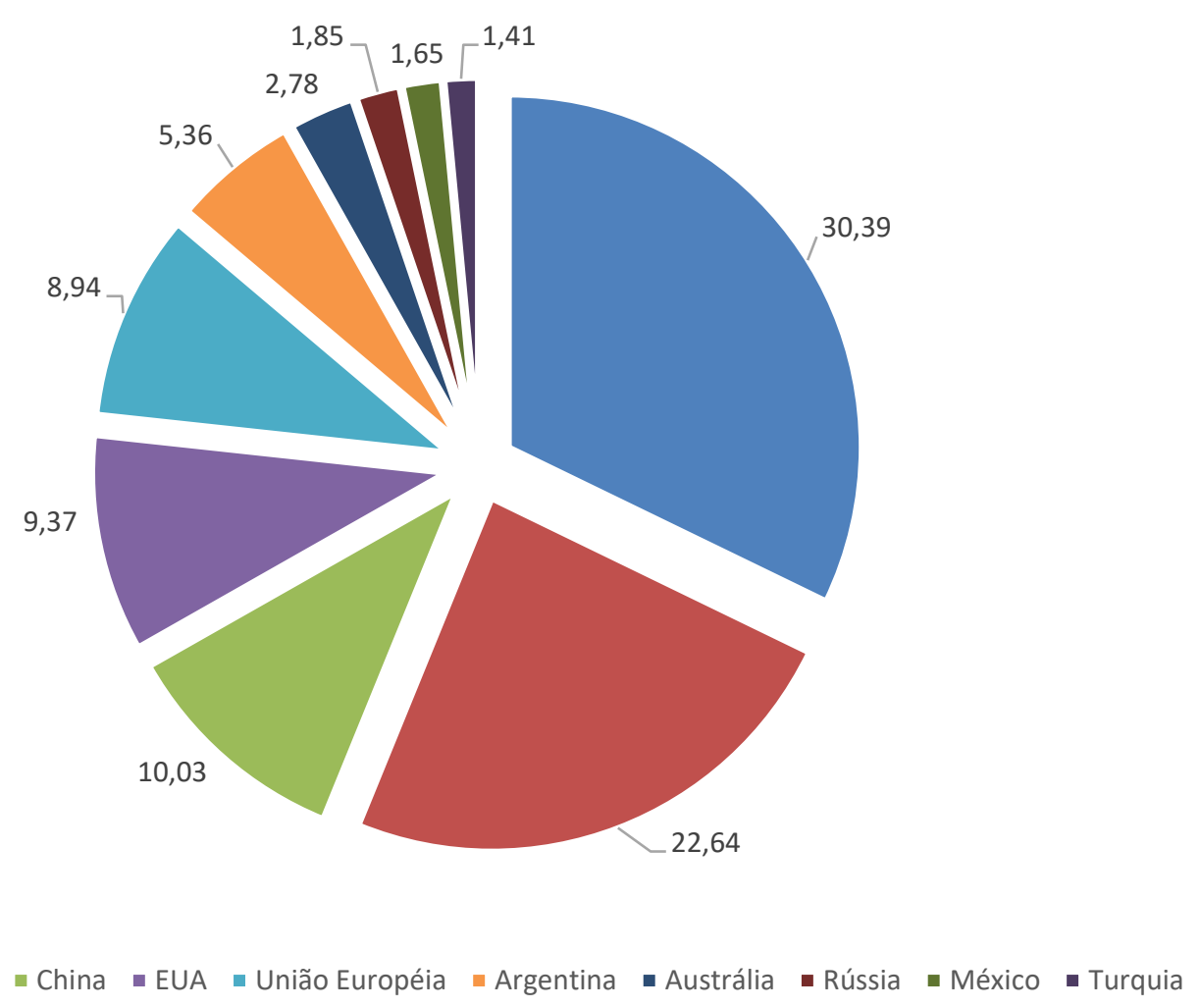

- Índia - Brasil - China - EUA - União Européia - Argentina - Austrália - Rússia - México - Turquia

Fonte: baseado em USDA/FAO (2016).

Segundo a publicação Agricultural Outlook 2016-2025 (Organização de Cooperação e de Desenvolvimento Econômico (OECD) -FAO (Organização das Nações Unidas para Alimentação e Agricultura, 2016), a produção de carnes deverá ser $16 \%$ maior em 2025. A produção de carne bovina também se projeta maior (20\%) nos países em desenvolvimento (Brasil, China, Rússia e África do Sul). O Brasil ocupa a segunda colocação no ranking mundial de produção de carne bovina, ficando atrás dos Estados Unidos da América (Gráfico 2). 
Gráfico 2. Produção de carne bovina em milhões de toneladas

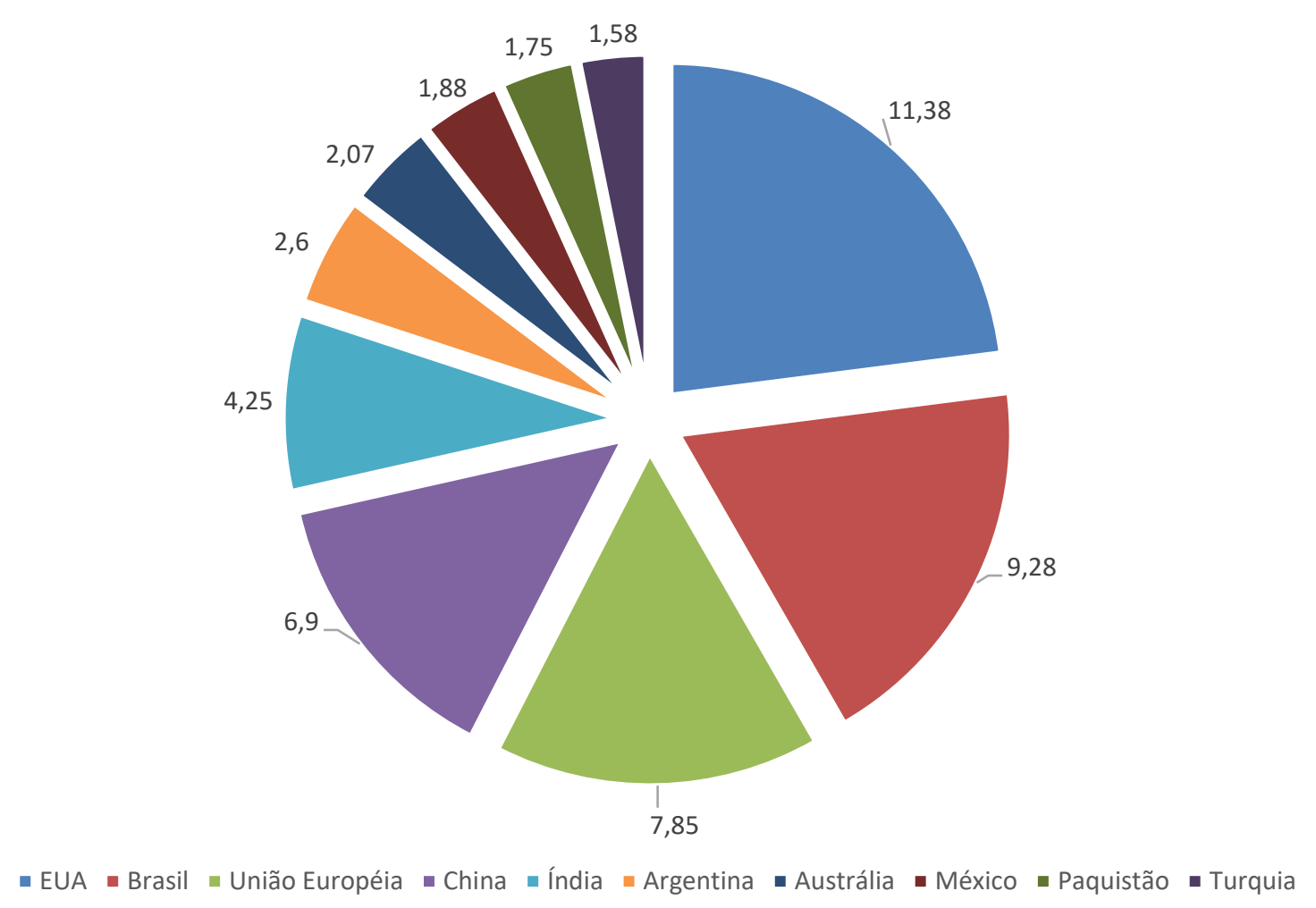

Fonte: baseado em USDA/FAO (2016)

A carne bovina apresenta participação significativa na dieta mundial. De acordo com o Departamento de Agricultura dos Estados Unidos (USDA)/FAO (2016) o mundo consumiu 58,74 milhões de toneladas de carne no ano de 2016, o que representa uma média mundial de 7,90 $\mathrm{kg} / \mathrm{hab} / \mathrm{ano}$. Os cinco maiores consumidores, em ordem decrescente são: Uruguai (56,30 kg/hab/ano), Argentina (54,50 kg/hab/ano), Hong Kong (51,90 kg/hab/ano), Estados Unidos da América (36,00 kg/hab/ano) e Brasil (35,80 kg/hab/ano). Vale ressaltar que a média mundial encontra-se bastante abaixo dos principais consumidores, o que indica um grande potencial de crescimento.

A ingestão de carne vermelha no Brasil (USDA/FAO, 2016) corresponde a 98,08 g/per capta/dia. Segundo a última pesquisa de análise dos hábitos alimentares dos brasileiros (IBGE, 2011) o consumo diário de frutas é de $86,1 \mathrm{~g} /$ dia, leguminosas 40,7 g/dia e vegetais 24,60 g/dia.

No país, mesmo sendo reconhecido por sua disponibilidade de terras e a possiblidade de produção extensiva, as altas flutuações dos preços do boi gordo ao longo do ano, o giro mais rápido 
do capital investido e o fato de conseguir contornar a sazonalidade de produção de forrageiras (GOMES, 1975), foram fatores determinantes para a adoção do sistema de confinamento. Embora esse sistema tenha a necessidade de adaptações e ou construções de instalações, compra de maquinários específicos, demandando um alto investimento inicial (PEIXOTO; MOURA; DE FARIA 1986), e o Brasil apresente condições climáticas favoráveis a produção de bovinos a pasto, o sistema de confinamento demonstra adoção significativa nos últimos anos.

Na última década o Brasil deu grandes saltos na evolução de animais terminados em confinamentos. Em 1991 eram apenas 785 mil cabeças, segundo o Anuário Estatístico da Pecuária de Corte - ANUALPEC 1999. Em meados da década de 2000 estimava-se que dos 40 milhões de bovinos abatidos anualmente apenas $10 \%$ desse total eram oriundos de sistemas de confinamentos (ANUALPEC 2012).

Até o início da década de 90 o confinamento de bovinos no Brasil era justificado pela possibilidade do aproveitamento do diferencial de preços do boi gordo na entressafra (BURGÜI, 2001). Atualmente, a abordagem é outra, não só é importante o diferencial de preços, mas também como estratégia para a fase de terminação dos animais, com o propósito de melhorar a produtividade do produto carne (SAINZ, 2009). Devido às margens de retorno econômico nas atividades pecuárias serem cada vez mais limitadas, a busca por maior eficiência produtiva se torna uma questão de sobrevivência.

Outras vantagens do sistema de confinamento são: antecipação da idade de abate dos animais, maior controle da alimentação e seus ingredientes, maior produtividade por área, liberação de áreas para outras categorias e maior qualidade da carcaça (MEDEIROS, 2014).

Segundo Rabobank (2014) o volume de animais confinados no Brasil deverá mais do que dobrar nos próximos dez anos, a capacidade anual de confinamento de bovinos no país deve passar dos atuais 4,5 milhões de cabeças para mais de 9 milhões de cabeças em 2023. De acordo com a Associação Nacional dos Confinadores (ASSOCON) em 2017 o número de bovinos confinados cresceu 5,5\% em relação ao ano anterior, e em 2018 deverá crescer cerca de 12\%, chegando a 5 milhões de cabeças. Embora se verifique o aumento dos animais confinados e que essa tendência se consolide por ser um sistema de produção viável e rentável, ainda existem desafios a serem transpostos a fim de propiciar maior eficiência produtiva ao sistema. 


\subsection{PEGADA HÍDRICA}

Neste item serão abordados os conceitos, a metodologia e as contribuições que a abordagem da pegada hídrica pode dar para a produção animal.

\subsubsection{Conceitos e metodologias}

O conceito dominante de desenvolvimento sustentável consiste em entender como o planeta pode proporcionar recursos suficientes para assegurar o bem-estar das pessoas no presente e no futuro (SILVA et al., 2013).

Dentro desse contexto a avaliação ambiental das atividades humanas pela abordagem metodológica de "pegadas" é crescente, sendo as pegadas ecológica e de carbono mais conhecidas e mais presentes nas iniciativas científicas e empresariais. $\mathrm{O}$ conceito de pegada hídrica $(\mathrm{PH})$ foi introduzido em 2002 por Arjen Hoekstra na reunião de peritos internacionais sobre o comércio de água virtual realizada em Delft, Holanda (HOEKSTRA, 2003). O termo PH foi escolhido por Hoekstra em analogia à pegada ecológica. Muito embora os conceitos tenham objetivos e métodos diferentes de medição, para alguns aspectos têm abordagens semelhantes, pois traduzem o consumo de recursos naturais pela humanidade (HOEKSTRA et al., 2009). Desde então a PH tem sido usada como um indicador do consumo de água por pessoas, produtos e processos (ZHAO et al., 2009; ROMAGUERA et al., 2010; FENG et al., 2011; RIDOUTT et al., 2014; TOM et al., 2016; SHI et al., 2017). A PH pode ser entendida como uma ferramenta de gestão da água, fornecendo informações quantitativas que possibilitam ações mitigatórias e de melhoria da eficiência de uso do recurso, além de auxiliar na avaliação do impacto socioeconômico.

Atualmente, as principais metodologias para cálculo da PH são a proposta pela Water Footprint Network (www.waterfootprint.org) e a abordagem de Análise de Ciclo de Vida (ACVbaseada na ISSO 14044:2006; RIDOUTT; PFISTER, 2010, DE BOER et al., 2013).

A ACV, consiste em uma metodologia que, por meio da mensuração das entradas e saídas de um sistema associado a um produto ou serviço, realiza a avaliação dos impactos ambientais relacionados a estas entradas e saídas, fazendo a interpretação dos resultados alcançados, de acordo com os objetivos estipulados pelo estudo (ABNT, 2009). Apesar de ser uma metodologia consolidada de avaliação de impacto ambiental que avalia e mensura os principais aspectos e impactos ambientais de produtos e serviços, não tem considerado o uso da água e as consequências de seu esgotamento de forma suficientemente detalhada e abrangente (MULLER, 2012). A norma 
NBR ISO 14044 (ABNT, 2009) sugere uma estrutura metodológica para a execução da ACV, porém segundo a norma, o método apresenta algumas limitações, tais como, subjetividade nas suposições, falta de dimensões temporais e espaciais dos dados o que induz a incertezas nos resultados. A norma ISO 14046:2014 (Environmental management- Water Footprint- Principles, requirements and guidelines) propõe como avaliar a pegada hídrica a partir da metodologia ACV. A ISO 14046 ressalta que a avaliação da pegada hídrica por si só não é suficiente para descrever os impactos ambientais potenciais aos recursos hídricos.

Com relação à metodologia da Water Footprint Network, ela foi desenvolvida para ser aplicada especificamente na avaliação do consumo dos recursos hídricos. O resultado é um indicador volumétrico dos consumos diretos e indiretos da água, conforme as fontes de uso e as condições locais. Entretanto, apesar de ser amplamente aceita e empregada por diversos países e empresas, no Brasil, o potencial desta abordagem ainda é pouco explorado (MULLER, 2012).

Neste estudo optou-se por utilizar a metodologia da Water Footprint Network, pois o método permite o cálculo da água efetivamente consumida e não só a captada, além de inserir o cálculo das águas verde e cinza (HOEKSTRA et al., 2011). No método o cálculo é feito a partir da diferenciação da demanda de água verde (água da chuva, não considerando a água que escorre ou infiltra a qual não é utilizada pela cultura agrícola), da água azul (extraída de fontes superficiais e subterrâneas e utilizada na irrigação das culturas, dessedentação dos animais e serviços) e da água cinza (definida como o volume de água necessário para diluir os efluentes da atividade, considerando os padrões ambientais e legais dos corpos d'água receptores). Portanto, a PH é composta por componentes indiretos (ex. água utilizada na produção dos alimentos para os animais) e diretos (ex. água consumida na dessedentação dos animais) conforme Figura 1.

Figura 1. Representação esquemática dos componentes diretos e indiretos em cada estágio da cadeia de suprimentos de um produto de origem animal

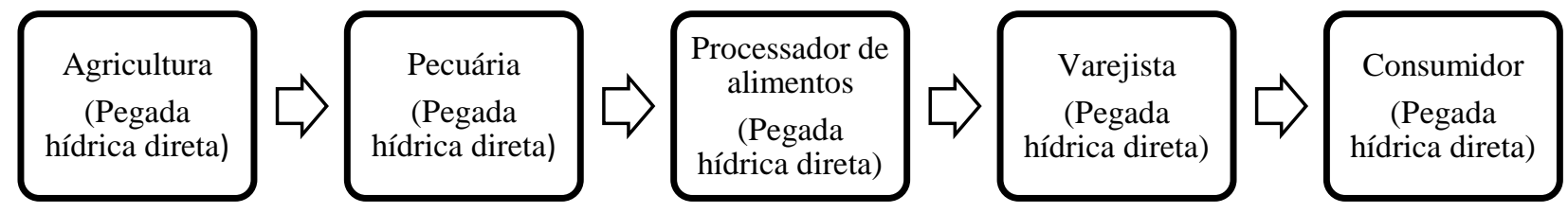

PH indireta

$\mathrm{PH}$ indireta

$\mathrm{PH}$ indireta

$\mathrm{PH}$ indireta

Fonte: Adaptado de Hoekstra et al., 2011 
A avaliação da pegada hídrica consiste de quatro fases distintas (Figura 2).

Figura 2. Fases da avaliação da pegada hídrica

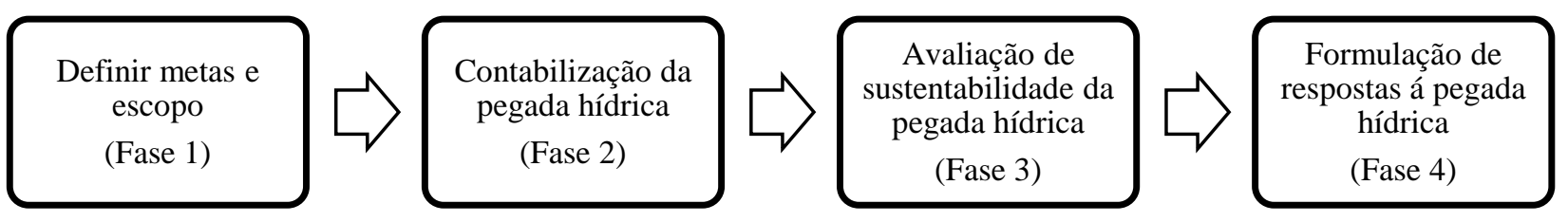

Fonte: Adaptado de Hoekstra et al., 2011

A primeira etapa consiste na definição clara dos objetivos e do escopo do estudo, pois a pegada hídrica pode ser calculada para um produto, para um processo ou para etapas destes. Por exemplo, o comitê de bacia hidrográfica pode estar interessado em saber se as pegadas hídricas agregadas das atividades humanas na bacia violam as vazões disponíveis e/ou os padrões de qualidade de água (HOEKSTRA, 2012).

Na segunda etapa faz-se o inventário das informações necessárias para quantificação dos consumos de água. Nesta etapa se realiza todos os cálculos.

É necessário enxergar os dados por uma perspectiva ambiental, social e econômica, essa é a etapa de avaliação da sustentabilidade. Na etapa final são formuladas opções de respostas, estratégias ou políticas. As informações geradas pelo cálculo da pegada hídrica possibilitam, para o setor agropecuário, identificar as fontes e quais as quantidades de água utilizada para atender as demandas dentro de cada processo da cadeia produtiva, de forma a identificar as pressões impostas pela atividade produtiva ao meio ambiente (HOEKSTRA et al., 2011).

\subsubsection{Cálculo da pegada hídrica na produção animal}

O sistema alimentar mundial está sujeito às pressões conflitantes: satisfazer a demanda por alimentos de uma população em expansão. É esperado que a população global chegue a 9,6 bilhões até 2050 (JALAVA et al., 2014), e ter sustentabilidade ambiental. Além do aumento da população, a elevação das taxas de consumo de commodities, como carne e leite, devido ao aumento dos rendimentos, o aumento da demanda não-alimentar das commodities agrícolas, principalmente para a bioenergia, aumentam a pressão sobre a agricultura (MORAN et al.,1999). A maior parte do aumento da produção e consumo de produtos de origem animal vai se dar em países em desenvolvimento (RAN et al., 2016). 
A água é um recurso fundamental para todas as produções animais, mas como objeto de pesquisa, tem recebido pouca atenção. Há muitas razões para essa falta de interesse no tema. A água para a maior parte da produção pecuária mundial está disponível, senão abundante. No Brasil existe um fator agravante, que é a cultura da abundância da água, pois o país é reconhecido pelo seu potencial hídrico (PALHARES, 2013). A grande diversidade dos sistemas produtivos pecuários e suas interações fazem com que a análise do uso da água na agropecuária seja complexa e muitas vezes, contraditória (FAO, 2006). Como ela não é comercializada como os outros insumos da produção, há pouco incentivo financeiro para estudar as relações da água com a pecuária (PATIENCE, 2012).

A agricultura representa $92 \%$ do consumo mundial de água (MEKONNEN; HOEKSTRA, 2012). Entre os alimentos, os produtos de origem animal são os que apresentam os maiores consumos de água (MEKONNEN; HOEKSTRA, 2012). A redução da pressão sobre os recursos hídricos a partir dos produtos alimentares é um grande desafio para a humanidade e o conhecimento do consumo de água para produção desses é relevante para os governos planejarem e avaliarem a sua política ambiental e de segurança alimentar (MEKONNEN; HOEKSTRA, 2012).

Na Tabela 1 observa-se produtos de origem vegetal e animal e seus respectivos valores de pegada hídrica.

Vanham e Bidoglio (2013) realizaram a avaliação da pegada hídrica de consumo de produtos agrícolas nos países da Comunidade Europeia. Os produtos de origem animal representaram mais de $50 \%$ do valor total. Os países consumiram um total de 41 milhões de toneladas de carne $(84,5 \mathrm{~kg} / \mathrm{capta} / \mathrm{ano})$. Os produtos com maior impacto no valor da pegada hídrica foram o leite (569 L/capta/dia), carne bovina (478 L/capta/dia) e suína (464 L/capta/dia). 
Tabela 1. Pegada hídrica de alguns tipos de alimentos

\begin{tabular}{cc}
\hline Produto & Pegada Hídrica \\
\hline Alface & $2371 / \mathrm{kg}$ \\
Arroz & $2.4971 / \mathrm{kg}$ \\
Batata & $2871 / \mathrm{kg}$ \\
Café & $8801 / 1$ \\
Carne bovina & $15.4151 / \mathrm{kg}$ \\
Carne de frango & $4.3251 / \mathrm{kg}$ \\
Carne suína & $5.9881 / \mathrm{kg}$ \\
Feijão & $1.2671 / \mathrm{kg}$ \\
Leite & $1.0201 / 1$ \\
Macarrão & $1.8491 / \mathrm{kg}$ \\
Pão & $1.6081 / \mathrm{kg}$ \\
Tomate & $3531 / \mathrm{kg}$ \\
\hline
\end{tabular}

Fonte: Elaborada pela autora baseado em (Silva et al., 2016).

A quantidade de água consumida na produção de carne vermelha e na produção de grãos utilizados na alimentação animal influenciam a visão da sociedade sobre a sustentabilidade desta produção em comparação com as outras fontes de proteína (PETERS et al., 2010). Na Tabela 2 se observa a influência da escolha metodológica no consumo de água para produção de carne bovina.

A aplicação de diferentes métodos de cálculo da pegada hídrica não permite a comparação de resultados entre produtos e países, dificulta a comunicação com as partes interessadas (stakeholders) e a identificação de estratégias de mitigação (ZONDERLAND-THOMASSEN et al., 2014). Para compreender os impactos sobre o uso da água associados a cada produto ou sistema de produção pecuária, as avaliações devem considerar as diferenças temporais e espaciais no manejo da água, da terra e dos animais e como estes afetam a hidrologia local (RAN et al., 2016). 
Tabela 2. Valores de demanda hídrica do produto carne bovina

\begin{tabular}{|c|c|c|}
\hline Autores & Método & Valor $(\mathbf{L} / \mathbf{k g})$ \\
\hline Beckett e Oltjen (1993) & Água virtual & 3.682 \\
\hline Pimentel et al. (1997) & Água virtual & 100.000 \\
\hline Thomas apud Pimentel et al. (1997) ${ }^{1}$ & Água virtual & 200.000 \\
\hline $\begin{array}{l}\text { Barthelemy apud Renault and Wallender } \\
(2000)^{2}\end{array}$ & Água virtual & 13.500 \\
\hline Deusch et al. (2010) & Água virtual & 40.500 \\
\hline Chapagain e Hoekstra (2003) & Pegada Hídrica & 14.516 \\
\hline Hoekstra e Chapagain (2007) & Pegada Hídrica & 15.497 \\
\hline Mekonnen e Hoekstra (2012) & Pegada Hídrica & 15.415 \\
\hline Peters et al. (2010) & $\begin{array}{c}\text { Análise de Ciclo de } \\
\text { Vida }\end{array}$ & $27-540$ \\
\hline Ridoutt et al., (2012) & $\begin{array}{c}\text { Análise de Ciclo de } \\
\text { Vida }\end{array}$ & $12-117$ \\
\hline
\end{tabular}

Fonte: Elaborada pela autora baseado em (Ridoutt et al., 2012) e (Peters et al., 2010)

O valor de $15.497 \mathrm{~L} / \mathrm{kg}$ de carne bovina foi um dos de maior repercussão na sociedade. Esse valor é uma média global e se refere a um sistema produtivo com as seguintes características: sistema industrial, média de três anos para o animal ser abatido e produzir $200 \mathrm{~kg}$ de carne. Nesse sistema o animal consumiu: $1.300 \mathrm{~kg}$ de grãos, $7.200 \mathrm{~kg}$ de volumosos, $24 \mathrm{~m}^{3}$ de água de dessedentação e $7 \mathrm{~m}^{3}$ de água para serviços. Por quilograma de carne foram $6,5 \mathrm{~kg}$ de grãos, $36 \mathrm{~kg}$ de volumosos e 155 litros de água (MEKONNEN; HOEKSTRA, 2010). Os autores ressaltam que a pegada de um quilograma de carne deve ser calculada para cada sistema produtivo, pois irá depender do local onde o sistema está localizado, o tipo de animal, a composição e origem dos alimentos e as formas de uso da água (dessedentação, irrigação, resfriamento, lavagem). Essa afirmação justifica a necessidade de que os estudos em pegada hídrica tenham um caráter local, considerando as realidades produtivas e sociais do país.

Schneider e Carra (2016) calcularam a pegada hídrica dos suínos abatidos nos municípios que compõem o Conselho Regional de Desenvolvimento da Serra (Corede Serra/ RS) e verificaram valores de pegada muito diferentes entres os municípios (Nova Prata =0,02343 km $\mathrm{ano}^{-1}$; Paraí = $0,02187 \mathrm{~km}^{3}$ ano $^{-1}$ e Serafina Corrêa $=0,01658 \mathrm{~km}^{3} \mathrm{ano}^{-1}$; São Marcos $=0,000006 \mathrm{~km}^{3}$ ano $^{-1}$, Bento

\footnotetext{
1 Thomas, G.W. Water: critical and evasive resource on semiarid lands. Water and water policy in world food supplies. College Station: Texas A \& M University Press, v.1, p. 83-90, 1987.

${ }^{2}$ Barthelemy, F.D. Water for a sustainable human nutrition: inputs and resources analysis in arid areas. MS Thesis. Ecole Nationale du Geânie Rural, des Eaux et des Foreãts, Stage de ®n d'eâtudes, Paris, France, 1993.120 pp.
} 
Gonçalves $=0,00002 \mathrm{~km}^{3}$ ano $^{-1}$ e Boa Vista do $\mathrm{Sul}=0,00004 \mathrm{~km}^{3}$ ano $^{-1}$ ). Os autores atribuíram as diferenças de valores entre as pegadas aos aspectos de produtividade de milho e número de animais abatidos no município e concluíram que na gestão dos recursos hídricos se deve também contemplar a produção de grãos.

Ridoutt, Sanguansri e Harper (2011) calcularam a pegada hídrica pelo método ACV para seis sistemas de produção de gado bovino no sul da Austrália e encontram intervalo de valores

de 3,3 a $221 \mathrm{~L} \mathrm{H}_{2} \mathrm{O}$ de $\mathrm{kg}^{-1}$ peso vivo. $\mathrm{O}$ que pode ser atribuído a grande diversidade de sistemas de produção estudados, além do fator local (índice de estresse hídrico). Palhares, Morelli e Costa Junior (2017) calcularam a pegada hídrica de bovinos em confinamento e mostraram como a relação volumoso:concentrado e a produtividade agrícola impactam nos valores da pegada hídrica.

Ainda há na literatura científica nacional poucos estudos abordando a pegada hídrica do produto carne bovina. O Brasil precisa avaliar a pegada hídrica desse produto por ser um dos maiores produtores e exportadores mundiais e por possuir características produtivas inerentes a região tropical e ao seu nível tecnológico. Caso contrário, o país será sempre refém de estudos internacionais.

Palhares (2013) considera que as limitações para o cálculo da pegada hídrica na pecuária brasileira são: inexistência de cultura hídrica nas cadeias produtivas; falta de informações para o cálculo, que aumenta a necessidade de inferências, as incertezas e os conflitos; ausência de visão e políticas sistêmicas dos atores das cadeias e tomadores de decisão.

Aumentar o conhecimento da utilização da água pela pecuária e desenvolver métodos padronizados para quantificação desta utilização é a melhor forma, senão a única, para atingir o equilíbrio hídrico (GIRARD, 2012).

\subsection{MANEJO NUTRICIONAL E O USO DE COPRODUTOS}

Embora os conceitos nutricionais tenham avançado ao longo do tempo, a formulação das dietas foi e deve estar baseada na relação custo-benefício, conforme afirma Martin (1987, p.93):

"Tendo em vista o papel da alimentação nos custos de produção em confinamento de bovinos de corte, o aspecto balanceamento de dietas torna-se um fator dos mais delicados. Assim, de nada valerão os altos conhecimentos teóricos sobre nutrição de ruminantes e uma dieta perfeitamente equilibrada ao ganho de peso proposto se a resposta não for econômica. Todo aspecto de formulação deve basear-se na relação custo-benefício”. 
O manejo nutricional correto é relevante uma vez que a dieta representa aproximadamente 85\% dos custos de produção. Deve-se preocupar, além dos custos das dietas, com os ingredientes utilizados, pois nem sempre os insumos de menor preço retornam os melhores desempenhos, e por isso, maiores lucros, uma vez que as flutuações sazonais nos preços dos produtos agropecuários provocam instabilidade na renda do produtor (CAMPOS, 2007).

As atividades agroindustriais geram grande quantidade de resíduos que tem valor nutricional na alimentação animal (Tabela 3) (GOES et al., 2008). O uso de coprodutos e/ou subprodutos dos processos produtivos das atividades agrícolas ou agroindustriais na alimentação é uma prática antiga (OLIVEIRA et al., 2012). Denominam-se coprodutos os resíduos que tem valor de mercado e subprodutos os que são vendidos dependendo da viabilidade econômica (QUINTELLA et al., 2009).

Reduções da dependência da produção animal por produtos que poderiam servir como alimento para humanos é uma das razões pelo interesse histórico e crescente no uso de coprodutos na alimentação animal. Ruminantes são capazes de transformar ingredientes que não são úteis à alimentação humana em produtos com elevado valor nutricional (CARRERA et al., 2012). 
Tabela 3. Composição bromatológica de diferentes coprodutos utilizados na alimentação de ruminantes

\begin{tabular}{|c|c|c|c|c|c|c|}
\hline \multirow{3}{*}{ Coprodutos } & \multicolumn{5}{|c|}{ Fração analítica ${ }^{1}$} & \multirow{3}{*}{ Fonte } \\
\hline & MS & MM & PB & EE & FDN & \\
\hline & \multicolumn{5}{|c|}{$(\% \mathrm{MS})$} & \\
\hline $\begin{array}{c}\text { Caroço de } \\
\text { algodão }\end{array}$ & 92,60 & 3,60 & 21,03 & 21,20 & 44,97 & $\begin{array}{l}\text { Melo et al. } \\
\quad(2006)\end{array}$ \\
\hline $\begin{array}{c}\text { Casca de } \\
\text { soja }\end{array}$ & 92,60 & 7,22 & 15,45 & 2,43 & 60,74 & $\begin{array}{l}\text { Hashimoto } \\
\text { et al. (2007) }\end{array}$ \\
\hline $\begin{array}{l}\text { Farelo de } \\
\text { algodão }\end{array}$ & 89,40 & 5,20 & 47,50 & 1,20 & 33,10 & $\begin{array}{c}\text { Malafaia et } \\
\text { al. (1998) }\end{array}$ \\
\hline $\begin{array}{l}\text { Farelo de } \\
\text { amendoim }\end{array}$ & 96,00 & 6,00 & 49,20 & 14,20 & 14,20 & $\begin{array}{l}\text { Queiroz et } \\
\text { al. (2008) }\end{array}$ \\
\hline $\begin{array}{l}\text { Farelo de } \\
\text { arroz } \\
\text { integral }\end{array}$ & 61,52 & - & 11,54 & 15,30 & - & $\begin{array}{c}\mathrm{CT} \\
\text { Embrapa }\end{array}$ \\
\hline $\begin{array}{l}\text { Farelo de } \\
\text { glúten de } \\
\text { milho } 60\end{array}$ & 92,20 & 2,30 & 53,80 & 0,90 & 3,80 & $\begin{array}{l}\text { Silveira et } \\
\text { al. (2009) }\end{array}$ \\
\hline $\begin{array}{l}\text { Gérmen de } \\
\text { milho }\end{array}$ & 89,91 & 4,2 & 14 & - & 26,04 & $\begin{array}{c}\text { Ezequiel et } \\
\text { al. (2006) }\end{array}$ \\
\hline $\begin{array}{c}\text { Polpa } \\
\text { Cítrica } \\
\text { peletizada }\end{array}$ & 91,40 & 8,30 & 17,30 & & 24,60 & $\begin{array}{l}\text { Rodrigues } \\
\text { et al. (2008) }\end{array}$ \\
\hline $\begin{array}{l}\text { Farinha de } \\
\text { varredura }\end{array}$ & 91,3 & 1,3 & 1,2 & - & 7,3 & $\begin{array}{l}\text { Prado et al. } \\
\quad(2006)\end{array}$ \\
\hline $\begin{array}{l}\text { Raspas de } \\
\text { mandioca }\end{array}$ & 88,70 & 3,6 & 3,6 & - & 8,5 & $\begin{array}{l}\text { Prado et al. } \\
\quad(2006)\end{array}$ \\
\hline
\end{tabular}

${ }^{1}$ MS (Matéria seca); MM (Matéria mineral); PB (Proteína bruta); EE (Extrato etéreo); FDN (Fibra em detergente neutro).

Porém o uso de coprodutos segue a oferta sazonal e de proximidade dos polos produtores. De acordo com Bellaver e Ludke (2004), sempre que se avalia a oportunidade de uso de um ingrediente alternativo, alguns pontos devem ser observados: i) disponibilidade comercial; ii) quantidade de nutrientes e energia; iii) qualidade dos nutrientes; iv) características físicas do ingrediente.

Tem se estudado sobre o uso de coprodutos na alimentação animal (RESTLE et al., 2004, NEIVA et al., 2005; RIBEIRO et al., 2007; ABDALLA et al., 2008; BRAGA et al., 2010; GERON et al., 2011; ORNAGHI et al., 2016, SILVA et al. 2016; FABRINI et al., 2017) principalmente sobre seus efeitos em substituição aos ingredientes convencionais. 
Um estudo conduzido por Millen et al. (2014) sobre as práticas de gestão e recomendações nutricionais usadas nos confinamentos do Brasil verificou que o nível de inclusão de grãos nas dietas brasileiras é muito menor do os níveis utilizados em dietas fornecidas em confinamentos nos EUA e que a inclusão de forragem e o uso de coprodutos é maior nas dietas de confinamento brasileiras. Os mesmos autores ainda verificaram quais são os coprodutos mais utilizados: semente de algodão $(45,2 \%)$, polpa cítrica peletizada $(35,5 \%)$, casca de soja $(16,1 \%)$ e resíduos de soja $(3,2 \%)$. Na pesquisa a maioria dos produtores entrevistados usou algum tipo de coproduto nas dietas de terminação.

Valença et al. (2016) em uma revisão sobre o uso de bagaço de laranja na alimentação de bovinos, concluíram que este pode ser utilizado na alimentação de ruminantes, principalmente na em forma de silagem, sendo caracterizado como um excelente alimento, todavia o seu valor nutricional sofre variações a depender do tipo da laranja e da indústria.

Pereira et al. (2007) avaliaram a substituição do milho moído fino (MMF) por farelo de trigo (FT) ou farelo de glúten de milho (FGM) na ração de bovinos não castrados, em terminação. A ração continha $24 \%$ de silagem de capim e $76 \%$ de concentrado, constituído por polpa cítrica, farelo de soja, ureia, minerais, bicarbonato de sódio e monensina sódica. Os autores concluíram que o MMF pode ser substituído na íntegra por FT ou por FGM, sem que haja queda na eficiência alimentar ou no teor de energia das rações. Ezequiel et al (2006) ao avaliar a substituição parcial (50\%) do milho por farelo de gérmen de milho, casca do grão de soja ou polpa cítrica na dieta de bovinos Nelore em confinamento não verificaram alterações no ganho de peso e nem nas características de carcaça.

Além dos fatores nutricionais e de desempenho o uso de coprodutos também apresenta viabilidade econômica. A busca por estratégias que permitam aumentar a produção de bovinos em confinamento, sem inviabilizar o custo de produção, fez aumentar a participação de coprodutos possíveis de utilização pelos ruminantes (PRADO et al., 2010).

Geron et al. (2014) avaliaram a viabilidade econômica da utilização de rações contendo diferentes teores de caroço de algodão - CRA ( $0 \% ; 10 \% ; 20 \%$ e 30\%) e concluíram que a utilização de até 30\% de CRA na alimentação dos animais mantém o ganho médio diário e pode gerar uma receita líquida por mês $85 \%$ maior do que o uso de ração sem caroço de algodão. Prado et al. (2006) estudaram a viabilidade econômica da substituição do milho grão por subprodutos do processamento da mandioca (raspa- RAM, farinha de varredura- FAV e casca de mandioca-CAM). 
Os autores não verificaram diferenças no desempenho do animal, porém todos os tratamentos tiveram menor custo por animal por dia do que o controle ( $\mathrm{R} \$ 1,20$ controle; $\mathrm{R} \$ 0,90 \mathrm{CAM}$; $\$$ 0,67 FAV e R\$ 1,06 RAM). Ezequiel et al. (2006), também encontraram viabilidade econômica no uso de coprodutos em substituição ao milho, foi observado um menor custo por arroba no tratamento com polpa de cítrica ( $\mathrm{R} \$ 44,20)$, seguido do farelo de gérmen de milho $(\mathrm{R} \$ 48,80)$ e da casca de soja ( $\mathrm{R} \$ 50,80)$; porém, quando utilizado somente o milho, o custo da arroba foi de $\mathrm{R} \$$ 51,80 .

Segundo Palhares, Morelli e Costa Junior (2017) os valores de pegada hídrica em confinamentos são determinados em grande parte pelos indicadores de desempenho do animal e pelo tipo de dieta, onde a relação volumoso/concentrado e o tipo de volumoso influenciam significativamente os valores da pegada hídrica.

O uso de coprodutos tem um impacto positivo na redução dos valores de pegada hídrica dos produtos de origem animal, uma vez que apenas uma porcentagem do produto primário é alocada como água consumida na produção do produto animal. Porém ainda são escassos na literatura científica trabalhos nessa temática.

\subsection{CUSTO DE PRODUÇÃO E CUSTO DA ÁGUA}

$\mathrm{Na}$ teoria econômica, o cálculo do custo de produção é ferramenta de controle e gerenciamento das atividades produtivas, gerando informações importantes para subsidiar as tomadas de decisão dos empresários e podendo servir ainda para a formulação de estratégias pelo setor público (Companhia Nacional de Abastecimento - CONAB, 2010). A análise dos custos é essencial para o produtor conhecer detalhadamente os fatores de produção, identificando os gargalos da produção e permite concentrar esforços gerenciais e tecnológicos para se obter sucesso na atividade e atingir os objetivos de minimização de custos e maximização de lucros (LOPES; CARVALHO, 2002).

Estudos de análise de custo, análise econômica e de rentabilidade são bastante difundidos (LOPES; MAGALHÃES, 2005; KUBIAK, 2008; MOREIRA et al., 2009; ZILIOTTO et al., 2010; SIPP, 2011; PACHECO et al., 2014; MOREIRA et al., 2015; PACHECO et al., 2016; OLEGÁRIO, 2017).

Um sistema de custos completo possui objetivos amplos, refletindo a importância da ferramenta para a gestão e administração de qualquer empreendimento agropecuário, exigindo 
técnicas especiais para apresentação dos custos e resultados do empreendimento (MARION; SEGATTI, 2010).

Moreira et al. (2009) calcularam o custo de produção e identificaram que os impostos, o manejo sanitário, a mão de obra, a alimentação e aquisição de animais foram os itens de maior peso em relação ao custo operacional na terminação de bovinos de corte confinados em Cristalina/GO. Ziliotto et al. (2010) avaliaram duas propriedades de criação de bovinos de corte no Nordeste do Rio Grande do Sul, uma em sistema de produção extensiva e a outra em sistema intensivo, os autores observaram que os melhores índices econômicos se deram no sistema de produção a pasto. Os autores concluíram que mesmo com maiores custos o confinamento se torna um sistema vantajoso.

Pacheco et al. (2016) avaliaram a viabilidade econômica do confinamento de bovinos em três ciclos produtivos (janeiro/abril; maio/agosto; setembro/dezembro) pelo método de simulação determinística. Olegário (2017) analisou a viabilidade econômica da terminação de novilhos acabados em confinamento recebendo dieta de alto grão, com diferentes pesos iniciais (240, 270, 300, 330, 360 e $390 \mathrm{~kg}$ ) por meio de métodos de simulação probabilística de Monte Carlo.

Segundo os fundamentos da Economia Ambiental, os recursos naturais não seriam necessariamente finitos, o que faz com que não existam maiores preocupações acerca da impossibilidade de manutenção do ritmo das atividades produtivas. A Economia Ambiental considera os problemas ambientais como externalidades das atividades econômicas. Estas ocorrem quando as possibilidades de consumo de um agente são afetadas pela utilização do recurso por outro agente, podendo ser positivas - caso a ação de um indivíduo beneficie o outro - ou negativas - caso resulte em custos para terceiros (VARIAN, 2003).

De acordo com OECD (1996), a água é um recurso sujeito a demandas competitivas e, portanto, deve ser tratada como um recurso que possui valor, de forma que a cobrança pode estimular o uso mais eficiente o mesmo, evitando o consumo excessivo. Entretanto, a água também é considerada como um bem social, uma vez que é uma necessidade básica para todos. Uma maneira de solucionar o problema do uso intenso e inadequado da água é estabelecendo uma tarifa para ela, de acordo com a quantidade utilizada por cada agente (STAMPE et al., 2013).

Na Conferência de Dublin em 1993, a água passou a ser considerada um recurso finito e vulnerável. Nesta Conferência foram aprovados dois documentos: A Declaração de Dublin sobre Água e Desenvolvimento Sustentável e o Relatório da Conferência, os quais destacam problemas 
que, por causar impacto sobre a sobrevivência futura da humanidade, exigem ações imediatas e eficazes (ABRH, 2015).

No Brasil, a Lei 9.433 de 08/01/1997, que instituiu a Política Nacional de Recursos Hídricos estabelece os instrumentos de gestão dos recursos hídricos, entre estes a outorga pelo direito de uso e a cobrança da água. A lei define a água como recurso natural limitado, dotado de valor econômico, que pode ter usos múltiplos (consumo humano, produção de energia, transporte e lançamento de esgotos). Além do mais, a lei prevê a descentralização da gestão dos recursos hídricos, contando com a participação do poder público, usuários e comunidades (CAMPOS; CAMPOS, 2014).

Segundo a Organização para a Cooperação e o Desenvolvimento Econômico (OCDE;1998): “apesar de diversos países entenderem a necessidade de aumentar a cobrança pelo uso da água na agricultura de forma a assegurar a estabilidade financeira dos seus sistemas de abastecimento, apenas poucos já deram passos decisivos nesta direção".

$\mathrm{Na}$ maior parte dos países, o preço da água na agricultura tende a refletir apenas os custos de operação e manutenção dos sistemas de irrigação, acrescendo-se, em alguns casos, a cobrança pelo uso da água, cujo objetivo é internalizar as "externalidades" econômicas e ambientais (KELMAN; RAMOS, 2005).

No Brasil a cobrança iniciou-se pelos comitês das bacias hidrográficas do Rio Paraíba do Sul, dos rios Piracicaba, Capivari e Jundiaí, do Rio São Francisco e do Rio Doce. Atualmente outros comitês já tem adotado a valoração, entre eles bacia do rio Jatobá e córrego do Onça, bacia do Paraíba do Sul, bacia do Rio Doce.

Todavia a cobrança pelo uso da água ainda é incipiente na realidade brasileira, principalmente para as atividades pecuárias. Na Tabela 4 apresenta-se um estudo de caso do impacto da cobrança da água na bacia do Paraíba do Sul sob as atividades agrícolas. 
Tabela 4. Impacto da cobrança pelo uso da água no setor agrícola da bacia do rio Paraíba do Sul

\begin{tabular}{|c|c|c|c|c|c|c|c|}
\hline $\begin{array}{l}\text { Produto } \\
\text { (UF) }\end{array}$ & $\begin{array}{c}\text { Receita } \\
(\mathbf{R} \$ / \mathbf{t})\end{array}$ & $\begin{array}{l}\text { Custo } \\
(\mathbf{R} \$ / \mathbf{t})\end{array}$ & $\begin{array}{c}\text { Rentabilidade } \\
\text { (R\$/t) }\end{array}$ & $\begin{array}{c}\text { Água } \\
\text { captada } \\
\left(\mathbf{m}^{3} / \mathbf{t}\right)\end{array}$ & $\begin{array}{c}\text { Cobrança } \\
\text { captação } \\
(\mathbf{R} \$ / \mathbf{t})\end{array}$ & $\begin{array}{c}\text { Impacto de } \\
\text { cobrança } \\
\text { sobre a } \\
\text { rentabilidade } \\
(\%)\end{array}$ & $\begin{array}{c}\text { Impacto } \\
\text { da } \\
\text { cobrança } \\
\text { pelo uso } \\
\text { da água } \\
\text { sobre o } \\
\text { custo } \\
(\%)\end{array}$ \\
\hline $\begin{array}{l}\text { Arroz } \\
\text { (SP) }\end{array}$ & 311,46 & 281,02 & 30,44 & 1.488 & 0,298 & 0,978 & 0,106 \\
\hline $\begin{array}{l}\text { Cebola } \\
\text { (SP) }\end{array}$ & 457,01 & 151,11 & 305,90 & 87 & 0,017 & 0,006 & 0,012 \\
\hline $\begin{array}{l}\text { Goiaba } \\
\text { (RJ) }\end{array}$ & 260,00 & 157,80 & 102,20 & 199 & 0,040 & 0,039 & 0,025 \\
\hline $\begin{array}{l}\text { Batata } \\
\text { (MG) }\end{array}$ & 500,00 & 340,54 & 159,46 & 117 & 0,023 & 0,015 & 0,007 \\
\hline $\begin{array}{c}\text { Maracujá } \\
(\mathrm{RJ})\end{array}$ & 350,00 & 82,51 & 267,49 & 140 & 0,028 & 0,010 & 0,034 \\
\hline
\end{tabular}

Fonte: adaptado de Kelman e Ramos (2005)

Utilizando dados climáticos e produtivos de 17 fazendas localizadas no estado de São Paulo Morelli e Palhares (2015a) calcularam o custo da água em confinamentos de bovinos. O valor da cobrança por cabeça seria de $R \$ 0,0015$, portanto, valor baixo em relação aos demais custos de produção.

Tanto para as atividades agrícolas como para as pecuárias o impacto da cobrança pelo uso da água se mostra pouco efetivo em promover o uso eficiente do recurso a esses níveis de preços. O conhecimento das demandas quantitativas de água para se produzir os produtos agropecuários analisados em conjunto com outros aspectos produtivos, culturais, políticos, sociais e econômicos, poderão fomentar políticas, programas e mecanismos de mercado, que visem reduzir as perdas e desperdícios de água pela agropecuária.

Segundo Kelman e Ramos (2005) somente o investimento em infraestrutura hídrica não basta, é necessário que todos os participantes da cadeia estejam envolvidos no processo e que paguem, ainda que parcialmente pelo benefício recebido. A cobrança pelo uso da água é uma forma de assegurar que os usuários façam bom uso da mesma evitando desperdícios e contaminação. 


\section{MATERIAL E MÉTODOS}

Neste item se apresentam a condição experimental e a caracterização dos nove sistemas de confinamento comerciais, bem como os referenciais metodológicos para os cálculos da pegada hídrica, balanço de nutrientes e das avaliações econômicas.

\subsection{CONDIÇÃO EXPERIMENTAL E CARACTERIZAÇÃO DOS CONFINAMENTOS COMERCIAIS DE GADO DE CORTE}

A parte experimental do estudo foi conduzida no Sistema de Confinamento da Embrapa Pecuária Sudeste, localizada no município de São Carlos, Estado de São Paulo, 21 57’33.32” S 47 $50 " 33,28$ " W, a altitude de 856 metros.

O clima na região é de tipo $\mathrm{Cw}$, na classificação de Koeppen, subtropical com inverno seco e verão quente e úmido, durante o período experimental a temperatura média foi de $26^{\circ} \mathrm{C}$ e a precipitação média foi de 5,48 mm (Gráfico 3).

Gráfico 3. Temperaturas médias, máximas, mínimas $\left({ }^{\circ} \mathrm{C}\right)$ e precipitação $(\mathrm{mm})$ para o período experimental

\section{Climograma}

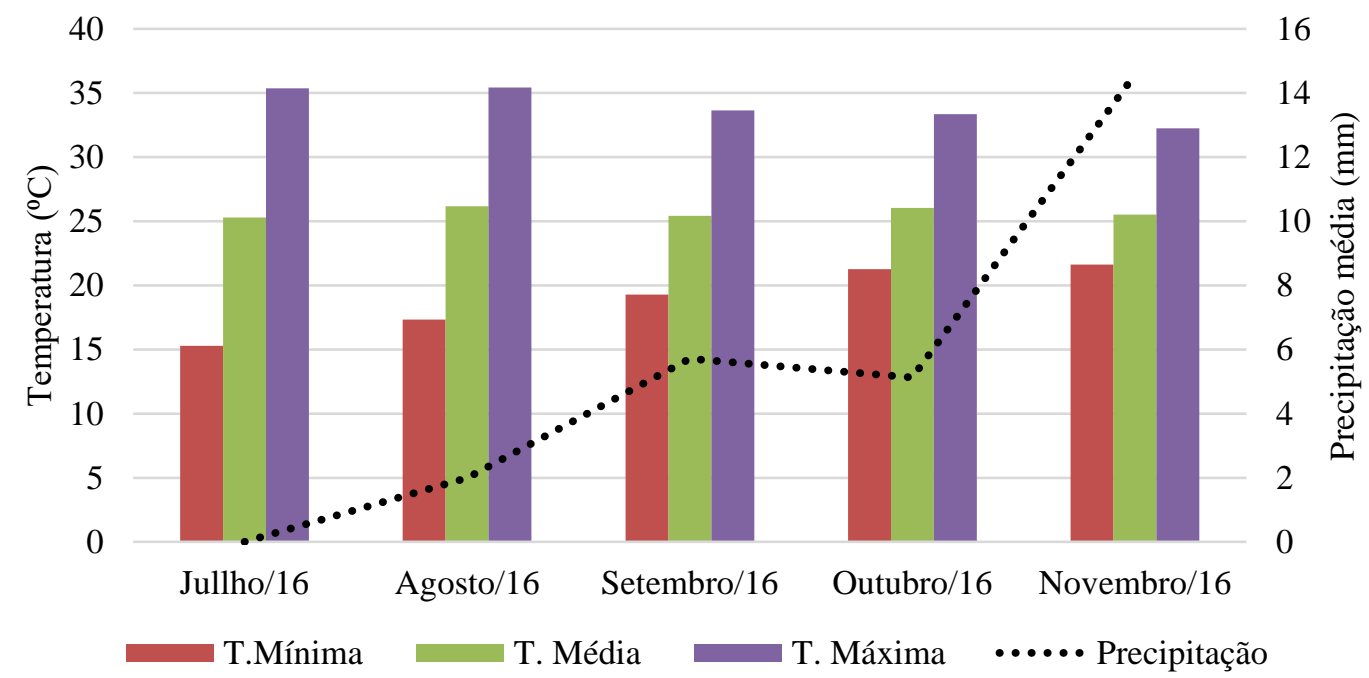

Fonte: Estação Meteorológica Embrapa Pecuária Sudeste.

Uma população de 52 machos Nelore não castrados foram pesados e divididos em dois grupos de 26 indivíduos, dieta convencional e dieta com coprodutos. Cada um desses grupos foi dividido em dois (animais leves e animais pesados), totalizando 13 animais por piquete. 
O experimento teve início no mês de julho de 2016 e término no mês de novembro do mesmo ano, com duração de 123 dias. Na Figura 3 apresentam-se as mudanças de dietas e os momentos de pesagem e coletas de fezes.

Figura 3. Linha do tempo dos eventos ocorridos durante o período experimental

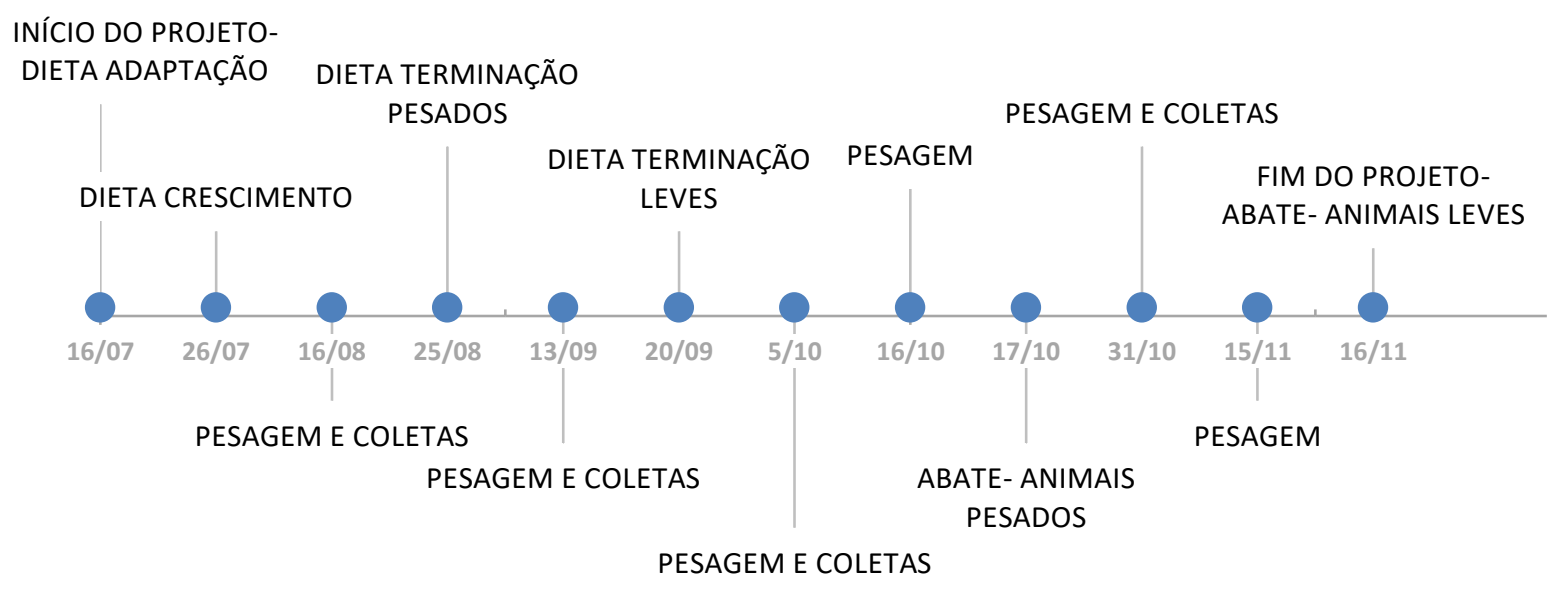

Fonte: Própria autoria.

O experimento foi conduzido em quatro piquetes coletivos, totalizando uma área de $396 \mathrm{~m}^{2}$ (Figura 4). Todos os piquetes eram equipadas com com dois cochos automatizados (GrowSafe® Systems Lt., Airdrie, Alberta, Canadá- Figura 5), onde era ofertado o alimento ad libitum . 
Figura 4. Vista da área experimental

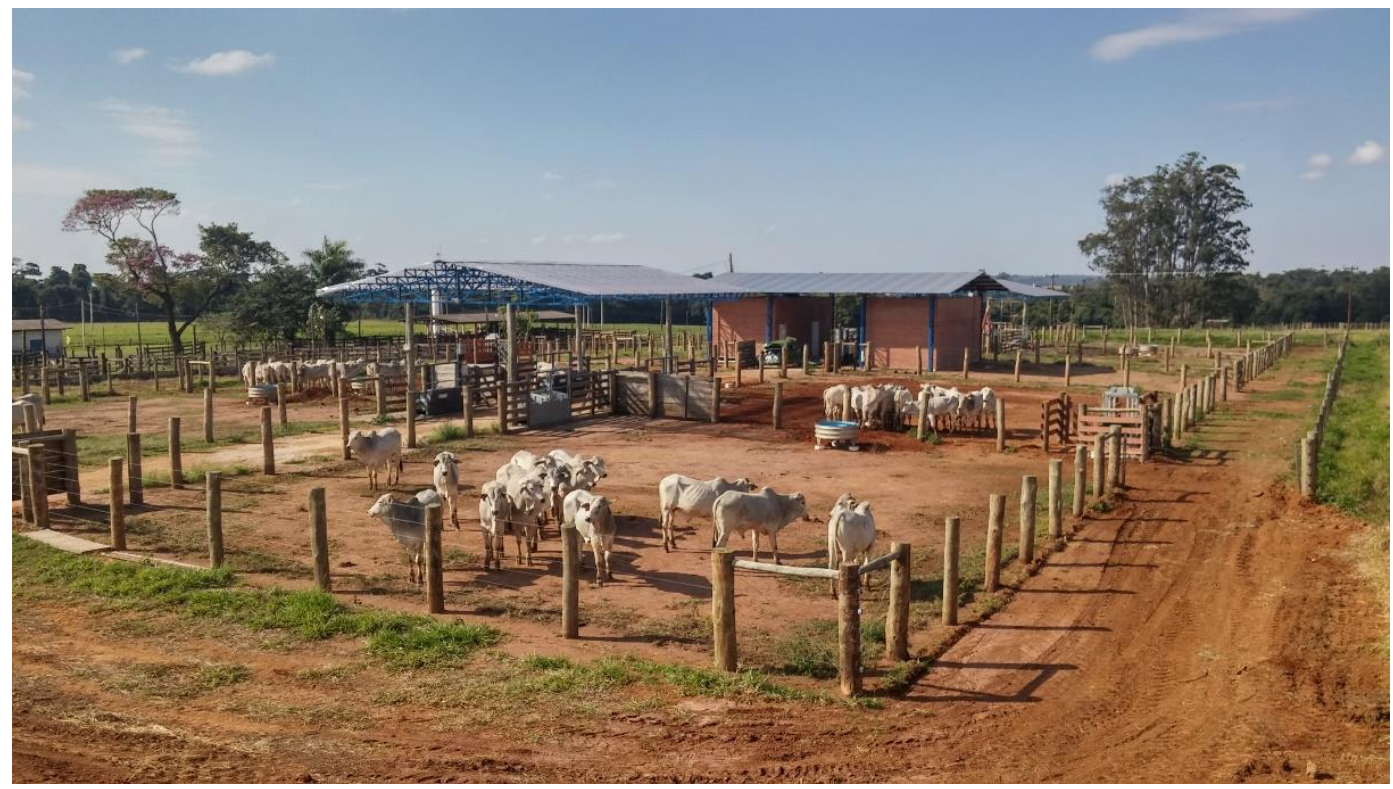

Fonte: Própria autoria.

O consumo de água dos animais foi avaliado por dois sistemas de medição. Dois piquetes possuiam bebedouros automáticos (Model AF-1000 Master, Intergado® Ltda), equipamento que possibilitava a medição do consumo por indivíduo (Figura 6). Cada animal possuía um brinco eletrônicos auricular o qual atuava como um dispositivo para dar acesso ao o bebedouro. O equipamento determina o volume de água consumido por diferença de peso do recipiente do bebedouro antes e após o acesso do animal. Os outros dois piquetes possuiam um bebedouro circular (Figura 7) com hidrômetro instalado (Figura 8) o que permitia a aferição do consumo médio diário de água dos animais. 
Figura 5. Cochos automatizados GrowSafe ${ }^{\circledR}$

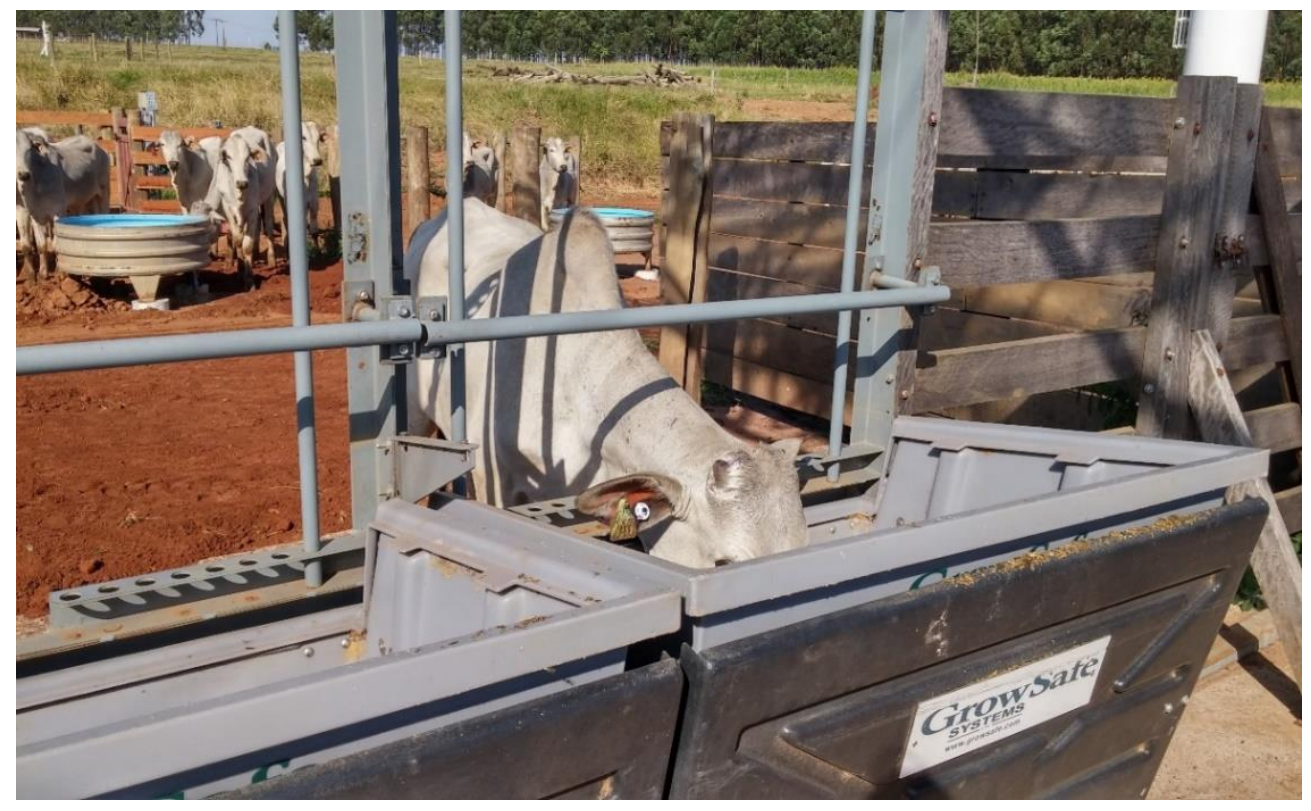

Fonte: Própria autoria.

Figura 6. Bebedouro automatizado modelo Intergado ${ }^{\circledR}$

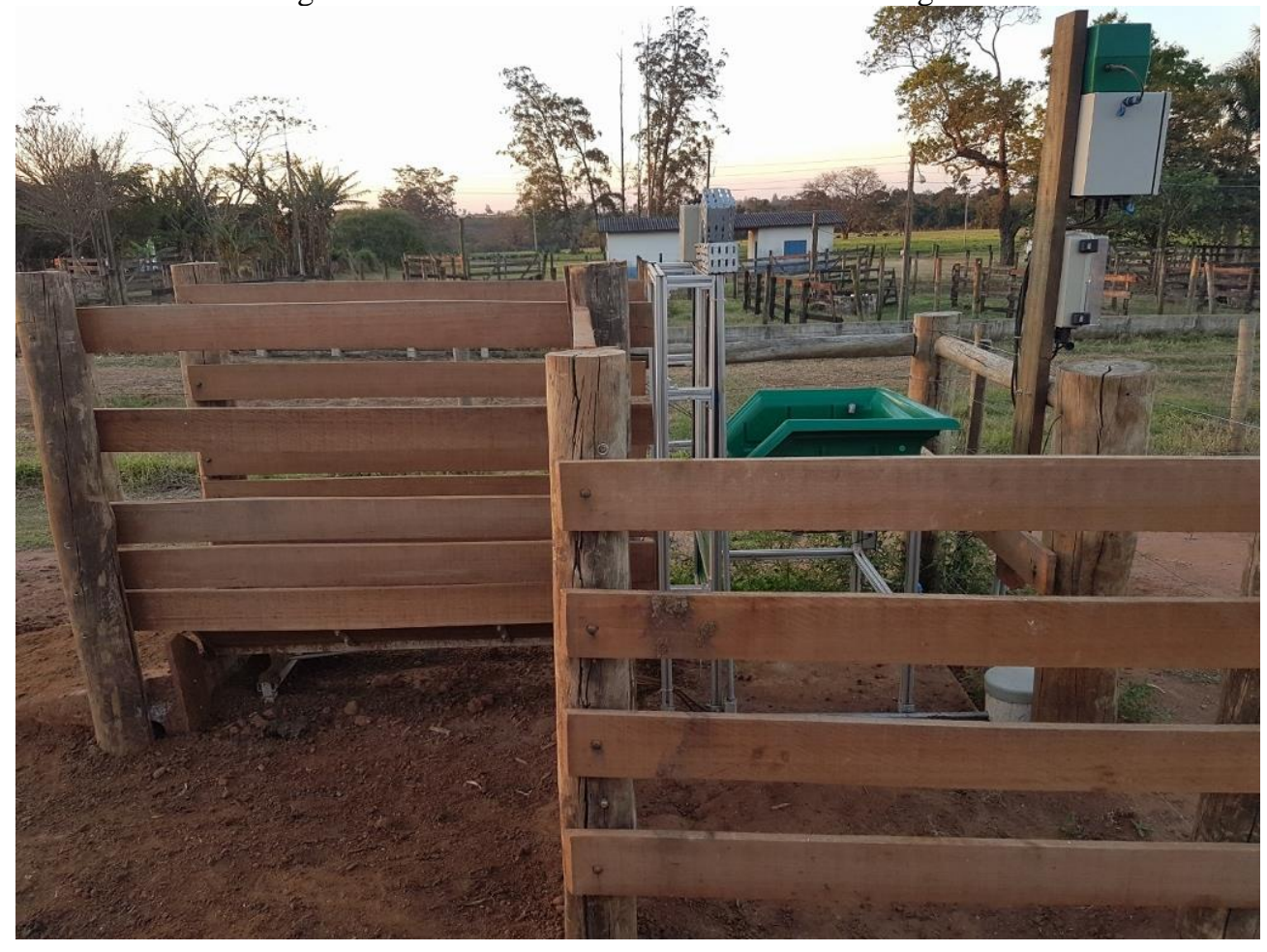

Fonte: Própria autoria. 
Figura 7. Bebedouro circular

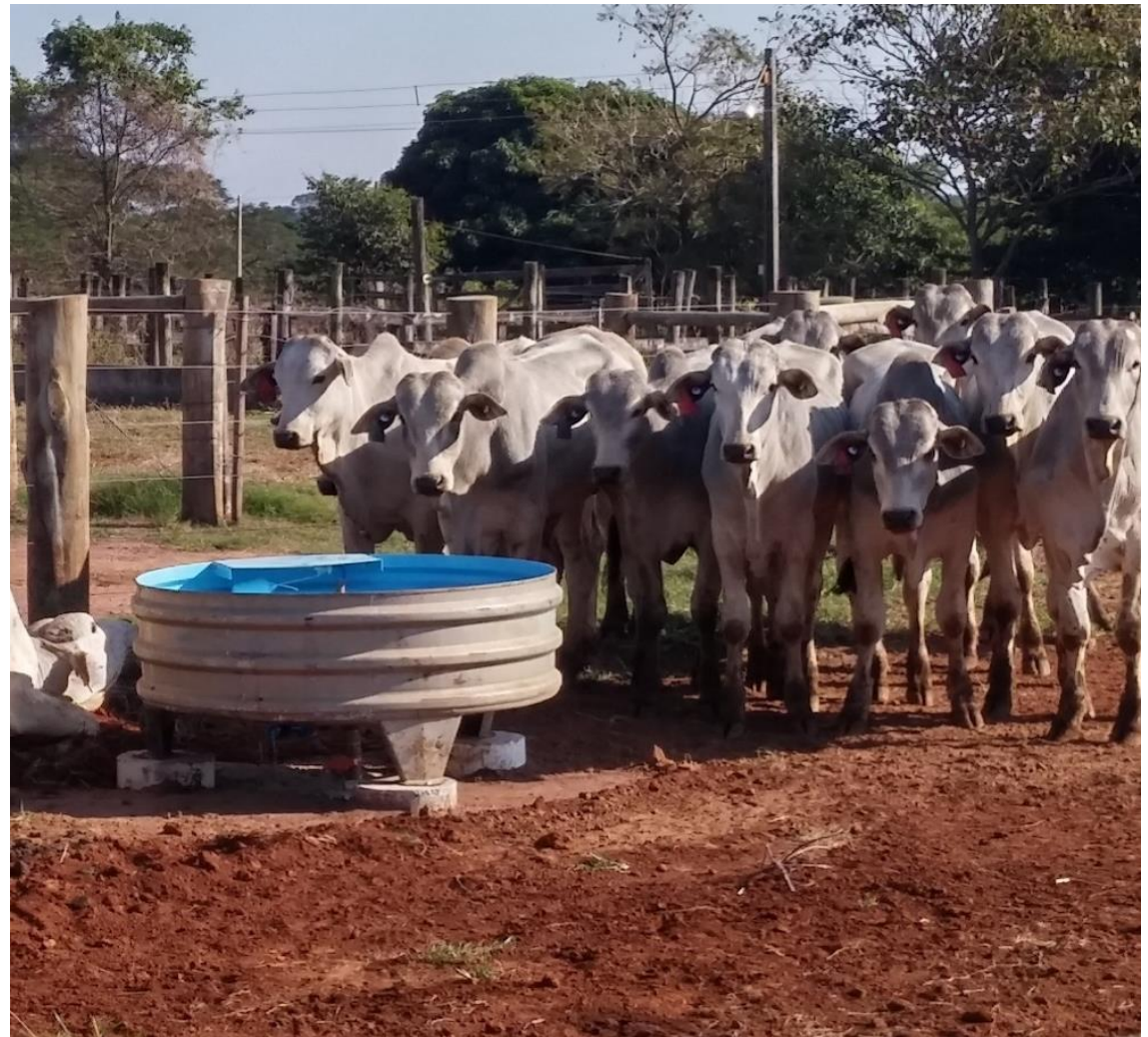

Fonte: Própria autoria.

Figura 8. Hidrômetro instalado nos bebedouros circulares

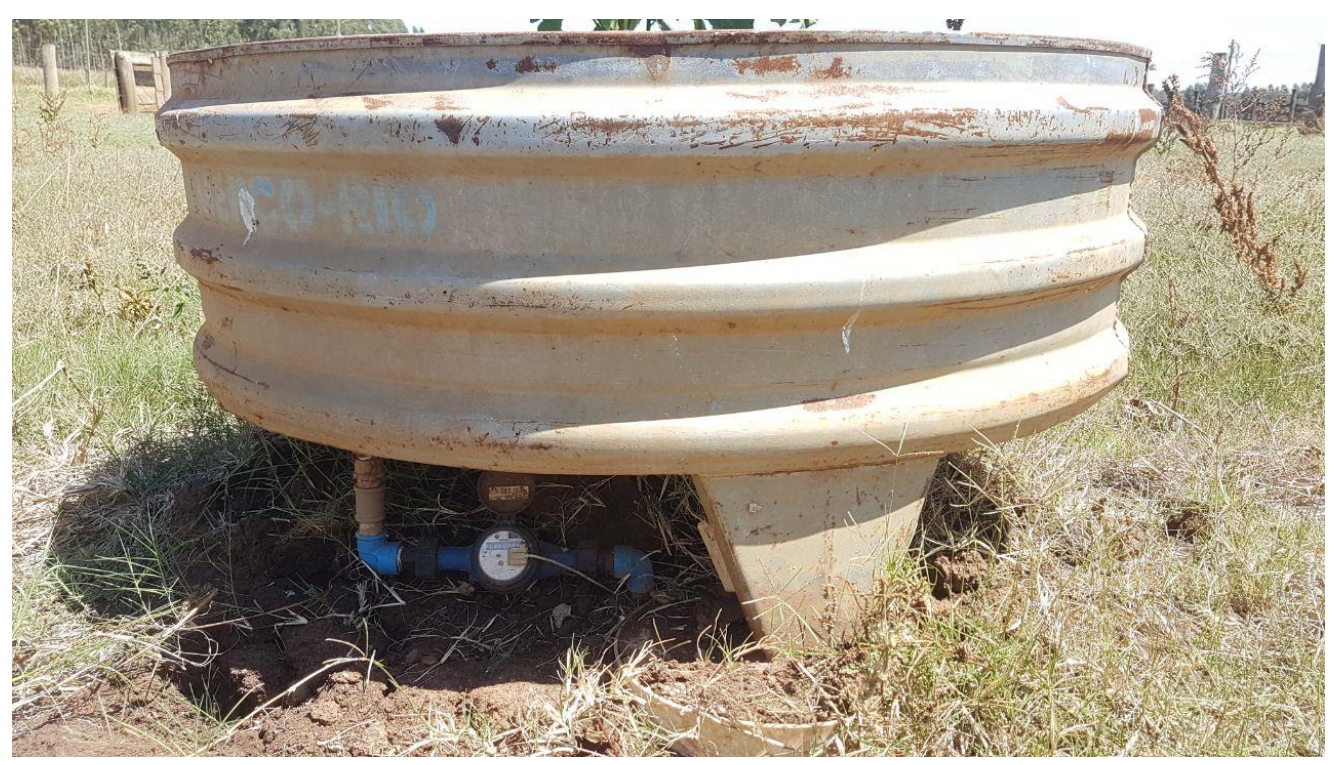

Fonte: Própria autoria. 
A caracterização dos nove confinamentos comerciais foi feita pelo envio de formulário eletrônico (Apêndice A) para o proprietário ou para o responsável pelo manejo do sistema. $\mathrm{Na}$ Tabela 5 apresentam-se as características produtivas e ambientais de cada confinamento as quais foram utilizadas como referenciais para os cálculos das pegadas hídricas. As informações do tipo de dieta e quais os ingredientes utilizados em cada fazenda encontram-se no Apêndice B. 


\begin{tabular}{|c|c|c|c|c|c|c|c|c|c|c|c|}
\hline & Cidade & $\begin{array}{c}\mathrm{N} . \\
\text { Animais }\end{array}$ & Raça & $\begin{array}{l}\mathbf{P I}^{2} \\
(\mathbf{k g})\end{array}$ & $\begin{array}{l}\mathbf{P F}^{3} \\
(\mathbf{k g})\end{array}$ & $\begin{array}{c}\mathbf{G P D}^{4} \\
(\mathrm{~kg})\end{array}$ & $\begin{array}{c}\text { Dias } \\
\text { em } \\
\text { Conf. }\end{array}$ & $\begin{array}{c}\text { Ciclo } \\
\text { no } \\
\text { ano }\end{array}$ & $\begin{array}{c}\mathrm{CMS}^{5} \\
\left(\mathrm{~kg}^{5}\right. \\
\mathrm{cab}^{-1} \\
\left.\mathrm{dia}^{-1}\right)\end{array}$ & $\begin{array}{l}\text { Temp. } \\
\left({ }^{0} \mathrm{C}\right) *\end{array}$ & $\begin{array}{l}\text { Precip. }^{7} \\
\text { (mm)* }\end{array}$ \\
\hline \multirow{2}{*}{1} & \multirow{2}{*}{ Nhandeara/SP } & 900 & Angus & 270 & 450 & 1,4 & \multirow{2}{*}{130} & \multirow{2}{*}{2,8} & \multirow{2}{*}{10,00} & \multirow{2}{*}{35,8} & \multirow{2}{*}{77,6} \\
\hline & & 900 & Wagyu & 380 & 659 & 2,1 & & & & & \\
\hline 2 & Nova Crixás/GO & 45.000 & Nelore/Anelorado/Cruzamento & 360 & 570 & 1,9 & 110 & 3,3 & 10,38 & 36,3 & 4,1 \\
\hline 3 & Chupinguaia/RO & 45.000 & Diversas & 359 & 533 & 1,7 & 105 & 3,5 & 11,70 & 31,8 & 2,9 \\
\hline 4 & Guarda Mor/MG & 50.000 & Nelore/Anelorado/Cruzamento & 369 & 514 & 1,4 & 100 & 3,6 & 10,15 & 28,8 & 2,8 \\
\hline 5 & Novo Mundo/MT & 7.000 & Nelore & 396 & 538 & 1,5 & 97 & 3,7 & 10,97 & 31,5 & 4,1 \\
\hline 6 & Rio Verde/GO & 10.000 & $\begin{array}{c}\text { Angus/ Brangus/ Senepol/ } \\
\text { Charolês/ Wagyu }\end{array}$ & 242 & 490 & 1,7 & 150 & 2,4 & 15,16 & 31,9 & 3,3 \\
\hline 7 & Chapadão do Sul/MS & 8.800 & Nelore/Angus/Composto & 357 & 530 & 1,3 & 135 & 2,6 & 10,35 & 32,0 & 4,1 \\
\hline 8 & Água Boa/MT & 30.000 & Nelore/Angus & 394 & 606 & 1,8 & 120 & 3,0 & 12,42 & 33,1 & 5,3 \\
\hline 9 & $\begin{array}{l}\text { Luís Eduardo } \\
\text { Magalhães/BA }\end{array}$ & 4.500 & Nelore/Cruzamento Industrial & 360 & 540 & 1,8 & 100 & 3,6 & 8,97 & 32,1 & 0,0 \\
\hline
\end{tabular}

${ }^{1}$ Número de animais por ciclo de confinamento; ${ }^{2}$ Peso médio inicial; ${ }^{3}$ Peso médio final; ${ }^{4}$ Ganho de peso médio diário; ${ }^{5}$ Consumo de matéria seca; ${ }^{6}$ Temperatura média no local durante o período de confinamento; ${ }^{7}$ Precipitação acumulada no local durante o período de confinamento. ${ }^{*}$ Dados climáticos obtidos do Sistema de Monitoramento Agrometeorológico da Embrapa (Agritempo). 


\subsection{INTERVENÇÕES NUTRICIONAIS AVALIADAS NA FASE EXPERIMENTAL}

As duas intervenções avaliadas foram: dieta 1- silagem de milho como volumoso e concentrado composto por milho e farelo de soja e dieta 2- silagem de milho como volumoso e concentrado composto por gérmen de milho gordo, polpa cítrica e farelo de amendoim. Os tratamentos testados neste ensaio foram: DCL: dieta 1 (convencional) oferecida para o grupo de animais leves; DCP: dieta 1 oferecida para o grupo de animais pesados; DSL: dieta 2 (uso de coprodutos) oferecida para o grupo de animais leves e DSP: dieta 2 (uso de coprodutos) oferecida para o grupo de animais pesados. A tabela 6 apresenta a caracterização inicial de cada tratamento. Durante o período de confinamento, as dietas foram fornecidas duas vezes ao dia, e ajustadas diariamente permitindo sobras de $10 \%$ na matéria natural $(\mathrm{MN})$.

Tabela 6. Caracterização dos grupos experimentais

\begin{tabular}{lcc}
\hline & \multicolumn{2}{c}{ Dietas } \\
\cline { 2 - 3 } Número de animais & Convencional & Coprodutos \\
Peso corporal inicial, kg & 26 & 26 \\
Peso metabólico inicial, kg & $297,13 \pm 3,81$ & $297,78 \pm 3,82$ \\
Idade inicial, dias & $71,49 \pm 0,69$ & $71,61 \pm 0,69$ \\
& $607,5 \pm 3,54$ & $604,6 \pm 3,54$ \\
\hline
\end{tabular}

As dietas foram ajustadas para as exigências de ganho dos animais de acordo com as fases do confinamento (adaptação, crescimento e terminação) e balanceadas para serem isoproteícas e isoenergéticas. A dieta de adaptação continha $16 \%$ PB e $72 \%$ de NDT. Na dieta de crescimento essas porcentagens foram de $15 \%$ PB e $74 \%$ de NDT. Na fase de terminação a dieta continha $14 \%$ PB e $76 \%$ NDT.

A Tabela 7 apresenta as quantidades e porcentagens de cada ingrediente por dieta e por fase. 
Tabela 7. Composição das dietas experimentais

\begin{tabular}{|c|c|c|c|}
\hline \multicolumn{4}{|c|}{ Adaptação } \\
\hline \multicolumn{2}{|c|}{ Convencional } & \multicolumn{2}{|c|}{ Coprodutos } \\
\hline Ingrediente & $\begin{array}{c}\text { Proporção na dieta } \\
(\%)\end{array}$ & Ingrediente & $\begin{array}{c}\text { Proporção na dieta } \\
(\%)\end{array}$ \\
\hline Silagem de milho & 89,10 & Silagem de milho & 82,3 \\
\hline Farelo de soja & 6,44 & $\begin{array}{l}\text { Farelo de } \\
\text { amendoim }\end{array}$ & 6,44 \\
\hline Milho grão & 3,93 & $\begin{array}{l}\text { Gérmen de milho } \\
\text { gordo }\end{array}$ & 6,68 \\
\hline Gordura protegida & 0,22 & Polpa cítrica & 4,13 \\
\hline Confinatto $\mathrm{N} 235^{1}$ & 0,17 & Confinatto N235 & 0,34 \\
\hline Ureia & 0,11 & Ureia & 0,09 \\
\hline \multicolumn{4}{|c|}{ Crescimento } \\
\hline \multicolumn{2}{|c|}{ Convencional } & \multicolumn{2}{|c|}{ Coprodutos } \\
\hline Ingrediente & $\begin{array}{c}\text { Proporção na dieta } \\
(\%)\end{array}$ & Ingrediente & $\begin{array}{c}\text { Proporção na dieta } \\
(\%)\end{array}$ \\
\hline Silagem de milho & 81,80 & Silagem de milho & 73,00 \\
\hline Farelo de soja & 4,95 & $\begin{array}{l}\text { Farelo de } \\
\text { amendoim }\end{array}$ & 3,22 \\
\hline Milho grão & 11,79 & $\begin{array}{l}\text { Gérmen de milho } \\
\text { gordo }\end{array}$ & 12,60 \\
\hline Gordura protegida & 0,65 & Polpa cítrica & 7,79 \\
\hline Confinatto N235 & 0,50 & Confinatto N235 ${ }^{1}$ & 0,64 \\
\hline Ureia & 0,32 & Ureia & 0,17 \\
\hline
\end{tabular}

\begin{tabular}{|c|c|c|c|}
\hline \multicolumn{4}{|c|}{ Terminação } \\
\hline \multicolumn{2}{|c|}{ Convencional } & \multicolumn{2}{|c|}{ Coproduto } \\
\hline Ingrediente & $\begin{array}{c}\text { Proporção na dieta } \\
(\%)\end{array}$ & Ingredientes & $\begin{array}{c}\text { Proporção na dieta } \\
(\%)\end{array}$ \\
\hline Silagem de milho & 72,80 & Silagem de milho & 57,30 \\
\hline Farelo de soja & 3,06 & $\begin{array}{l}\text { Farelo de } \\
\text { amendoim }\end{array}$ & 4,70 \\
\hline Milho grão & 21,44 & $\begin{array}{l}\text { Gérmen de milho } \\
\text { gordo }\end{array}$ & 22,59 \\
\hline Gordura protegida & 1,19 & Polpa cítrica & 13,96 \\
\hline Confinatto $\mathrm{N} 235^{1}$ & 0,91 & Confinatto $\mathrm{N} 235^{1}$ & 1,15 \\
\hline Ureia & 0,59 & Ureia & 0,30 \\
\hline
\end{tabular}

O consumo de matéria seca (CMS) foi calculado para cada fase de desenvolvimento do animal (adaptação, crescimento e terminação), o ganho médio diário (GMD) foi calculado por meio 
da regressão do peso nos dias em teste e o peso corporal metabólico $\left(\mathrm{PC}^{0,75}\right)$ calculado pelo peso vivo a metade do experimento elevado a 0,75 .

As pesagens iniciais e finais dos animais foram realizadas com prévio jejum de 16 horas de sólidos totais e água. Durante o experimento, a cada 28 dias, foram realizadas a pesagem dos animais e a coleta de fezes. Na pesagem foram cosiderados os cuidados com jejum, a fim de aumentar a acurácia de estimativa do ganho médio diário e evitar interferências de perdas de peso e/ou ganhos compensatórios durante os períodos.

A coleta de fezes foi realizada em 26 animais, escolhidos de forma aleatória, de forma a serem representativos de cada grupo. Para a coletas houve a imobilização dos animais em tronco de contenção, com infraestrutura adequada para proporcionar conforto ao animal e minimizar o estresse. As fezes foram retiradas diretamente da ampola retal dos animais e armazenadas em bandejas metálicas para posterior secagem em estufa de ventilação forçada $\left(65^{\circ} \mathrm{C}\right)$ por 72 horas e moídas em moinho do tipo Willey com peneira de $2 \mathrm{~mm}$ e armazenadas em recipientes plásticos.

As amostras dos resíduos foram analisadas no laboratório de nutrição da Embrapa Pecuária Sudeste para os parâmetros de nitrogênio, fósforo e potássio. A determinação do $\mathrm{N}$ foi feita pelo método semimicro Kjeldhal, segundo a Assocition of Oficial Analytical Chemists (AOAC, 1995) e o fator de conversão foi de 6,25. Para determinar as concentrações de P e K nas fezes foi utilizada a espectrometria de emissão óptica com plasma indutivamente acoplado (ICP-OES- Inductively Coupled Plasma Optical Emission Spectroscopy).

$\mathrm{Na}$ pesagem pré-abate os animais foram mantidos em jejum de alimento e água por 16 horas, dois dias anterior ao abate, para esvaziamento do rúmen e obtenção do peso vivo, e na véspera do abate, conforme normas vigentes do MAPA (Regulamento técnico de métodos de insensibilização para o abate humanitário de animais de açougue- IN 03/2000).

\subsection{CÁLCULO DAS PEGADAS HÍDRICAS}

Para mensuração das demandas hídricas agrícolas, zootécnicas e agroindustriais e para o cálculo das pegadas hídricas foi utilizado o método proposto por Hoekstra et al. (2011).

A escala espacial para o cálculo das pegadas hídricas foi o sistema de produção confinado e as áreas necessárias para produção dos ingredientes que compunham as dietas. Não se considerou as fases de cria e recria dos animais. A escala temporal foi um ciclo de confinamento. As fontes de dados foram primárias e secundárias para o cálculo dos consumos diretos e indiretos. 
A descrição do sistema de produção em investigação é essencial, uma vez que a utilização dos insumos em geral e do uso da água em particular, estão intimamente relacionados ao sistema e ao local de produção. Estes fatores também são fundamentais para o estabelecimento da fronteira do cálculo e para a proposição das intervenções mitigadoras. Neste estudo a fronteira de cálculo compreendeu o conceito de berço até o processamento do produto (cradle-to-processing gate).

A unidade funcional foi quilogramas de carne desossada. Para isso foi utilizada a soma da pesagem dos cortes cárneos desossados 24 horas após o abate dos animais (cupim, acém, pescoço, peito, retalho magro do dianteiro, bananinha, contrafilé, filé mignon, capa do filé, cordão, miolo de alcatra, maminha, picanha, coxão mole, coxão duro, lagarto, patinho, músculo do traseiro, aranha, fraldão, retalho magro do traseiro). Não foram contabilizados sebo e gordura. Nos nove sistemas de confinamento comercial o peso vivo do animal foi convertido em carne bovina de carcaça multiplicando o peso vivo pelo rendimento de carcaça de 54,5\%. Esse valor foi multiplicado por $1 \%$ (perda de água durante o congelamento) e $78 \%$ (porcentagem de carne na carcaça).

Para os cálculos das pegadas hídricas azul e cinza referentes ao abate, processamento e beneficiamento do produto carne foram monitorados por hidrômetros os consumos mensais de água de duas plantas frigoríficas, uma no Estado de São Paulo e outra no Estado do Mato Grosso. Também foram caracterizadas as qualidades dos efluentes dispostos nos corpos d'água superficiais, sendo considerados para ambos os Estados rios Classe 2.

\subsubsection{Pegada hídrica verde}

Para o cálculo da componente verde da pegada hídrica, estabeleceu-se que todas as culturas vegetais foram produzidas em sistema de sequeiro, portanto sem a necessidade de irrigação. A água verde é entendida como um uso indireto de água. Ela representa a água consumida na produção das culturas vegetais e água contida nesses produtos.

É necessária uma grande quantidade de dados para estimar a pegada hídrica verde. Quando o objetivo da avaliação é fazer uma estimativa aproximada é comum utilizar dados climáticos de locais próximos e dados de culturais obtidos a partir de estatísticas e médias regionais ou nacionais. Quando o estudo é realizado na escala de fazenda são necessários dados detalhados sobre o clima e as culturas vegetais. Tais cálculos são mais precisos, uma vez que geram estimativas de água diretamente relacionadas à quantidade de biomassa utilizada pelos animais. 
O cálculo dessa água se deu pela mensuração da evapotranspiração da cultura, considerando o seu coeficiente $(\mathrm{Kc})$ e a evapotranspiração de referência na região de cálculo, somado a quantidade de água no produto.

O cálculo da água verde é apresentado na Eq. 1.

$$
\text { PHverde }=\frac{\sum_{\mathrm{d}=1}^{\mathrm{n}} \text { (Evapo. da Cult. }[a, e]+\text { Produto }(d, e)}{\text { Tonelada de Carne }}
$$

em que:

$\mathrm{PH}_{\text {verde }}$ - Pegada Hídrica Verde $\left(\mathrm{m}^{3} \mathrm{t}^{-1}\right)$.

Evapo. da Cult. $[c, s]$ - Evapotranspiração de referência de cada ingrediente da dieta $d$ consumido pelos animais $a$ no experimento $e\left(\mathrm{~m}^{3} \mathrm{t}^{-1}\right)$.

Produto $[d, e]$ - Teor de água no ingrediente $d$ no experimento $e\left(\mathrm{~m}^{3} \mathrm{t}^{-1}\right)$. O teor de água no produto foi obtido pela porcentagem de matéria seca de cada ingrediente das dietas.

Os dados climáticos utilizados para o cálculo do consumo de água verde de cada cultura agrícola utilizada no arraçoamento dos animais corresponderam ao ciclo de desenvolvimento do plantio à colheita. A duração de cada ciclo foi estabelecida de acordo com o Zoneamento Agroclimático publicado pela Companhia Nacional de Abastecimento (CONAB). O zoneamento determina os períodos mais adequados para o plantio das culturas vegetais.

A quantidade de hectares necessários para produção de cada cultura agrícola que compôs as dietas dos animais foi determinada pela razão do consumo total de matéria natural do ingrediente na dieta pela produtividade da cultura $\left(\mathrm{t} \mathrm{ha}^{-1}\right)$.

Considerou-se que os ingredientes que constituíram o concentrado da fase experimental foram provenientes da safra 2015/2016. Estipulou-se que o milho foi produzido no estado do Paraná e o farelo de soja no estado do Mato Grosso. Esses dois estados foram selecionados devido a sua tradição produtiva para ambos os grãos e à proximidade com o estado de São Paulo, amentando a probabilidades que os grãos consumidos pelo sistema de produção de estudo fossem originados de ambos os estados. Para a polpa cítrica, gérmen de milho e o farelo de amendoim considerou-se o estado produtor como São Paulo devido à proximidade do local do estudo. Essa abordagem foi necessária devido a impossibilidade de se rastrear a origem dos grãos comprados. 
Selecionados os estados de origem dos grãos, a seleção dos municípios produtores foi feita pela consulta ao banco de dados do Instituto Brasileiro de Geografia e Estatística de Recuperação Automática (SIDRA). Analisando-se as séries históricas de produtividade de cada Estado, calculou-se a produtividade média estadual para cada grão na década 2004-2013. Com os valores de produtividade média, identificou-se os municípios com os valores mais próximo das médias na safra 2015-2016. Os municípios selecionados foram: Londrina/PR para o milho e gérmen de milho gordo, Alto Araguaia/MT para a soja, Pradópolis/SP para polpa cítrica e Barretos/SP para o farelo de amendoim.

Os coeficientes de cultura (Kc) utilizados para determinação da demanda hídrica do milho, da soja, do amendoim e da laranja foram os propostos na publicação Irrigação e Drenagem no 33 da Food and Agriculture Organization of the United Nations - FAO (DOORENBOS; KASSAM, 1979).

O volumoso na forma de silagem de milho foi produzido na fazenda da Embrapa Pecuária Sudeste. Para o cálculo da água consumida na produção desse ingrediente utilizou-se os dados climáticos da estação meteorológica localizado na Embrapa Pecuária Sudeste. Os coeficientes de cultura $(\mathrm{Kc})$ utilizados para determinação da demanda hídrica da silagem de milho estão de acordo com a publicação Irrigação e Drenagem no 33 da FAO (DOORENBOS; KASSAM, 1979).

A partir do grão de soja dois produtos são obtidos: o farelo e o óleo. Como o produto soja é consumido na forma de farelo só foi considerado no cálculo da pegada verde referente a esse grão a água consumida para se produzir esse produto. Para isso utilizou-se os fatores técnicos de conversão das commodities agropecuárias da FAO (2013). Os fatores recomendados para e realidade produtiva brasileira são $77 \%$ do grão é transformado em farelo e $23 \%$ em óleo. O farelo de amendoim, o gérmen de milho e a polpa cítrica são considerados coprodutos da produção de um produto principal. Dessa forma no cálculo da pegada hídrica só são considerados os consumos de água referentes ao coproduto. Para isso utilizou-se os fatores técnicos de conversão de commodities agropecuárias da FAO (2013). Os fatores recomendados para a realidade produtiva brasileira são: $56 \%$ do grão do amendoim é transformado em farelo, $5 \%$ do grão de milho é transformado em gérmen e $28 \%$ da produção de laranja é transformada em polpa.

No caso dos ingredientes dos concentrados de cada um dos nove sistemas de confinamento comercial considerou-se a produtividade $\left(\mathrm{t} \mathrm{ha}^{-1}\right)$ do ingrediente no município indicado como 
origem da compra. Caso a origem do ingrediente não fosse conhecida admitiu-se que foi produzido na propriedade rural do sistema de confinamento.

Os dados climáticos e os valores de evapotranspiração de referência (ETo) necessários para o cálculo das águas consumidas por cada cultura vegetal foram obtidos por consulta à base de dados do Sistema de Monitoramento Agrometeorológico da Embrapa (Agritempo). Selecionaram-se as estações meteorológicas dos municípios de cada fazenda ou mais próxima a esse. Para os municípios que não possuíam os dados na base do Agritempo a ETo foi calculada de acordo com o método de Thornthwaite de 1948, descrito por Pereira, Angelocci e Sentelhas (2002).

\subsubsection{Pegada hídrica azul}

A água azul e aquela extraída de fontes superficiais e subterrâneas e utilizada na irrigação das culturas, dessedentação dos animais, serviços na fazenda e no abate de animais e processamento dos produtos. Nos cálculos foram considerados os consumos de água de dessedentação animal e a utilizada no abate dos animais e processamento dos produtos. No estudo optou-se por não utilizar a água presente no produto para evitar dupla contabilização.

O cálculo da água azul é apresentado na Equação 2.

$$
\text { PHazul }=\frac{(\mathrm{Cd} * \mathrm{UA})+(\text { Cabate }+ \text { processamento })}{\text { Tonelada de Carne }}
$$

em que:

PHazul: pegada hídrica azul $\left(\mathrm{m}^{3} \mathrm{t}^{-1}\right)$;

Cd - Consumo de água de dessedentação $\left(\mathrm{m}^{3}\right)$;

UA: unidade animal;

Cabate + processamento - Consumo de água no abate dos animais e processamento dos produtos $\left(\mathrm{m}^{3}\right)$.

O consumo de água azul de uma planta agroindustrial é a soma dos volumes de água incorporado aos produtos, o volume evaporado nos processos de produção e funcionamento da planta e a 'vazão de retorno perdida'. Esta vazão se refere aos volumes de água lançados em outras bacias ou armazenados por um período suficientemente longo para alterar a disponibilidade de água na bacia. No cálculo do consumo de água no abate e processamento considerou-se a 'vazão 
de retorno perdida' referente ao volume de água armazenado por um período suficientemente longo para alterar a disponibilidade de água na bacia hidrográfica de localização da planta industrial. $\mathrm{O}$ cálculo da pegada azul teve como objeto de estudo dois abatedouros, sendo um localizado na cidade de Promissão-SP e o outro em Tangará da Serra-MT. O consumo de água azul foi calculado para os anos de 2012 a 2015, sendo a média do período utilizada para o cálculo da pegada hídrica azul.

Como nenhum dos nove sistemas de confinamento avaliados dispunha de um sistema de medição do consumo de água pelos animais, esse foi determinado pela equação de Hicks et al., (1988) recomendada pelo NRC (2000), apresentada na equação 3.

$$
\text { Cágua }=-18,67+(0,3937 * \text { Tmax })+(2,432 * \text { CMS })-(3,870 * \text { PP })-(4,437 * \text { Csal })
$$

em que:

Cágua: consumo de água $\left(\mathrm{L} \mathrm{dia}^{-1}\right)$;

Tmax: temperatura máxima média $\left({ }^{0} \mathrm{~F}\right)$;

CMS: consumo de matéria seca $\left(\mathrm{kg} \mathrm{dia}^{-1}\right)$;

PP: precipitação média $\left(\mathrm{cm} \mathrm{dia}^{-1}\right)$;

Csal: consumo de sal (\%).

O índice de escassez de água azul foi determinado de acordo com a metodologia de Hoekstra et al. (2012) e avaliou o volume de água alocado (pegada hídrica azul) em função da disponibilidade hídrica da fonte subterrânea que sustenta o Sistema de Confinamento da Embrapa Pecuária Sudeste. Neste caso entendeu-se disponibilidade hídrica como o volume outorgado pelo órgão responsável para o poço em questão.

Sendo a disponibilidade um fator local, o impacto da pegada hídrica azul depende da disponibilidade hídrica no local da atividade. Quanto mais próximo o índice estiver do valor zero, maior a segurança hídrica da atividade.

A fórmula é apresentada na Eq. 4.

$$
\text { IEA }=\frac{\text { Consumo de água Azul }}{\text { Disponibilidade Hídrica (Superficial + Subterrânea) }}
$$


em que:

IEA: Indicador de Escassez de água azul;

Consumo de água total de azul: $\mathrm{m}^{3}$;

Superficial: é a disponibilidade de água superficial $\left(\mathrm{m}^{3} \mathrm{ano}^{-1}\right)$. A disponibilidade hídrica superficial outorgada para a fazenda Canchim é de 411.194,4 $\mathrm{m}^{3}$ ano $^{-1}$;

Subterrânea: é a disponibilidade de água subterrânea $\left(\mathrm{m}^{3} \mathrm{ano}^{-1}\right)$. A disponibilidade hídrica subterrânea outorgada para a fazenda Canchim é de $138.758 \mathrm{~m}^{3} \mathrm{ano}^{-1}$.

O índice pode apresentar quatro níveis de escassez: <1 baixa escassez de água azul, 1-1,5 escassez moderada, 1,5 - 2,0 escassez significativa e >2,0 escassez severa.

\subsubsection{Pegada hídrica cinza}

A água cinza é definida como o volume de água necessário para assimilar a carga de poluentes com base nas concentrações naturais e nos padrões legais. No estudo só foi calculada a água cinza referente ao abate dos animais e processamento dos produtos. O cálculo da pegada cinza teve como objeto de estudo um abatedouro localizado na cidade de Tangará da Serra/MT.

Foram contabilizadas as águas residuais oriundas do recebimento dos animais, processos industriais, higienização e esgotamento sanitário. Para os efluentes líquidos existiam duas linhas, a linha verde (constituída por esterco e material orgânico proveniente da lavagem do rúmen) e linha vermelha (constituída basicamente de sangue). Os efluentes passavam por peneiramento estático e então o líquido proveniente da linha vermelha passava também por flotação. Ambos os efluentes se misturavam e eram direcionados a dois biodigestores em série. Após o tratamento pelos biodigestores o efluente era conduzido para um sistema de três lagoas, sendo o destino final o despejo em curso d'água superficial.

O consumo de água cinza foi calculado para os anos de 2012 a 2014, sendo a mediana do período utilizada para o cálculo da pegada hídrica cinza. O cálculo da água cinza para fonte de poluição pontual é apresentado na Equação 5 de acordo com Franke et al., 2013.

$$
\text { PHcinza }=\frac{(\text { Ceflu } x \text { Vol. Eflu. }) /(\text { Cmax. }- \text { Cnat. })}{\text { Tonelada de Carne }}
$$


em que:

PHcinza: pegada hídrica cinza $\left(\mathrm{m}^{3} \mathrm{t}^{-1}\right)$;

Ceflu - Concentração média do efluente para fósforo total $\left(\mathrm{mg} \mathrm{L}^{-1}\right)$, a partir dos dados do efluente fornecidos pela agroindústria;

Vol. eflu - Volume do efluente $\left(\mathrm{m}^{3} \mathrm{ano}^{-1}\right)$.

Cmax: concentração máxima do elemento no corpo d'água de acordo com a Resolução Conama no 357. Considerando rios Classe 2, concentração máxima aceitável de fósforo total é $0,1 \mathrm{mg} \mathrm{L}^{-1}$;

Cnat: concentração natural do elemento no corpo d'água. Considerou-se o valor zero para a concentração natural do elemento no corpo hídrico.

\subsection{BALANÇO DE NUTRIENTES}

O balanço de nutrientes foi calculado para os elementos nitrogênio $(\mathrm{N})$, fósforo $(\mathrm{P})$ e potássio (K) segundo metodologia proposta por Oenema et al (2001).

O balanço foi aplicado de acordo com a Equação 6. Nas entradas foram contabilizadas as quantidades de nutrientes ingeridas pelos animais em cada dieta (silagem de milho e o concentrado). Como saída foi considerado somente o produto carne e as fezes.

$$
\begin{array}{r}
\text { Balanço }_{[\mathrm{N}, \mathrm{P}, \mathrm{K}]}=\left(\sum_{\mathrm{i}=1}^{\mathrm{n}} \text { Quant. }_{[\mathrm{N}, \mathrm{P}, \mathrm{K}]} \text { na dieta }\right) \\
-\left(\sum_{\mathrm{i}=1}^{\mathrm{n}} \text { Quant. }_{[\mathrm{N}, \mathrm{P}, \mathrm{K}]} \text { na carne }+\sum_{\mathrm{i}=1}^{\mathrm{n}} \text { Quant. }_{[\mathrm{N}, \mathrm{P}, \mathrm{K}]} \text { na fezes }\right)
\end{array}
$$

em que:

Quant.[N,P,K] nas dietas: quantidade do elemento nos ingredientes das dietas (kg do elemento);

Quant.[N,P,K] carne: quantidade do elemento no produto $(\mathrm{kg})$;

Quant.[N,P,K] fezes: quantidade do elemento nas fezes $(\mathrm{kg})$.

O cálculo da eficiência de uso do nutriente (EU) foi realizado de acordo com a Equação 7.

$$
\% \mathrm{EU}_{[\mathrm{N}, \mathrm{P}, \mathrm{K}]}=\frac{\sum_{\mathrm{i}=1}^{\mathrm{n}} \text { saídas }}{\sum_{\mathrm{i}=1}^{\mathrm{n}} \text { entradas }} * 100(7)
$$


em que:

Saídas: quantidade do elemento no produto $(\mathrm{kg})$;

Entradas: quantidade do elemento nos ingredientes das dietas (kg).

As concentrações de $\mathrm{N}$ de cada ingrediente da dieta foram obtidas a partir do teor de proteína destes. Para os alimentos concentrados o teor de proteína e as quantidades dos elementos $\mathrm{P}$ e K foram obtidos pela consulta as tabelas Brasileiras de Composição de Alimentos para Bovinos (CQBAL 3.0; VALADARES FILHO et al., 2017). Para o teor de proteína da silagem de milho foram coletadas amostras durante o período do experimento e enviadas ao laboratório para análise.

Os elementos $\mathrm{P}$ e $\mathrm{K}$ foram quantificados na silagem de milho pela consulta a tabela Brasileira de Composição de Alimentos para Bovinos (CQBAL 3.0; VALADARES FILHO et al., 2017).

Como produto considerou-se a carne apta para o consumo, descontando os volumes de ossos, gordura e retalhos. A quantidade de carne contida em cada carcaça foi mensurada pela pesagem de todos os cortes 24 horas após o abate dos animais. Os dados dos nutrientes na carne foram obtidos pela consulta a tabela de composição de alimentos da Unicamp (NEPA-UNICAMP, 2011).

A cada pesagem dos animais no intervalo de 28 dias, foram realizadas coletas totais de fezes em 25 animais escolhidos de forma aleatória, de maneira que esses animais fossem representativos de cada grupo experimental. A partir das coletas, realizou-se as análises das concentrações de nitrogênio, fósforo e potássio.

\subsection{ANÁLISE DE CUSTO}

O método de cálculo dos custos de produção do sistema de confinamento experimental foi baseado no trabalho de Sartorello (2016), no qual o autor utilizou o método de custeio variável. Nesse método ocorre a classificação dos custos em variáveis e custos fixos. O autor também incluiu a classificação de custos semifixos, como recomendado por Powers (1987; Quadro 1).

Para o desenvolvimento do cálculo utilizou-se a planilha de custos, desenvolvida por Sartorello (2016) no software Microsoft Excel®, no qual foram inclusos todos os dados da atividade de confinamento de bovinos. No estudo todos os preços de insumos, serviços e bens de capital foram utilizados e baseados nos dados de Sartorello (2016) para setembro de 2017. Para adequar os dados do experimento aos valores a realidade produtiva brasileira, em particular ao 
estado de SP, foram considerados apenas bebedouros convencionais e utilizou-se 6.000 animais por ciclo de confinamento, dados médios obtidos de Palhares, Morelli e Costa Junior (2017).

Quadro 1. Descrição dos itens de produção.

\section{Itens do custo}

1- Custos variáveis

Aquisição de animais

Alimentação

Manejo sanitário

Manejo de identificação

Outros custos variáveis

Impostos variáveis

Subtotal custos variáveis

2- Custos semifixos

Energia elétrica

Telefonia e serviços de internet

Combustíveis

Outros custos semifixos

Subtotal custos semifixos

3- Custos Fixos

Mão de obra

Depreciação

Manutenção

Outros custos fixos

Subtotal custos fixos

4- Custo com renda dos fatores

Remuneração do capital de giro

Remuneração do capital fixo

Remuneração da terra

Subtotal renda dos fatores

5- Custo operacional efetivo

6- Custo operacional total

7- Custo total

Fonte: Adaptado de Silva et al. (2014) apud Sartorello (2016).

Para o cálculo dos custos dos ingredientes da dieta convencional foi considerado o preço médio mensal histórico para um período de 10 anos. Os preços históricos foram obtidos da base de dados do Centro de Estudos Avançados em Economia Aplicada (CEPEA/ESALQ/USP).

Os preços mensais foram obtidos na sua unidade original, para o período compreendido entre setembro de 2007 a setembro de 2017. Além disso, os preços foram deflacionados pelo Índice 
Nacional de Preços ao Consumidor (INPC, 2018) para o período de setembro de 2017. A justificativa para se trabalhar com dados históricos de preços se baseia no fato de que a maioria dos produtos de origem agropecuária apresenta significativa variação sazonal. Portanto, preços históricos tendem a representar mais satisfatoriamente a realidade.

Para o cálculo dos custos dos ingredientes da dieta com coprodutos foi considerado os preços pagos pelos insumos na data de compra, sendo estes deflacionados pelo INPC (2018) para o período de setembro de 2017. Nesse caso não foi utilizado a série histórica devido à ausência de informações.

A cobrança pelo uso da água na Região Hidrográfica do Rio Mogi-Guaçu, na qual está localizada a unidade da Embrapa Pecuária Sudeste ainda não foi implementada, desta forma a valoração dos recursos hídricos foi realizada seguindo-se a diretriz do Comitê das Bacias Hidrográficas dos Rios Piracicaba, Capivari e Jundiaí (PCJ). A escolha por tal diretriz se deve ao fato de que esta é a de maior histórico no Estado de São Paulo. O cálculo considerou as águas de consumo (Eq. 8) e captação (Eq.9).

$$
\text { Ág. consumo = Ág. dessen } * \text { valor comitê (8) }
$$

em que:

Ág. consumo: valor da água consumida pelos animais $\left(\mathrm{R} \$ \operatorname{ciclo}^{-1}\right)$;

Ág. dessen.: quantidade de água de consumida para dessedentação dos animais durante o ciclo produtivo $\left(\mathrm{m}^{3}\right)$;

Valor comitê: valor do custo da água de consumo pelo comitê do PCJ no ano de 2016, igual a R\$ 0,0235 por $\mathrm{m}^{3}$.

$$
\text { Ág. captação = Ág. dessen } * \text { valor comitê } * \text { fator de perda (9) }
$$

em que:

Ág. captação: valor da água captada pela propriedade $\left(\mathrm{R} \$\right.$ ciclo $\left.^{-1}\right)$;

Valor comitê: valor do custo da água de captação pelo comitê do PCJ no ano de 2016, R\$ 0,0127 por $\mathrm{m}^{3}$;

Fator de Perda: Foi atribuída uma perda de $40 \%$ entre o captado e o consumido, portanto o fator de perda é de 1,4 . 
A partir disso, foi calculado o valor total $\left(\mathrm{R} \$\right.$ ciclo $\left.^{-1}\right)$ de acordo com a Equação 10.

$$
\text { Valor total = Ág. consumo + Ág. captação (10) }
$$

em que:

Valor total: valor total da água $\left(\mathrm{R} \$\right.$ ciclo $\left.^{-1}\right)$;

Ág. consumo: valor encontrado na equação $8\left(\mathrm{R} \$\right.$ ciclo $\left.^{-1}\right)$;

Ág. captação: valor encontrado na equação $9\left(\mathrm{R} \$ \operatorname{ciclo}^{-1}\right)$.

\section{RESULTADOS}

Neste item são apresentados os resultados de desempenho animal nos grupos experimentais, os cálculos das pegadas hídricas, o balanço de nutrientes e a análise econômica do sistema de confinamento experimental.

\subsection{DESEMPENHO ANIMAL}

Os resultados de desempenho dos animais são apresentados na Tabela 8. Durante o período de experimentação os animais apresentaram iguais médias de peso $(392,36 \pm 5,02 \mathrm{~kg})$ para ambas as dietas. Os consumos diários de matéria seca apresentaram valores médios de 11,04 $\pm 0,39 \mathrm{~kg}$ $\mathrm{cab}^{-1} \mathrm{dia}^{-1}$ na dieta convencional e 10,17 $\pm 0,39 \mathrm{~kg} \mathrm{cab}^{-1} \mathrm{dia}^{-1}$ na dieta com coprodutos. Não foram observadas diferenças $(\mathrm{p}>0,05)$ quanto ao peso inicial $(\mathrm{PI})$, peso final $(\mathrm{PF})$ e $\mathrm{PC}^{0,75}$.

Tabela 8. Médias de desempenho dos animais de cada grupo experimental

\begin{tabular}{lccc}
\hline \multirow{2}{*}{ Variáveis } & \multicolumn{2}{c}{ Dieta } & \\
\cline { 2 - 3 } & Convencional & Coprodutos & P-value \\
\hline Número de animais & 26 & 26 & - \\
$\mathrm{PI}, \mathrm{kg}$ & $297,13 \pm 3,81^{\mathrm{a}}$ & $297,78 \pm 3,82^{\mathrm{a}}$ & 0,9050 \\
$\mathrm{PF}, \mathrm{kg}$ & $488,42 \pm 7,44^{\mathrm{a}}$ & $492,33 \pm 7,45^{\mathrm{a}}$ & 0,7114 \\
$\mathrm{PC}{ }^{0,75}, \mathrm{~kg}$ & $87,82 \pm 0,85^{\mathrm{a}}$ & $87,47 \pm 0,85^{\mathrm{a}}$ & 0,7762 \\
$\mathrm{GPD}, \mathrm{kg} \mathrm{dia}^{-1}$ & $1,21 \pm 0,04^{\mathrm{a}}$ & $1,15 \pm 0,04^{\mathrm{a}}$ & 0,3771 \\
$\mathrm{CMS}^{1}, \mathrm{~kg} \mathrm{dia}^{-1}$ & $11,04 \pm 0,39^{\mathrm{a}}$ & $10,17 \pm 0,39^{\mathrm{a}}$ & 0,1253 \\
\hline
\end{tabular}

a,b médias seguidas de letras minúsculas iguais nas linhas não diferem entre si a $(p>0,05)$, pelo teste de Tukey.

${ }^{1}$ consumo de matéria seca.

Os valores de ingestão de matéria seca são apresentados na Tabela 9. Os animais alimentados com a dieta de coprodutos apresentaram menor ingestão de concentrado. 
Tabela 9. Ingestão de matéria seca total por tipo de ingredientes durante o período de confinamento

\begin{tabular}{lccccc}
\hline \multirow{2}{*}{ Dieta } & \multicolumn{5}{c}{ Ingestão de matéria seca (kg) } \\
\cline { 2 - 5 } & Silagem & Concentrado & $\begin{array}{c}\text { Farelo de } \\
\text { Soja }\end{array}$ & $\begin{array}{c}\text { Farelo de } \\
\text { amendoim }\end{array}$ & Total \\
\hline Convencional $^{1}$ & $13.663,45$ & $2.044,58$ & $1.800,14$ & - & $17.508,17$ \\
Coprodutos $^{2}$ & $10.679,82$ & $1.350,40$ & - & $1.793,51$ & $13.823,73$ \\
\hline \multicolumn{7}{c}{ Fonte: Dados da pesquisa da autora. } \\
${ }^{1}$ Concentrado composto somente por milho e farelo de soja. \\
${ }^{2}$ Concentrado composto por gérmen de milho gordo, polpa cítrica, farelo de amendoim.
\end{tabular}

\subsection{PEGADA HÍDRICA TOTAL}

A soma das pegadas hídricas verde a azul do confinamento apresentou valor de $2.010,90 \mathrm{~L}$ $\mathrm{kg}^{-1}$ para a dieta convencional e de $1.927,92 \mathrm{~L} \mathrm{~kg}^{-1}$ para a dieta com coprodutos (Tabela 10). A pegada hídrica verde, representou 93,49\% do valor total para a dieta convencional e 93,78\% para dieta com coprodutos.

A formulação da dieta usando apenas coprodutos da agroindústria resultou em um impacto hídrico positivo, redução de $83 \mathrm{~L} \mathrm{~kg}^{-1}$ na pegada hídrica total. Embora o valor seja pequeno, nos estudos de pegada hídrica qualquer valor diferente de 0 é considerado. Pensando em economia de escala, e em uma fazenda produzindo duas toneladas de carne por ciclo produtivo, a economia de água com o uso da dieta de coprodutos seria de 116 mil litros de água. Em contrapartida, a pegada hídrica azul da dieta com coprodutos foi $20,7 \%$ maior, o que significa maior consumo de água de azul.

Ao se adicionar o valor de pegada hídrica do processo de abate as pegadas hídricas totalizam 2.125,54 $\mathrm{L} \mathrm{kg}^{-1}$ de carne para a dieta convencional e $2.042,56 \mathrm{~L} \mathrm{~kg}^{-1}$ de carne para a dieta com o uso de coprodutos, representando um adicional de 5,8\% em ambas as pegadas. Os valores de pegada do abatedouro não diferiram entre as dietas devido o processo de abate ser o mesmo para ambos os grupos. Ao somar a pegada hídrica do abatedouro os valores de água verde passaram a representar $88,45 \%$ para a dieta convencional e $88,52 \%$ para a dieta com uso de coprodutos.

Os valores totais de pegada hídrica encontrados no estudo foram abaixo do valor mais conhecido de $15.500 \mathrm{~L} \mathrm{~kg}^{-1}$ de carne. Vale ressaltar, que esse valor é uma média global e não condiz com a realidade produtiva brasileira. Além disso, a análise, do presente estudo, ocorreu do período de confinamento até o abate, não sendo contabilizando as fases anteriores a esse período, também não houve a utilização de irrigação nas culturas para a produção do alimento animal. 
Tabela 10. Valores de pegada hídrica total e por tipo de água dos grupos experimentais

\begin{tabular}{lcc}
\hline & \multicolumn{2}{c}{ Dieta } \\
\cline { 2 - 3 } Pegada Hídrica & Convencional & Coprodutos \\
\hline Verde, $\mathrm{L} \mathrm{kg}^{-1}$ & $1.880,05$ & $1.808,06$ \\
Azul, $\mathrm{L} \mathrm{kg}^{-1}$ & 7,23 & 8,73 \\
\hline Pegada hídrica total confinamento, $\mathrm{L} \mathrm{kg}^{-1}$ & $2.010,90$ & $1.927,92$ \\
\hline \multicolumn{3}{c}{ Pegada do abatedouro } \\
\hline Azul, $\mathrm{L} \mathrm{kg}^{-1}$ & 7,34 & 7,34 \\
Cinza, $\mathrm{L} \mathrm{kg}^{-1}$ & 107,3 & 107,3 \\
\hline Pegada hídrica total abatedouro, $\mathrm{L} \mathrm{kg}^{-1}$ & 114,64 & 114,64 \\
\hline Pegada hídrica total, $\mathbf{L ~} \mathbf{~ k g}^{-1}$ & $\mathbf{2 . 1 2 5 , 5 4}$ & $\mathbf{2 . 0 4 2 , 5 6}$ \\
\hline
\end{tabular}

\subsection{PEGADA HÍDRICA VERDE}

Os consumos de água verde e as pegadas hídricas verde são apresentados na Tabela 11. A pegada hídrica verde do grupo alimentado com a dieta convencional foi de $1.880,05 \mathrm{~L} \mathrm{~kg}^{-1} \mathrm{de} \mathrm{carne}$ e do grupo alimentado com a dieta contendo coprodutos foi de $1.808,06 \mathrm{~L} \mathrm{~kg}^{-1}$ de carne. A dieta com coprodutos proporcionou uma redução de 3,83\% no valor da pegada hídrica verde. 
Tabela 11. Consumos de água verde, teor de água nos produtos e pegada hídrica verde por tipo de dieta.

\begin{tabular}{|c|c|c|}
\hline \multirow{2}{*}{ Água Verde } & \multicolumn{2}{|c|}{ Dieta } \\
\hline & Convencional & Coprodutos \\
\hline \multicolumn{3}{|c|}{ Consumo de água verde } \\
\hline Silagem de milho, $\mathrm{m}^{3}$ & $2.975,49$ & $2.239,64$ \\
\hline Milho grão, $\mathrm{m}^{3}$ & $5.197,77$ & - \\
\hline Farelo de soja, $\mathrm{m}^{3}$ & $4.269,83$ & - \\
\hline Gérmen de milho gordo, $\mathrm{m}^{3}$ & - & $4.839,82$ \\
\hline Farelo de amendoim, $\mathrm{m}^{3}$ & - & $3.832,90$ \\
\hline Polpa cítrica, $\mathrm{m}^{3}$ & - & $1.327,96$ \\
\hline \multicolumn{3}{|c|}{ Água no produto } \\
\hline Silagem de milho, $\mathrm{m}^{3}$ & 25,26 & 19,01 \\
\hline Milho grão, $\mathrm{m}^{3}$ & 0,84 & - \\
\hline Farelo de soja, $\mathrm{m}^{3}$ & 0,22 & - \\
\hline Gérmen de milho gordo, $\mathrm{m}^{3}$ & - & 0,78 \\
\hline Farelo de amendoim, $\mathrm{m}^{3}$ & - & 0,19 \\
\hline Polpa cítrica, $\mathrm{m}^{3}$ & - & 0,53 \\
\hline Total, $\mathrm{m}^{3}$ & $12.469,42$ & $12.260,83$ \\
\hline Produção total de carne, $\mathrm{kg}$ & $6.632,50$ & $6.781,20$ \\
\hline Pegada hídrica verde, $L$ kg $^{-1}$ & $1.880,05$ & $1.808,06$ \\
\hline
\end{tabular}

A Tabela 12 apresenta os valores do consumo de água verde total e alocada para cada alimento utilizado no experimento e o fator de alocação utilizado para cada coproduto.

Tabela 12. Consumos de água verde total e alocada e os fatores de alocação de coproduto utilizado FAO (2013).

\begin{tabular}{cccc}
\hline Cultura & $\begin{array}{c}\text { Consumo total de } \\
\text { água verde }\end{array}$ & Fator de alocação & $\begin{array}{c}\text { Consumo de água } \\
\text { verde alocada }\end{array}$ \\
\hline Milho grão, $\mathrm{m}^{3}$ & $5.198,61$ & - & $5.198,60$ \\
Farelo de soja, $\mathrm{m}^{3}$ & $4.270,05$ & - & $4.270,05$ \\
Gérmen de milho gordo, $\mathrm{m}^{3}$ & $96.812,00$ & $5 \%$ & $4.840,60$ \\
${\text { Farelo de amendoim, } \mathrm{m}^{3}}^{\text {Polpa cítrica, } \mathrm{m}^{3}}$ & $6.844,80$ & $56 \%$ & $3.833,09$ \\
\hline
\end{tabular}

Os valores de água ingerido pelos animais via dieta encontram-se na Tabela 13. A dieta convencional apresentou valor médio de $10,56 \mathrm{~L} \mathrm{cab}^{-1} \mathrm{dia}^{-1}$ para o grupo pesado e de $8,48 \mathrm{~L} \mathrm{cab}^{-1}$ dia $^{-1}$ para o grupo leve. Na dieta com coprodutos os valores médios foram 7,91 $\mathrm{L} \mathrm{cab}^{-1} \mathrm{dia}^{-1}$ e 6,54 


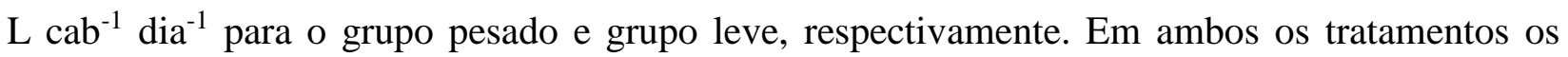
animais pesados apresentaram valores de consumo de água superior ao dos animais leves.

Tabela 13. Consumo total de água por tipo de dieta

\begin{tabular}{|c|c|c|c|c|c|c|}
\hline Dieta & & & nsumo t & tal de água & & \\
\hline Convencional & Silagem & Concentrado $^{1}$ & $\begin{array}{c}\text { Farelo } \\
\text { de } \\
\text { soja }\end{array}$ & $\begin{array}{c}\text { Farelo de } \\
\text { amendoim }\end{array}$ & Total & L $\mathrm{cab}^{-1} \mathrm{dia}^{-1}$ \\
\hline Pesado & $12.280,15$ & 112,98 & 103,22 & - & $12.496,35$ & 10,56 \\
\hline Leve & $13.094,82$ & 117,35 & 119,27 & - & $13.331,45$ & 8,48 \\
\hline Coprodutos & Silagem & Concentrado $^{2}$ & $\begin{array}{c}\text { Farelo } \\
\text { de } \\
\text { soja }\end{array}$ & $\begin{array}{c}\text { Farelo de } \\
\text { amendoim }\end{array}$ & Total & L cab $^{-1}$ dia $^{-1}$ \\
\hline Pesado & $12.229,96$ & 94,54 & - & 122,28 & $12.446,78$ & 7,91 \\
\hline Leve & $7.603,99$ & 58,38 & - & 78,74 & $7.741,12$ & 6,54 \\
\hline
\end{tabular}

${ }^{1}$ Concentrado composto somente por milho e farelo de soja. ${ }^{2}$ Concentrado composto por gérmen de milho gordo, polpa cítrica, farelo de amendoim.

\subsection{PEGADA HÍDRICA AZUL}

A pegada hídrica azul do grupo convencional foi $7,23 \mathrm{~kg}^{-1}$ e do grupo com dieta de coprodutos foi de $8,73 \mathrm{~L} \mathrm{~kg}^{-1}$, portanto para se produzir um quilograma de produto, os animais alimentados com a dieta com coprodutos consumiram $1,50 \mathrm{~L} \mathrm{~kg}^{-1}$ de carne a mais do que os animais alimentados com a dieta convencional. Essa diferença é explicada pela maior ingestão de água de dessedentação no período de confinamento.

Os dados de consumo de água de dessedentação são apresentados na Tabela 14. Os resultados demonstram que a dieta composta somente por coprodutos impactou a ingestão de água. O consumo médio do grupo com dieta convencional foi de $19,75 \mathrm{~L} \mathrm{cab}^{-1} \mathrm{dia}^{-1}$ e da dieta com coprodutos foi de $23,12 \mathrm{~L} \mathrm{cab}^{-1} \mathrm{dia}^{-1}$. O consumo médio de água de dessedentação, considerando todos os animais, foi de $21,43 \mathrm{~L} \mathrm{cab}^{-1} \mathrm{dia}^{-1}$.

O consumo total de água azul do grupo experimental alimentado com a dieta convencional foi de 47.993,73 L. No grupo da dieta com coprodutos esse consumo totalizou 59.231,41 L. 
Tabela 14. Consumos médios de água de dessedentação de acordo com o tipo de dieta

\begin{tabular}{cc}
\hline Grupos & $\begin{array}{c}\text { Consumo de água dessedentação } \\
\left(\mathbf{L ~} \mathbf{c a b}^{-\mathbf{1}} \mathbf{d i a}^{\mathbf{- 1}}\right)\end{array}$ \\
\hline Convencional & 19,75 \\
Coprodutos & 23,12 \\
\hline & Fonte: Dados da pesquisa da autora.
\end{tabular}

O valor do índice de escassez hídrica foi de $0,64 \%$ para a dieta com uso de coprodutos e de 0,52\% para a dieta convencional, consequência do maior consumo de água azul pelos animais alimentados com coprodutos.

Nos gráficos 4 e 5 observam-se os valores de pegada azul nos anos de 2012, 2013, 2014 e 2015 para os abatedouros de Tangará da Serra/MT e de Promissão/SP. Os valores médios das pegadas hídricas azul no período foram 7,4 $\mathrm{L} \mathrm{kg}^{-1}$ de carne em Tangará da Serra e de 7,3 $\mathrm{L} \mathrm{kg}^{-1}$ de carne em Promissão.

Os valores médios da pegada hídrica azul em Promissão foram de 5,4 $\mathrm{L} \mathrm{kg}^{-1}$ de carne em 2015, 6,0 L kg-1 de carne em 2014, 6,9 L kg-1 de carne em 2013 e de 9,4 L kg-1 de carne em 2012. O valor máximo de pegada em Promissão foi de $11,8 \mathrm{~L} \mathrm{~kg}^{-1}$ de carne em fevereiro de 2012. Em Tangará da Serra os valores médios das pegadas hídricas anuais foram mais constantes, $7,0 \mathrm{~L} \mathrm{~kg}^{-1}$ de carne, 6,9 $\mathrm{L} \mathrm{kg}^{-1}$ de carne, 7,6 $\mathrm{L} \mathrm{kg}^{-1}$ de carne e 7,3 $\mathrm{L} \mathrm{kg}^{-1}$ de carne para 2015, 2014, 2013 e 2012, respectivamente. O valor máximo de $8,83 \mathrm{~L} \mathrm{~kg}^{-1}$ de carne ocorreu no mês de junho de 2012. 
Gráfico 4. Valores de pegada hídrica azul ( $\mathrm{L} \mathrm{kg}^{-1}$ carne) no abatedouro de Tangará da Serra/MT nos anos de 2012,2013,2014 e 2015

\section{Tangará da Serra/MT}

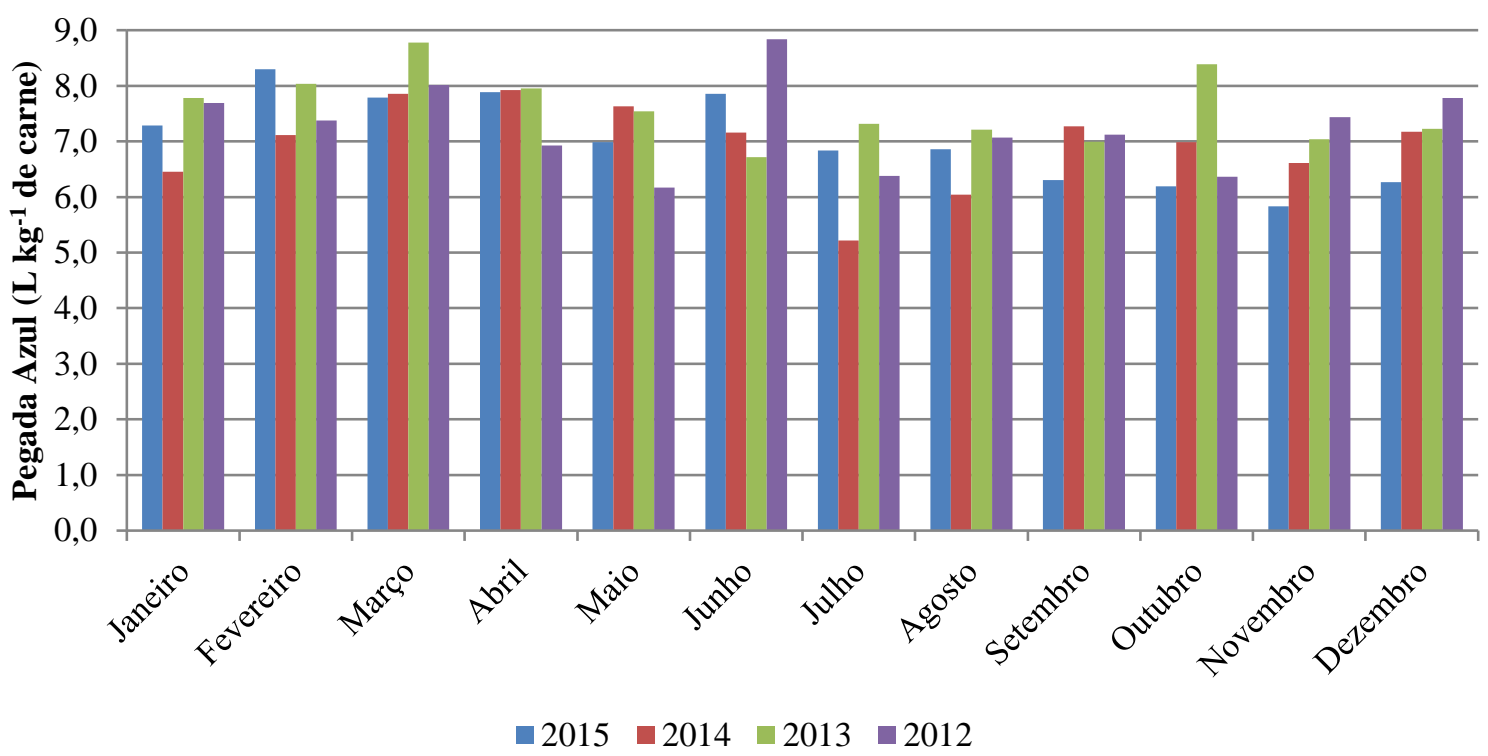

Fonte: Dados da pesquisa da autora.

Gráfico 5. Valores de pegada hídrica azul ( $\mathrm{L} \mathrm{kg}^{-1}$ carne) no abatedouro de Promissão/SP nos anos de 202,2013,2014 e 2015

\section{Promissão/SP}

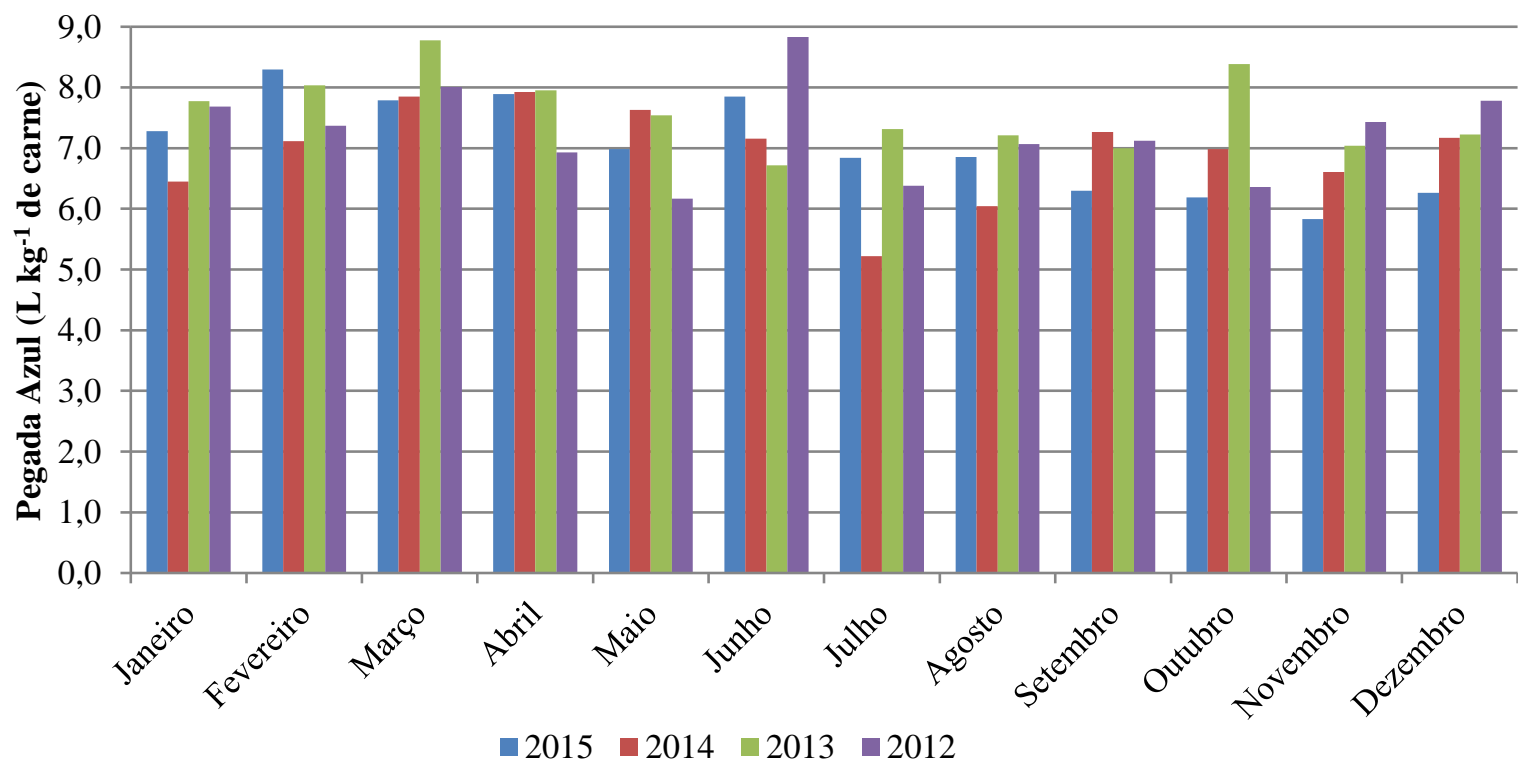

Fonte: Dados da pesquisa da autora. 


\subsection{PEGADA HÍDRICA CINZA}

No gráfico 6 apresenta-se a pegada hídrica cinza média para o abatedouro de Tangará da Serra/MT nos anos de 2012, 2013 e 2014.

Gráfico 6. Valores de pegada hídrica cinza ( $\mathrm{L} \mathrm{kg}^{-1}$ carne) no abatedouro de Tangará da Serra/MT nos anos de

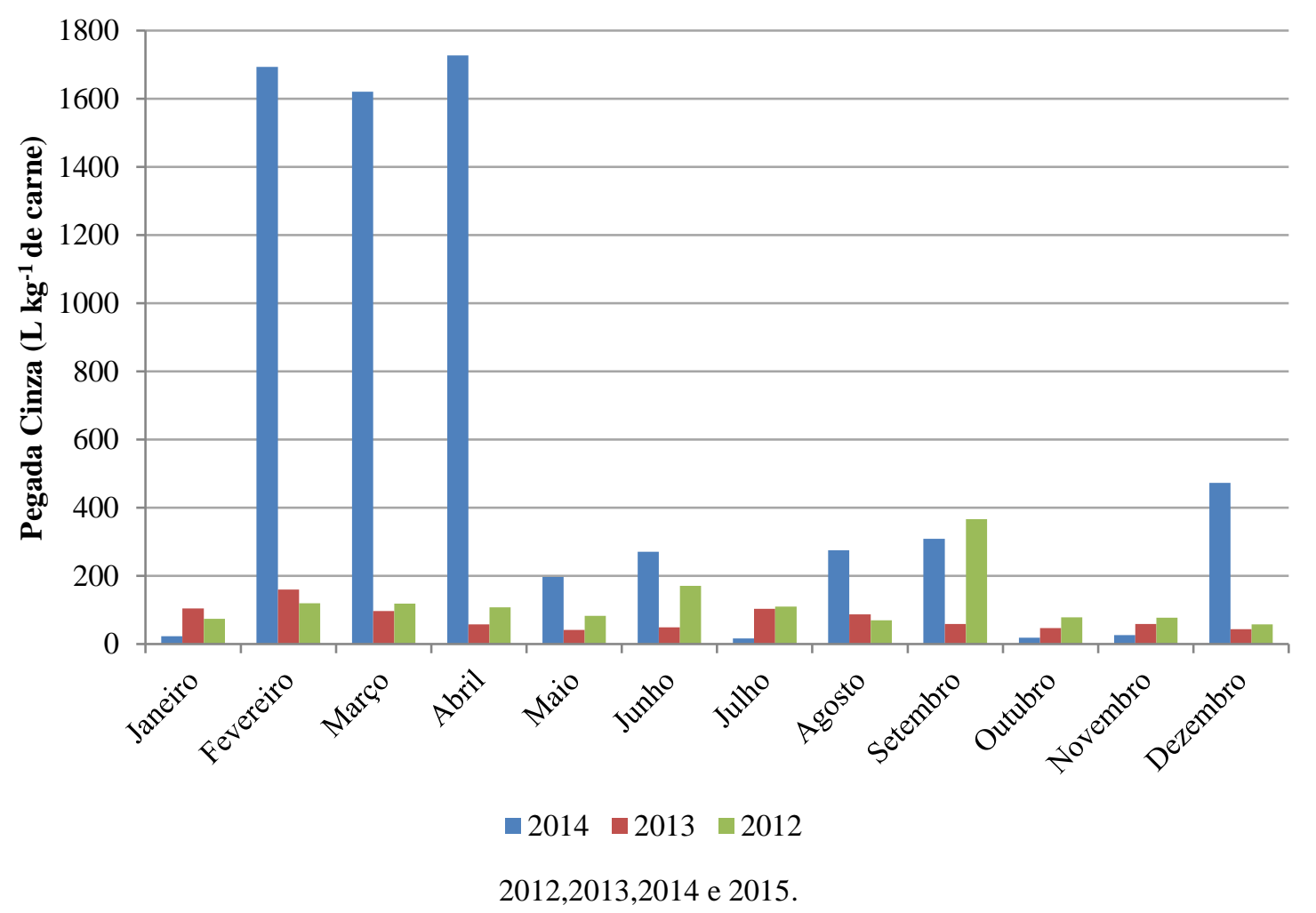

Fonte: Dados da pesquisa da autora.

O valor médio de pegada hídrica cinza no ano de 2014 foi de 554,00 $\mathrm{L} \mathrm{kg}^{-1}$ carne, em 2013 esse valor foi de 75,4 $\mathrm{L} \mathrm{kg}^{-1}$ carne e em $2012119,8 \mathrm{~L} \mathrm{~kg}^{-1}$ carne. Considerando os três anos de avaliação, o mês de abril de 2012 foi o que apresentou o maior valor de pegada cinza $1.727 \mathrm{~L} \mathrm{~kg}^{-1}$ carne e o mês de julho do mesmo ano o menor valor, $15,9 \mathrm{~L} \mathrm{~kg}^{-1}$ carne.

Os picos de valores identificados nos meses de fevereiro, março e abril de 2014, foram resultado de alguma alteração de manejo dentro da unidade ou mesmo decorrente de algum tipo de vazamento, porém não foram fornecidos para esse estudo os dados de produção, não podendo gerar resultados conclusivos. 


\subsection{Pegada hídrica das fazendas}

A Tabela 15 apresenta os valores das pegadas hídricas azul, verde e total das fazendas. A pegada hídrica total variou de $3.730,30 \mathrm{~L} \mathrm{~kg}^{-1}$ a $10.447,61 \mathrm{~L} \mathrm{~kg}^{-1}$ de carne. Essa variabilidade é resultado das diferentes condições ambientais e produtivas de cada sistema de produção. A água verde representou em média 99,56\% e água azul 0,44\% do valor da pegada hídrica total.

As maiores percentagens da pegada hídrica verde na pegada total foram verificadas nas fazendas 5 e 6 e a menor na fazenda 4 , sendo a diferença de $0,3 \%$. A elevada representatividade da pegada verde no valor total da pegada hídrica demonstra a relevância dos consumos indiretos (água consumida na produção agrícola) na pegada hídrica do produto carne bovina.

A maior contabilização dos ingredientes das dietas nos cálculos da pegada foi de 96,8\% para as fazendas 5 e 6 , seguida por $96,7 \%$ para as fazendas 1 e 8 . A menor representatividade da pegada verde no valor total da pegada foi de 99,5\% para a fazenda 4, ressaltando que nesta fazenda só foi possível calcular as pegadas referentes a $80 \%$ dos alimentos ingeridos devido a falta de informações prestadas pelos proprietários.

A pegada hídrica azul variou de $66 \mathrm{~L} \mathrm{~kg}^{-1}$ de carne a $18 \mathrm{~L} \mathrm{~kg}^{-1}$. No caso da fazenda $1 \mathrm{o}$ valor de $66 \mathrm{~L} \mathrm{~kg}^{-1}$ de carne representa a soma das pegadas azuis de dois grupos de animais (Angus $30 \mathrm{~L} \mathrm{~kg}^{-1}$ de carne e Wagyu $36 \mathrm{~L} \mathrm{~kg}^{-1}$ de carne, sendo esse último abatido com $660 \mathrm{~kg}$ de peso o que correspondeu a um ciclo de confinamento de 236 dias). Os menores valores de pegada azul estão relacionados a menores ciclos produtivos, fazenda 4, 100 dias de confinamento e fazenda 5, 97 dias de confinamento. 
Tabela 15. Valores das pegadas hídricas azul, verde e total e as porcentagens que cada pegada representa no valor total de cada fazenda.

\begin{tabular}{ccccccccc}
\hline \multirow{2}{*}{ Fazenda } & \multicolumn{4}{c}{ Pegada $\left(\mathbf{L ~ k g}^{-\mathbf{1}} \mathbf{c a r n e}\right)$} & & \multicolumn{2}{c}{$\%$} \\
\cline { 2 - 4 } \cline { 7 - 8 } \cline { 7 - 8 } & Azul & Verde & Total & \% & & Água Azul & Água Verde \\
\hline 1 & 66 & 4.896 & 4.962 & 96,0 & & 1,3 & 98,7 \\
2 & 21 & 5.199 & 5.219 & 96,9 & & 0,4 & 99,6 \\
3 & 21 & 5.045 & 5.066 & 91,4 & & 0,4 & 99,6 \\
4 & 18 & 3.712 & 3.730 & 80,0 & & 0,5 & 99,5 \\
5 & 18 & 9.784 & 9.802 & 93,7 & & 0,2 & 99,8 \\
6 & 20 & 9.970 & 9.990 & 70,2 & & 0,2 & 99,8 \\
7 & 20 & 4.960 & 4.979 & 96,7 & & 0,4 & 99,6 \\
8 & 25 & 8.892 & 8.917 & 96,0 & & 0,3 & 99,7 \\
9 & 22 & 10.431 & 10.453 & 93,8 & & 0,2 & 99,8 \\
\hline
\end{tabular}

\subsection{CUSTO DE PRODUÇÃO}

Na Tabela 16 são apresentados os preços considerados de cada ingrediente das dietas e o valor total da proteína bruta. Para o milho e para o farelo soja os valores foram considerados os valores médios de um período de 10 anos e deflacionados para o período de setembro de 2017. Já para os coprodutos cosiderou-se o valor pago pelo insumo na data de compra, deflacionado para o período de setembro de 2017.

Tabela 16. Custos, baseados em valores de setembro de 2017, para cada ingrediente utilizado na dieta experimental e os valores em $\mathrm{R} \$$ por tonelada de proteína bruta.

\begin{tabular}{ccc}
\hline Ingredientes & $\mathbf{R} \$ / \mathbf{t}$ MN & $\mathbf{R} \$ \mathbf{t} \mathbf{P B}$ \\
\hline Silagem de milho & 180,00 & $2.482,76$ \\
Farelo de soja & $1.226,09$ & $2.515,57$ \\
Milho grão & 592,52 & $7.104,56$ \\
Gérmen de milho gordo & 850,00 & $7.671,48$ \\
Polpa cítrica & 670,73 & $9.354,67$ \\
Farelo de Amendoim & $1.510,00$ & $2.661,26$ \\
\hline
\end{tabular}

Embora o farelo de soja e o farelo de amendoim apresentem preços mais elevados em comparação aos demais ingredientes, por possuírem altos valores altos de proteína, são alternativas viáveis do ponto de vista econômico. O farelo de amendoim pode ser utilzado como alternativa 
protéica ao farelo de soja, mas é necessário avaliar os custos do coproduto em relação a soja, pois pode não ser viável em determinadas épocas e regiões.

Na Tabela 17 são apresentados os valores de custo, em reais por arroba, da alimentação dos animais de acordo com cada fase. Para produzir uma arroba o custo total foi de $\mathrm{R} \$ 151,00$ para a dieta convencional e na dieta de coprodutos foi de $\mathrm{R} \$ 157,47$, considerando um rebanho com 6.000 animais confinados.

Os custo da alimentação por arroba produzida foram de $\mathrm{R} \$ 33,59$ e $\mathrm{R} \$ 38,14$ para a dieta convencional e dieta de coprodutos, respectivamente. A alimentação representou 53,24\% do custo total para dieta convencional e $60,08 \%$ para dieta com coprodutos.

Tabela 17. Custos, baseados em valores de setembro de 2017, para um confinamento no estado de SP com 6.000 animais.

\begin{tabular}{|c|c|c|c|c|}
\hline \multirow[b]{2}{*}{ Dieta } & \multicolumn{3}{|c|}{ Custos da alimentação } & Custo total \\
\hline & $\mathbf{R} \$ \mathrm{cab}^{-1} \mathrm{dia}^{-1}$ & R\$ kg MS -1 $^{-1}$ & $\mathbf{R} \$$-1 $^{-1}$ & R\$@-1 \\
\hline Convencional & 3,75 & 0,48 & 33,59 & 151,00 \\
\hline Coprodutos & 4,25 & 0,55 & 38,14 & 157,47 \\
\hline
\end{tabular}

Fonte: Dados da pesquisa da autora.

Os custos variáveis representaram 91,52\% dos custos totais. Os custos semifixos, fixos e de renda dos fatores representaram $0,42 \%, 3,32 \%$ e $4,74 \%$ do custo total, respectivamente. Os fatores que mais oneraram no custo foi a aquisição de animais. Se fossem contabilizados somente 52 animais, as porcentagens do custo do total seriam 17,54\% para os custos variáveis, 9,30\% para os custos semifixos, 55,31\% para os custo fixos e 17,85\% para a remuneração dos fatores. A mão de obra e a depreciação seriam os pontos de maior custo para o sistema de produção, representando $35,22 \%$ do custo total.

O custo total da dieta convencional foi de $\mathrm{R} \$ 3,75 \mathrm{cab}^{-1} \mathrm{dia}^{-1}$ e de $\mathrm{R} \$ 0,48 \mathrm{~kg}$ MS e da dieta com uso de coprodutos foi de $\mathrm{R} \$ 4,25 \mathrm{cab}^{-1} \mathrm{dia}^{-1}$ e de $\mathrm{R} \$ 0,55 \mathrm{~kg}$ MS. A dieta com coprodutos apresentou um custo $9,25 \%$ maior por cabeça por dia.

A Tabela 18 apresenta os valores totais (captação e consumo de água) a serem pagos pela água e o custo por cabeça para o ciclo de confinamento de cada grupo (26 animais). O valor total que seria pago utilizando-se a dieta convencional é de $\mathrm{R} \$ 1.764,00$ e para dieta com coprodutos de $\mathrm{R} \$ 2.445,00$. 
Tabela 18. Valores pagos ( $\mathrm{R} \$$ ) pelo uso da água, considerando o ciclo total do confinamento, para cada tipo de dieta.

Tabela 18. Valores pagos (RS) pelo uso da água, considerando o ciclo total do confinamento, para cada tipo de dieta.

\section{Variáveis}

Valor pago pela água captada $\left(\mathrm{R} \$ / \mathrm{m}^{3}\right)$

\section{Convencional}

1,22

$\mathbf{2 , 0 7}$

0,0006

0,0009
0,85

Coprodutos

1,05

Valor pago pela água consumida $\left(\mathrm{R} \$ / \mathrm{m}^{3}\right)$

Valor Total de Pagamento pela Água $\left(\mathrm{R} \$ / \mathrm{m}^{3}\right)$

Custo Médio da água cabeça ${ }^{-1} \operatorname{dia}^{-1}$ (animais leves) ${ }^{1}$

Custo Médio da água cabeça ${ }^{-1}$ dia $^{-1}$ (animais pesados) ${ }^{2}$

${ }^{1}$ Animais leves: 125 dias de confinamento.

Fonte: Dados da pesquisa da autora.

${ }^{2}$ Animais pesados: 91 dias de confinamento.

Para ambas as dietas o valor pago pelo consumo de água representou 58,92\% do valor total e a captação, $41,08 \%$. Neste estudo, determinou-se que o volume captado representaria $140 \%$ do volume consumido. O Brasil não dispõe de dados sobre eficiência de uso do volume captado pelo consumido na área rural e essa eficiência será variável para cada fazenda, dependendo de sua estrutura de captação, distribuição, armazenamento e manejo da água. Portanto, a implementação de boas práticas de uso da água na unidade rural é uma forma de reduzir o custo da água de captação devido a melhoria de eficiência de uso do recurso.

\subsection{BALANÇO DE NUTRIENTES}

O balanço de nutrientes foi positivo para todos os elementos e para ambas as dietas, ou seja, as entradas foram maiores que as saídas (Tabela 19). 
Tabela 19. Balanço de nutrientes por dieta, referente ao período de estudo

\begin{tabular}{|c|c|c|c|c|}
\hline \multirow{2}{*}{ Elemento } & \multicolumn{4}{|c|}{ Dieta } \\
\hline & & Coprodutos & Convencional & \\
\hline & \multicolumn{4}{|c|}{ Entradas $(\mathrm{Kg})$} \\
\hline Nitrogênio $(\mathrm{N})$ & & 410,29 & 470,70 & \\
\hline Fósforo (P) & & 74,13 & 72,48 & \\
\hline \multirow[t]{3}{*}{ Potássio (K) } & & 234,38 & 222,93 & \\
\hline & Convencional & Coprodutos & Convencional & Coprodutos \\
\hline & \multicolumn{2}{|c|}{ Saídas $(\mathrm{Kg})$ : carne } & \multicolumn{2}{|c|}{ Saídas $(\mathrm{Kg})$ : carne + fezes } \\
\hline Nitrogênio (N) & 53,96 & 56,14 & 255,16 & 236,08 \\
\hline Fósforo (P) & 2,86 & 2,97 & 60,22 & 42,72 \\
\hline \multirow[t]{2}{*}{ Potássio (K) } & 7,30 & 7,59 & 160,69 & 164,31 \\
\hline & \multicolumn{4}{|c|}{ Balanço (Kg) } \\
\hline Nitrogênio $(\mathrm{N})$ & 356,32 & 414,56 & 155,13 & 234,63 \\
\hline Fósforo (P) & 71,27 & 69,51 & 13,90 & 29,76 \\
\hline Potássio (K) & 277,08 & 215,34 & 73,69 & 58,62 \\
\hline
\end{tabular}

Na tabela 20 é apresentado a eficiência de uso dos nutrientes, a qual indica o quanto das entradas foi recuperada como produto. $\mathrm{O}$ elemento com a maior percentagem de recuperação na forma de produto foi o nitrogênio. As diferentes dietas apresentaram diferenças quanto ao aproveitamento dos elementos $\mathrm{N}, \mathrm{P}$ e K. A dieta convencional é menos eficiente em recuperar o elemento $\mathrm{P}$ no produto, ocorrendo grande perda desse elemento para o ambiente. Já na dieta com uso de coprodutos a maior perda para o ambiente ocorre para o elemento K. Quando o balanço é feito contabilizando as fezes as eficiência são maiores.

Tabela 20. Médias de eficiência de uso dos nutrientes (EUN) por grupo experimental

\begin{tabular}{|c|c|c|c|c|}
\hline \multirow{3}{*}{ Elemento } & \multicolumn{4}{|c|}{ Dietas } \\
\hline & Convencional & Coprodutos & Convencional & Coprodutos \\
\hline & \multicolumn{2}{|c|}{ Balanço- carne } & \multicolumn{2}{|c|}{ Balanço- carne + fezes } \\
\hline & \multicolumn{4}{|c|}{ Média EUN $(\%)$} \\
\hline Nitrogênio $(\mathrm{N})$ & 13,15 & 11,93 & 37,81 & 49,85 \\
\hline Fósforo (P) & 3,85 & 4,10 & 18,76 & 41,06 \\
\hline Potássio (K) & 3,11 & 3,41 & 31,44 & 26,30 \\
\hline
\end{tabular}

\section{DISCUSSÃO}

Os dados de desempenho dos animais encontrados no presente estudo estão de acordo com os dados encontrados na literatura. Van Cleef et al. (2017) avaliando o desempenho de Nelores em 
confinamento encontraram valores médios de 279,5 kg de PI; 413,9 kg PF e 1,54 kg dia ${ }^{-1}$ GPD. Morelli et al. (2015) observaram valores médios PI de 351,50 $\pm 14,60 \mathrm{~kg}$, GMD de 1,31 \pm 0,33 kg $\mathrm{dia}^{-1}$ e CMS de $10,33 \pm 1,38 \mathrm{~kg}$ para Nelores em confinamento. A resposta produtiva dos animais é função do consumo, da digestibilidade e do metabolismo dos nutrientes dietéticos. O consumo corresponde de 60 a 90\% da variação do desempenho animal (MERTENS, 1994), enquanto apenas 10 a $40 \%$ são relacionadas à digestibilidade dos componentes nutritivos.

A maior parte dos estudos relacionados ao uso de coprodutos na alimentação de bovinos avaliam a substituição parcial ou total de algum ingrediente da dieta, mas não a substituição total dos ingredientes convencionais pelos coprodutos. Os resultados deste estudo demonstram que é possível utilizar uma dieta formulada somente com coprodutos e manter os níveis de desempenho verificados com o uso de dietas convencionais. A utilização da dieta com coprodutos também não promoveu diferenças no CMS durante as fases do ciclo produtivo.

Stelzleni, Segers e Stewart Jr. (2016) avaliaram o uso de glúten de milho e de grãos secos de destilaria na dieta de bovinos em confinamento no sudeste dos EUA e concluíram que o uso destes coprodutos tem um impacto mínimo sobre o desempenho e sobre as características de carcaça. Ezequiel et al. (2006) avaliaram o ganho de peso de Nelores alimentados com bagaço de cana-de-açúcar como volumoso e concentrado contendo farelo de gérmen de milho, casca do grão de soja ou polpa cítrica em substituição parcial (50\%) ao milho e concluíram que a substituição não teve impactos negativos. Henrique et al. (2004) estudaram o efeito da substituição do milho pela polpa cítrica peletizada nos níveis $0,25,40$ e 55\% sobre o desempenho de tourinhos confinados e não confinados e encontraram efeito do nível de polpa cítrica na dieta sobre o CMS, GPD e eficiência alimentar. Avaliando o efeito do uso de coprodutos do etanol no desempenho, digestibilidade aparente e características de carcaça, Opheim et al. (2016) não observaram diferenças entre o CMS, PF e GPD.

Anteriormente ao conceito de pegada hídrica ser proposto, Beckett e Oltjen (1993), objetivaram mensurar a quantidade de água utilizada para se produzir produtos agropecuários. Os autores relataram ser necessário $3.682 \mathrm{~L}$ de água para se produzir um quilograma de carne desossada, considerando os consumos de água de dessedentação, água contida nos alimentos e a água usada no processamento das carcaças. Mekonnen e Hoestra (2012) encontraram valores de pegada hídrica para carne bovina de $7.477 \mathrm{~L} \mathrm{~kg}^{-1}$ de carne. Após a proposição do conceito da pegada hídrica o valor de $15.415 \mathrm{~L} \mathrm{~kg}^{-1}$ de carne bovina foi o mais divulgado entre os valores para 
os produtos de origem animal, causando conflitos entre o setor de produção de bovinos e a sociedade, por essa entender que se consome muita água para produção de um quilograma de produto. Como já citado, esse valor se refere a uma média global, considerando um sistema de produção industrial, média de três anos para o animal ser abatido e produção de $200 \mathrm{~kg}$ de carne por animal.

A dieta formulada com coprodutos promoveu uma redução no valor da pegada hídrica total de 82,98 L kg-1 em comparação a dieta convencional. Palhares, Morelli e Costa Junior (2017) encontraram valores pegada hídrica (azul e verde) variando de $1.934 \mathrm{~L} \mathrm{~kg}^{-1}$ a $9.672 \mathrm{~L} \mathrm{~kg}^{-1}$ de carne para sistema de bovinos em confinamento. $\mathrm{O}$ total de água verde consumida na produção dos ingredientes da dieta convencional é considerada na produção do produto carne bovina, enquanto na dieta com coprodutos somente parte desta água é considerada devido ao ingrediente não ser o produto principal da cultura vegetal que foi considerada. Os resultados demonstram que é possível se formular dietas com coprodutos em substituição total aos ingredientes convencionais e ter impactos positivos na melhoria da eficiência hídrica do produto carne.

O consumo de água azul foi maior na dieta com coprodutos, pois os animais alimentados com essa dieta ingeriram em média maior quantidade de matéria seca e essa dieta apresentava menor teor de umidade o que irá determinar maior consumo de água via bebedouro. Segundo Bosire et al. (2015) dietas bem formuladas resultam em melhor conversão alimentar e, por consequência melhor uso da água. O consumo de água em bovinos de corte é influenciado pela qualidade da dieta e pela digestibilidade de seus ingredientes (RAN et al., 2016).

O consumo de água verde é predominante na pegada hídrica dos produtos agropecuários, representando em média 80\% do valor total da pegada (ROCKSTRÖM et al., 2014). Nos produtos de origem animal, a pegada hídrica verde representa em média 90\% do total (MEKONNEN; HOEKSTRA, 2012). Para todos os produtos de origem animal, a água verde é o principal consumo no total da pegada hídrica (ATZORI et al., 2016). Até cem vezes mais água é usada na produção dos alimentos da dieta do que na dessedentação dos animais (BLÜMMEL et al., 2014; GERBENSLEENES et al., 2013). Ressalta-se que o consumo de água verde é considerado menos impactante do que os das águas azul e cinza, porque apresenta um custo de oportunidade mais baixo (ATZORI et al., 2016)

No estudo a água verde consumida na produção dos alimentos representou mais $88,5 \%$ do valor total da pegada hídrica para ambas as dietas. Murphy et al. (2017) verificam o maior consumo 
de água verde e concluíram que a participação dos consumos verde e azul em maior ou menor proporção na contabilização do volume final, difere de uma região para outra, isto porque a proporção de cada água é determinada em função da dieta dos animais, do sistema agrícola e do regime de chuvas da região. Palhares, Morelli e Costa Junior (2017) confirmaram a maior porcentagem de água verde na pegada hídrica total de bovinos em confinamento e afirmam que essa é uma vantagem competitiva da pecuária brasileira. Segundo Bekele et al. (2017) a principal restrição a produção de ruminantes na maioria dos países em desenvolvimento é a falta de alimentos, cuja produção é, muitas vezes, impedida pela escassez de água.

Neste estudo, a ingestão de volumoso representou 22,4\% e 17,2\% do consumo total de água verde nas dietas convencional e com uso de coprodutos, respectivamente. Os animais alimentados com a dieta de coprodutos ingeriram 33,95\% menos concentrado em relação aos animais da dieta convencional. Portanto, como verificado a pegada hídrica total da dieta com coprodutos foi menor.

Uma vez que a água verde é o maior contribuinte no valor da pegada hídrica, deve ser dada especial atenção a produção dos alimentos, em especial os alimentos concentrados, (OWUSUSEKYERE et al., 2016). A relação volumoso/concentrado e o tipo de volumoso são os aspectos nutricionais que mais influenciaram nos valores de pegada hídrica de bovinos em confinamento (PALHARES; MORELLI; COSTA JUNIOR, 2017). A maior ingestão de concentrado resulta em maior consumo de água porque a água utilizada para a produção dos alimentos concentrados é cinco vezes maior que a usada para volumosos (HOEKSTRA, 2012). Mekonnen e Hoekstra (2012) observam que a pegada hídrica por quilo de alimento concentrado é geralmente maior do que por quilo de volumoso.

Na abordagem da pegada hídrica, o uso de coprodutos na alimentação dos animais tem como aspecto positivo o fato que somente parte da água evapotranspirada pela produção do produto principal é alocada na pegada hídrica do coproduto, bem como o fato de se converter um coproduto agroindustrial em um produto nobre, carne bovina. Foram necessários 0,75 ha e $4.257,4 \mathrm{~m}^{3}$ de água verde para produção de 2,0 t de farelo de soja destinada a alimentação de todos os animais durante o período experimental. O consumo de água verde para a produção de 1,8 $\mathrm{t}$ de farelo de amendoim foi de $3.808,79 \mathrm{~m}^{3}$ e utilizou-se um total de 0,54 ha. $\mathrm{O}$ amendoim apresentou produtividades de 3,5 $\mathrm{t} \mathrm{ha}^{-1}$ e a soja $2,7 \mathrm{t} \mathrm{ha}^{-1}$. No ponto de vista da pegada hídrica, o uso de coprodutos tem como aspecto positivo, o fato de toda a água utilizada para a produção de uma determinada cultura não é de fato utilizada, por exemplo, apenas $5 \%$ da água gasta para produzir o milho é utilizada para a produção 
do gérmen de milho. No estudo das fazendas, a fazenda 1, apresentou o menor valor de pegada hídrica verde (4.569,98 $\mathrm{L} \mathrm{kg}^{-1}$ carne), dentro das porcentagens contabilizadas no cálculo (96\% da dieta) devido ao fato da mesma apresentar a maior proporção de coprodutos na dieta, 63,31\%.

No cálculo do consumo de água verde das dietas só foi contabilizado o alimento efetivamente consumido pelos animais, portanto sem considerar as perdas e sobras de alimento. Caso as sobras alimentares fossem consideradas, os valores de pegada hídrica total seriam de $1.907,6 \mathrm{~L} \mathrm{~kg}^{-1}$ de carne (2,65\% maior) e $2.122,5 \mathrm{~L} \mathrm{~kg}^{-1}$ de carne (14,82\% maior) para as dietas convencional e com coprodutos, respectivamente. A maior porcentagem verificada na dieta com coprodutos foi decorrente de uma maior sobra de dieta devido à dificuldade de se ajustar a quantidade diária fornecida aos animais no cocho até a adaptação destes a dieta. Não só a formulação de dietas, mas o manejo dos alimentos durante os períodos de armazenamento e de oferta aos animais pode impactar, positiva ou negativamente os valores da pegada hídrica. As sobras também significam perda de alimento, consequentemente irão impactar de forma negativa os custos de produção. Adaptar a dieta de acordo com a fase de produção e fazer ajustes diários do alimento fornecido de acordo com as sobras são ações mitigatórias que podem ser utilizadas para reduzir o valor da pegada hídrica verde.

Ao avaliar a pegada hídrica azul de bovinos Mekonnen e Hoekstra (2012) verificaram que a água azul representou 3,6\% da pegada hídrica total para sistemas de bovinos a pasto e $8 \%$ quando os bovinos são confinados. Neste estudo a representatividade da água azul foi de $6 \%$ para ambas as dietas. Os consumos de água considerados no cálculo, bem como os aspectos produtivos (raça do animal, tipo de dieta e ingestão de matéria seca) e ambientais (temperatura ambiente e precipitação) irão determinar diferenças nos valores de pegada hídrica, mesmo quando se tem como objeto de estudo o mesmo sistema produtivo. ALI et al (1994) são inúmeros os fatores que afetam o consumo voluntário de água pelos bovinos, os ambientais, temperatura ambiente, precipitação, umidade relativa e velocidade do vento e os produtivos, consumo de matéria seca, consumo de sal, tamanho corporal e raça. A influência dos aspectos ambientais na ingestão de água dos animais é de difícil identificação, pois o consumo é fortemente afetado por outros aspectos como o manejo nutricional (FUQUAY ${ }^{3,} 1981$ citado por KADZERE et al. 2002).

\footnotetext{
${ }^{3}$ FUQUAY, J.W., 1981. Heat stress as it affects animal production. Journal of Animal Science, v.32, p.164-174, 1981.
} 
As médias de consumo de água de dessedentação observadas no estudo foram de 19,75 L $\mathrm{cab}^{-1} \mathrm{dia}^{-1}$ para a dieta convencional e de $23,12 \mathrm{~L} \mathrm{cab}^{-1} \mathrm{dia}^{-1}$ para dieta com coprodutos. Zanetti (2017) observou consumo médio de $15,7 \mathrm{~L} \mathrm{cab}^{-1} \mathrm{dia}^{-1}$, variando de $31,3 \mathrm{~L} \mathrm{cab}^{-1} \mathrm{dia}^{-1}$ a 2,3 $\mathrm{L} \mathrm{cab}^{-1}$ $\mathrm{dia}^{-1}$, para Nelore em confinamento em condições tropicais. Brew et al. (2011) identificaram que o consumo de água de bovinos de corte na fase de crescimento com medição automática foi de 29,9 $\pm 8,5 \mathrm{~L} \mathrm{cab}^{-1} \mathrm{dia}^{-1}$.

Winchester e Morris (1956) e Valente et al. (2015) relataram maiores valores de ingestão de água para Bos taurus do que para Bos indicus criados em condições semelhantes. Arias e Mader (2013) estudando bovinos Angus em confinamento obtiveram valores médios de 32,4 $\mathrm{L} \mathrm{cab}^{-1} \mathrm{dia}^{-}$ ${ }^{1}$ durante o verão e 17,3 $\mathrm{L} \mathrm{cab}^{-1} \mathrm{dia}^{-1}$ no inverno. Meyer et al. (2006) avaliando 62 touros holandeses encontraram valores de 17,8 $\mathrm{L} \mathrm{cab}^{-1} \mathrm{dia}^{-1}$. Olkowski (2009) propõe um intervalo de consumo de 26 a $66 \mathrm{~L} \mathrm{cab}^{-1} \mathrm{dia}^{-1}$ para bovinos em idade adulta.

Segundo Zanetti (2017) em geral o consumo de água é superestimado pelas equações de consumo quando comparadas ao consumo real observado de animais Nelore criados em condições tropicais. Se o consumo de água de dessedentação para cada tipo de dieta tivesse sido calculado a partir de uma equação que considera a temperatura máxima no local, a precipitação do período e as ingestões de sal e matéria seca (HICKS et al., 1988), os valores de consumo médio seriam 37,3 $\mathrm{L} \mathrm{cab}^{-1} \mathrm{dia}^{-1}$ para a dieta convencional e $38,4 \mathrm{~L} \mathrm{cab}^{-1} \mathrm{dia}^{-1}$ para a dieta de coprodutos. O que representaria um acréscimo de $88,7 \%$ e de $66,1 \%$, nos valores de consumo de água e de 53,1\% e 60,1\% nos valores de pegada hídrica azul para as dietas convencional e de coprodutos, respectivamente. Isso demonstra a importância de se ter sistemas de medição de precisão do consumo de água a fim de se ter valores de consumo e de pegada que reflitam a realidade produtiva. Na literatura científica ainda são escassos dados de consumo de água para zebuínos em condições tropicais. Ressalta-se que a medição do consumo de água na propriedade também é importante para subsidiar a gestão do recurso natural. Devido ao elevado custo dos bebedouros automatizados, a alternativa mais viável para medição do consumo de água na propriedade seria pela utilização de hidrômetros. Este tipo de mensuração se insere na abordagem de zootecnia de precisão.

O conceito de zootecnia de precisão tem contribuído de forma relevante para a atividade pecuária, fornecendo meios ao produtor de monitorar seus empreendimentos de forma prática e alcançar índices produtivos com base em informações geradas por sistemas especialistas (PANDORFI; ALMEIDA; GUISELINI, 2012). Legesse et al. (2018) estudou a intensidade de uso 
da água na produção canadense de carne bovina em 1981 comparando a 2001 e encontraram que o uso de água por animal foi $14 \%$ maior em 2001, fato devido ao maior número de animais e maior peso corporal, gerando uma maior demanda por ração e água. Por sua vez quando esse valor é analisado pelo ponto de vista de intensidade de uso, o uso da água por quilo de carne bovina desossada diminuiu $17 \%$ em relação a 1981. Ou seja, o uso da zootecnia de precisão aliado a melhoras de manejo animal e nutricional resultou em melhores resultados mesmo com aumento de número de animais.

A ingestão de água por um animal é dividida em três fontes: água contida no alimento, água de bebida e a água metabólica. A água metabólica é considerada uma fonte insignificante comparada aos consumos via a água de bebida e a água contida nos alimentos (NRC, 2001). A somatória destas três fontes resulta no total de água consumida pelo animal por dia. Segundo Zanetti (2017) as dietas brasileiras, quando comparadas a dietas norte-americanas, apresentam ingredientes que contêm maior umidade impactando nos menores valores de ingestão de água via dessedentação. Esse fato também pode ser aplicado a diferença encontrada entre as dietas em estudo. A somatória dos consumos de água de bebida com os de água ingerida via alimento, resultou em um consumo total médio de $29,25 \mathrm{~L} \mathrm{cab}^{-1} \mathrm{dia}^{-1}$ para a dieta convencional e de 30,34 L $\mathrm{cab}^{-1} \mathrm{dia}^{-1}$ para a dieta com coprodutos. A dieta convencional apresentou valores de água ingerida via dieta de $26,32 \mathrm{~m}^{3}$ contra $20,51 \mathrm{~m}^{3}$ da dieta com coprodutos. O que influenciou nos menores valores de água de dessedentação da dieta convencional. É necessária uma menor quantidade de água de bebida para atingir a necessidade diária do animal.

A relação entre o CMS e consumo de água foi muito estudada (WINCHESTER; MORRIS, 1956; WILLIANS, 1959; UTLEY et al., 1970; LONERAGAN et al., 2001). As estimativas da relação CMS e consumos de água para bovinos de corte é de 1,4 a 2,3 $\mathrm{kg}$ água por 0,5 $\mathrm{kg} \mathrm{MS}$ ingerida, em temperaturas de $15^{\circ} \mathrm{C}$ a $25^{\circ} \mathrm{C}$ segundo o NRC (2000). No presente estudo esses valores foram de 1,60 $\mathrm{L} \mathrm{kg}^{-1} \mathrm{MS}$ na dieta convencional e de 1,77 $\mathrm{L} \mathrm{kg}^{-1} \mathrm{MS}$ na dieta de coprodutos, abaixo da faixa estipulada pelo NRC. Meyer, Sthal e Flachowsky (2006) encontraram valores de 2,3 $\mathrm{L} \mathrm{kg}^{-}$ ${ }^{1} \mathrm{MS}$, assim como Utley et al., (1970) que encontraram valores de 2,9 $\mathrm{L} \mathrm{kg}^{-1} \mathrm{MS}$. Vários fatores podem ajudar a explicar o porquê dos valores maiores encontrados em relação ao presente estudo, um dos fatores é que as equações testadas foram desenvolvidas em ambientes de clima temperado usando predominantemente animais Bos taurus. Csiro (2007) recomendou diferentes equações de previsão de consumo de água, para $20^{\circ} \mathrm{C}, 25^{\circ} \mathrm{C}$ e $30^{\circ} \mathrm{C}$ e os valores são $4,0 \mathrm{~L} \mathrm{~kg}^{-1} \mathrm{MS}$; 5,5 $\mathrm{L} \mathrm{kg}^{-1}$ 
MS e 7,5 $\mathrm{L} \mathrm{kg}^{-1} \mathrm{MS}$ para Bos taurus e 3,5 $\mathrm{L} \mathrm{kg}^{-1} \mathrm{MS} ; 4,5 \mathrm{~L} \mathrm{~kg}^{-1} \mathrm{MS}$ e $6,0 \mathrm{~L} \mathrm{~kg}^{-1} \mathrm{MS}$ para Bos indicus, respectivamente.

Ao analisar a pegada hídrica azul pelo contexto do índice de escassez hídrica avaliou-se o volume de água consumido em função da disponibilidade hídrica superficial e subterrânea do local de estudo. A dieta com o uso de coprodutos apresentou um índice maior do que o da dieta convencional, porém ambas as dietas consumiram $1 \%$ da disponibilidade de água superficial e/ou subterrânea anual da propriedade. Isso demonstra que o consumo de água azul não significou um impacto negativo na disponibilidade de água azul e nos fluxos ambientais. Em situações onde, embora, possa não existir a necessidade de se reduzir a pegada hídrica azul, o uso eficiente de água deve sempre fazer parte da estratégia de gestão do sistema. Palhares e Pezzopane (2015) defendem a economia de água, como forma de manter a produção e os serviços ambientais, bem como para disponibilizar água para outras atividades.

Para Hoekstra et al. (2012) o índice de escassez de água azul quando analisado anualmente pode apresentar uma visão incompleta da escassez do recurso, pois mesmo em áreas com abundância do recurso, há variabilidade sazonal que pode limitar a disponibilidade de água azul em certo período. Essa situação não ocorreu no estudo em questão, devido ao fato do período de confinamento ser de 123 dias e em uma mesma estação climática. Em estudos que abrangem ciclo produtivos maiores e diferentes estação do ano, deve se considerar o cálculo do índice para cada mês a fim de se identificar os períodos do ciclo produtivo em que o índice de escassez possa apresentar valores que ameassem a segurança hídrica do local de produção.

Ao analisar a pegada hídrica azul do abatedouro de Promissão/SP observou-se um declínio do valor de pegada hídrica ao longo do período, de 9,35 $\mathrm{L} \mathrm{kg}^{-1}$ de carne em 2012 para 6,91 $\mathrm{L} \mathrm{kg}^{-1}$ de carne em 2013, 5,40 L kg${ }^{-1}$ de carne em 2014 e 5,35 $\mathrm{L} \mathrm{kg}^{-1}$ de carne em 2015. O abatedouro de Tangará da Serra/MT apresentou valores máximos e mínimos de pegada hídrica azul de 7,58 $\mathrm{L} \mathrm{kg}^{-}$ ${ }^{1}$ de carne em 2013 e de $6,95 \mathrm{~L} \mathrm{~kg}^{-1}$ de carne em 2014, respectivamente. Estimativas de uso de água em abatedouros bovinos norte-americanos variam de 3.630 a 12.518 litros por tonelada de peso vivo (CAST, 2012). No Brasil a CETESB (2004) indica um consumo de $3.864 \mathrm{~L}_{\text {cabeça }}{ }^{-1}$, considerando um animal de $500 \mathrm{~kg}$ de peso vivo e rendimento de carcaça de $55 \%$, equivale a $14 \mathrm{~L}$ por kg de carcaça. O Banco mundial (1999) indica uma variação de 2,5 a $40 \mathrm{~L}$ por kg de carcaça bovina. Legesse et al. (2018) consideraram $11 \mathrm{~L} \mathrm{~kg}^{-1}$ de carne desossada. A variação de valores de pegada hídrica entre os anos e entre as unidades agroindustriais é resultado de práticas operacionais 
e uso de tecnologias diferenciadas no abate e processamento do produto, havendo uma indicação que a eficiência hídrica de ambas as plantas melhorou no período. Na avaliação dos abatedouros não foi possível separar os consumos de água por setor da unidade agroindustrial devido à somente haver um hidrômetro instalado na captação de água.

No processo de abate de bovinos são consumidos de 500 a 2.500 litros de água por animal, sendo $900 \mathrm{~L} \mathrm{cab}^{-1}$ gastos na sala de abate, $1.000 \mathrm{~L} \mathrm{cab}^{-1}$ nas demais dependências (triparia, bucharia, sanitários) e $600 \mathrm{~L} \mathrm{cab}^{-1}$ nos anexos externos (pátios, currais e lavagem dos caminhões). Dentro de cada unidade e de cada planta frigorífica existe grande variação dos valores de consumo de água, em função de vários fatores, tais como: tipo de unidade (só abate, abate e industrialização da carne, presença ou não de graxaria), tipo de equipamentos e tecnologias e a influência da mão de obra (SENAI, 2003). Para Pacheco e Yamanaka (2006) o consumo de água varia bastante de unidade para unidade, em função de vários aspectos como: tipo de unidade (só abate, abate e industrialização da carne, com/sem graxaria, etc.), tipos de equipamentos e tecnologias em uso, "layout" da planta e de equipamentos, procedimentos operacionais, entre outros. Estratégias para redução do consumo de água podem envolver soluções tecnológicas (melhorias de equipamentos e das instalações atuais ou a instalação de novos equipamentos, por exemplo). Porém, uma revisão dos procedimentos e práticas operacionais, tanto de produção como de limpeza e higienização, podem representar alguns dos ganhos e benefícios mais significativos para os abatedouros.

As diferenças na composição dos ingredientes das dietas e as produtividades agrícolas de cada ingrediente tem impacto significativo nas pegadas hídricas verde e total. Os resultados indicam que a formulação da dieta influenciou os valores das pegadas das fazendas em análise. A fazenda com maior ingestão de MS por cabeça $\operatorname{dia}^{-1}\left(12,4 \mathrm{~kg} \mathrm{cab}^{-1} \mathrm{dia}^{-1}\right)$ não foi a que apresentou o maior valor de pegada hídrica $\left(8.917,25 \mathrm{~L} \mathrm{~kg}^{-1}\right.$ carne $)$, devido à grande quantidade de coprodutos na dieta, impactando para uma menor demanda de água verde.

É difícil ser preciso na formulação da dieta, considerando as diversas características produtivas de um mesmo sistema de produção, devido as alterações nos preços dos ingredientes o que irá afetar o nível de inclusão de cada um destes na dieta.

A otimização da nutrição animal é uma forma de melhorar a sustentabilidade dos sistemas de produção de ruminantes (WHITE et al., 2015). A pesquisa em nutrição animal concentrou-se em melhorar a eficiência do uso de fontes de energia e proteína, mas ainda pouco explora o potencial da relação nutrição animal e consumo de recursos naturais (WHITE et al., 2016). 
O uso dos coprodutos na alimentação de ruminantes, o que também significa conhecer a disponibilidade de energia e nutrientes de cada coproduto, é um desafio para pesquisa em produção animal por ser essa prática uma forma de melhorar a eficiência do uso de recursos naturais e insumos. Manejos alimentares que considerem a substituição do milho e da soja na dieta por outros ingredientes e a oferta de volumoso de elevada qualidade nutricional são práticas que auxiliarão na redução dos impactos o solo, a água e o ar (WILKINSON, 2011).

Drastig et al. (2016) avaliaram a produtividade hídrica de sistemas de frango de corte no Brasil. Os autores verificaram que a soja produzida no estado de São Paulo apresentou menor produtividade hídrica quando comparada com a produzida na região Centro-Oeste. No cálculo da pegada hídrica de cada uma das fazendas, essa condição foi verificada, impactando o valor final da pegada hídrica verde de cada propriedade, pois os valores de produtividade da soja variaram de 2,4 t ha $^{-1}$ em Rio Verde/GO a 3,3 $\mathrm{t} \mathrm{ha}^{-1}$ em Três Lagoas/MS. Na fazenda 9 todo o alimento foi produzido na própria fazenda localizada em Luiz Eduardo Magalhães/BA. Devido às baixas produtividades do milho e do sorgo no ano de análise, ambos representando $73 \%$ da dieta, a fazenda apresentou a maior pegada hídrica entre as fazendas analisadas. A produtividade do sorgo foi de $1,0 \mathrm{t} \mathrm{ha}^{-1}$, muito abaixo da produtividade da região Sul, maior produtor em 2016, com produtividade de 3,5 $\mathrm{t} \mathrm{ha}^{-1}$ (SIDRA, 2016).

O contexto local é de fundamental importância na abordagem da pegada hídrica. O uso da água por determinada cultura vegetal está relacionado com as condições edafoclimáticas e de manejo do local de produção. Segundo Mekonnen e Hoestra (2012), as diferenças de pegada hídrica entre países de devem sim as diferenças de eficiência alimentar dos animais, mais o impacto mais relevante na variação são as diferenças no clima e nas práticas agrícolas utilizadas. Willers et al. (2014) afirmam que é necessário identificar o consumo total e os pontos críticos no processo de produção, ou seja, aqueles com impactos negativos significativos.

A representatividade da pegada hídrica azul no valor da pegada total de cada fazenda variou de $0,20 \%$ a 1,33\%. Legesse et al. (2018) encontraram que o consumo de água azul foi responsável por $1 \%$ do total da pegada hídrica do produto carne bovina. De Boer et al., (2013) avaliaram que $76 \%$ da pegada hídrica azul teve origem na água de irrigação, $15 \%$ na água para produção de concentrados e $8 \%$ na água de dessedentação dos animais e serviços de limpeza. Novelli (2017) avaliando a pegada hídrica azul de vacas em lactação, verificou que a irrigação das pastagens representou mais de $90 \%$ do valor total, seguido pela água de dessedentação (aproximadamente 
$5,5 \%$ ) e água no produto (valores inferiores a $2 \%$ ). A variabilidade na representatividade da água azul é justificada pelos tipos de consumo considerados no cálculo, por exemplo água contida no produto, uso de irrigação na produção das culturas vegetais, entre outros.

Uma dificuldade em se calcular a pegada hídrica de produtos de origem animal se deve a escassez de informações quanto ao consumo de água na produção de premixes, núcleos, ureia e sais. Devido a essa carência de dados, em duas fazendas não foram considerados $20 \%$ e $29,8 \%$ das dietas por serem constituídos dos produtos citados acima. Essa realidade indica que a agroindústria de alimentos para animais precisa evoluir em sua cultura hídrica, bem com compartilhar as informações de seus consumos de água com a pesquisa para que os cálculos de pegada hídrica de produtos de origem animal sejam mais completos.

Grande parte da água consumida no frigorífico, 80 a 95\%, são descarregadas na forma de efluentes líquidos (UNEP, 2000). Os padrões de qualidade e sanitários requeridos pelas autoridades públicas e pela agroindústria são os fatores de maior impacto no uso da água pelos abatedouros (PACHECO; YAMANAKA, 2008; SENAI, 2003). O abate de animais é uma atividade agroindustrial de relevante impacto ambiental, pois os efluentes de abatedouro podem ter a presença de sangue, esterco, conteúdo intestinal não digerido, agentes de limpeza, entre outros, lhes conferindo alta carga orgânica, flutuações de pH e temperatura e altas concentrações de nitrogênio, fósforo e outros elementos (PACHECO; YAMANAKA, 2008). A geração desses efluentes são um dos pontos que contribuem para imagem negativa que a sociedade tem da atividade e o setor público considera os abatedouros como uma significativa fonte de poluição (MORALES, 2006; SILVA, 2011).

O valor médio da pegada hídrica cinza no ano de 2014 foi de 554,00 $\mathrm{L} \mathrm{kg}^{-1}$ carne, em 2013, 75,4 $\mathrm{L} \mathrm{kg}^{-1}$ carne e em 2012, 119,8 $\mathrm{L} \mathrm{kg}^{-1}$ carne, indicando grande variabilidade na eficiência do sistema de tratamento da unidade agroindustrial. Os valores da pegada nos meses de fevereiro, março e abril de 2014 ainda ressaltam que ocorreu algum tipo de alteração no processo produtivo e/ou manejo da estação de tratamento. Considerando os três anos de avaliação, o mês de abril de 2012 foi o que apresentou o maior valor de pegada cinza $1.727 \mathrm{~L} \mathrm{~kg}^{-1}$ carne e o mês de julho do mesmo ano o menor valor, $15,9 \mathrm{~L} \mathrm{~kg}^{-1}$ carne.

Os valores de pegada hídrica cinza estão relacionados à quantidade e a qualidade do efluente e ao desempenho da estação de tratamento. Segundo BRAILE; CAVALCANTI (1993) a carga poluidora e o volume de efluente de um abatedouro são dependentes dos processos 
industriais, da quantidade e do tipo de carne processada e das condições e dos tipos de equipamentos. Portanto, o uso de práticas e tecnologias para redução do uso da água ao longo do processo de abate e a melhoraria da eficiência do sistema de tratamento significarão a redução dos valores da pegada hídrica cinza.

Segundo Nascimento et al. (2011) verificaram que com a implantação de um sistema de reaproveitamento do efluente consegue-se uma redução de até $60 \%$ na captação de água dos mananciais. Isso teria um impacto positivo na pegada hídrica do processo de abate, reduzindo os consumos das águas azul e cinza. Entre as medidas que podem ser executadas a fim de reduzir a água utilizada na indústria, segundo Gunduz (2015), está o uso de tecnologias de economia de água e práticas de reutilização. Porém, Fronza (2004) expõe que o reuso de água em abatedouros tem suas exceções. O reuso poderá ser empregado em processos onde o uso de água potável não se faz necessário. É possível fazer o reuso da água utilizada no banho dos animais, necessitando apenas de um sistema de tratamento simplificado seguido de cloração, representando uma economia de aproximadamente $28 \%$ do consumo de água no abatedouro.

O conhecimento dos custos efetivos da atividade agropecuária, possibilita a gestão dos recursos, indicando os gargalos produtivos além de torna-la mais flexível em épocas de crise e preparar para novas oportunidades (OIAGEN et al., 2006).

Dentro do sistema de confinamento a alimentação pode chegar até $70 \%$ dos custos (CERVIERI; CARVALHO, 2009). Segundo Lopes et al. (2005), excluindo-se a compra de animais, a alimentação pode chegar a representar 95,6\% dos custos diretos.

Para Oliveira et al. (2013), a inclusão de coprodutos, no caso torta de oleaginosas, na dieta de bovinos foi vantajosa, pois reduziu os custos e mantém a produtividade e a qualidade dos produtos. Prado et al. (2006), Ezequiel et al. (2006) e Geron et al. (2011) também encontraram valores menores no custo total da dieta quando usaram os subprodutos. Todos os autores citados usaram apenas a substituição parcial ou total de algum ingrediente da dieta.

Ao fazer a substituição total dos ingredientes por coprodutos a dieta não compensou economicamente. Houve um acréscimo de 9,25\% no custo por cabeça dia. O uso de coprodutos então, quando em substituição de algum ingrediente ou mesmo em consórcio com os ingredientes convencionais demostram melhores resultados econômicos. Os coprodutos são indicados para uso então á aqueles que possam adquiri-los a preços baixos, próximos de sua propriedade, caso contrário haverá redução nas margens de lucro (OLIVEIRA et al., 2012). 
A maior representação da mão de obra nos custos quando a escala de produção foi menor, $35,22 \%$ do custo total, atesta a existência de uma maior eficiência de produção alcançada pela maior escala, pois os salários pagos aos colaboradores independem do número de animais e sim das horas trabalhadas.

Palhares, Morelli e Costa Jr. (2017) afirmam que o consumo absoluto de água pela produção animal aumentou nas últimas décadas devido a intensificação dos sistemas de produção. Segundo Palhares, Afonso e Gameiro (2018), o custo da água em sistemas de produção de suínos representou 0,22 a $0,06 \%$ dos custos totais de produção. Os autores demonstraram que dietas com uso de tecnologias mais avançadas e o melhor gerenciamento dos resíduos como fertilizante promovem a redução do valor pago pela água. Para Brueck e Lammel (2016) a demanda por água aumentará a preocupação da sociedade com o valor do recurso para as commodities agropecuárias, consequentemente, a sociedade exigirá cada vez mais a transparência em se mostrar o quanto de água é consumida na produção dos alimentos. Isso incentivará os produtores a implementarem boas práticas de manejo e gestão hídrica da propriedade. Além da adoção de tecnologias de tratamento de efluentes e de reuso de água. Também pode representar um novo nicho de mercado, de consumidores dispostos a pagar mais pelo alimento "hidricamente correto".

O valor total a ser pago pela água consumida pelos animais na dieta convencional foi de $\mathrm{R} \$$ 2,07 e de R \$ 2,56 para a dieta com coprodutos. A precificação da água nesse estudo, representou um custo máximo de $\mathrm{R} \$ 0,0011$ por animal $\mathrm{dia}^{-1}$, valor irrisório quando comparado ao demais custos da produção. Por arroba de animal o custo médio da água foi de $\mathrm{R} \$ 0,006$ para dieta com coprodutos e de $\mathrm{R} \$ 0,005$ para dieta convencional, variando de $\mathrm{R} \$ 0,003$ a $\mathrm{R} \$ 0,008$.

Considerando um confinamento para 6.000 animais e ciclo de 100 dias o valor do custo da água, utilizando a dieta de coprodutos seria de $\mathrm{R} \$ 660,00$ e para dieta convencional de $\mathrm{R} \$ 420,00$, diferença de $\mathrm{R} \$ 240,00$. Ambos os valores podem ser considerados baixos, comparando-se aos outros custos de produção de um confinamento. Morelli e Palhares (2015a) encontraram valores de custo da água por cabeça dia $^{-1}$ de $\mathrm{R} \$ 0,0015$ e os valores totais médios, em confinamento de bovinos no estado de $\mathrm{SP}$, de $\mathrm{R} \$ 856,00$ por ciclo, com valores máximos e mínimos de $\mathrm{R} \$ 7.126,00$ e $\mathrm{R} \$ 23,00$, respectivamente. Segundo os autores a fazenda que apresentou maior número de confinados por ciclo foi a que apresentou os maiores valores custo da água.

Percebe-se que o instrumento de gestão hídrica, cobrança pelo uso da água, poderia não atingir o objetivo de dar mais eficiência ao uso do recurso natural. Segundo Gomez-Limon e Berbel 
(1999) a precificação da água não é serve apenas um instrumento eficaz para reduzir as ineficiências do uso da água pelos agricultores, mas também é um meio de apoiar financeiramente a gestão da água. A precificação da água em primeiro momento será menos acessível para alguns produtores, em especial aos pequenos produtores, mas diminuirá a incerteza sobre o futuro da água (RABOBANK, 2016). É importante salientar que embora a cobrança seja uma condição necessária, ela não é o suficiente para se ter eficiência hídrica.

Para Brueck e Lammel (2016) a demanda por água aumentará a preocupação pública com os custos da água das commodities agrícolas, consequentemente, as sociedades exigirão cada vez mais a transparência do "consumo de água" por trás dos produtos alimentícios. O que obrigará aos produtores a implementação de boas práticas de manejo e gestão hídrica da propriedade. Além da adoção de tecnologias de tratamento de efluentes e de reuso de água. Isso a primeiro momento também pode representar um novo nicho de mercado, de consumidores dispostos a pagar mais pelo alimento "hidricamente correto".

Morelli e Palhares (2015b) verificaram que a escala de produção não reflete a eficiência de produção, em se tratando da eficiência de uso dos nutrientes, quando essa é avaliada pelo balanço de nutrientes. Independentemente da escala de produção, apenas uma fração dos nutrientes são incorporados ao produto. A quantidade de nutrientes que saem na forma de carne depende de fatores como tamanho e desempenho dos animais (NRC, 2000). Ao analisar o balanço de nutrientes, do ponto de vista da saída somente carne, ambas as dietas tiveram valores muito próximos de saídas de $\mathrm{N}, \mathrm{P}$ e $\mathrm{K}$, pois não houveram diferenças nas características de desempenhos dos animais no estudo. Sendo o restante incorporado ao sistema na forma de dejetos ou perdido por emissões no caso do nitrogênio.

Soberon et al. (2013) destacam que em sistemas biológicos nunca haverá eficiência de uso de nutrientes de $100 \%$. Comumente menos de $20 \%$ dos nutrientes consumidos pelos animas são convertidos em produto animal (NRC, 2000; COLE; TODD, 2009). Para Knowlton e Ray (2013) os bovinos utilizam os nutrientes de forma ineficiente excretando 60-80\% do consumo. No balanço do nitrogênio de bovinos de corte confinados cerca de $15 \%$ do $\mathrm{N}$ permanece como tecido animal, $44 \%$ é perdido para a atmosfera ou na forma de escoamento superficial e $41 \%$ estão na forma de resíduos (MORELLI; PALHARES, 2015b). Valores que corroboram aos valores de EUN analisando somente a saída pelo produto carne para as duas dietas. Morelli e Palhares (2015b) verificaram que a escala de produção não impacta na eficiência na eficiência de uso dos nutrientes. 
Independentemente da escala de produção, apenas uma fração dos nutrientes que entram no sistema de produção são transformados em produto.

Ao analisar o balanço para carne, ambas as dietas tiveram valores muito próximos de saídas de nutrientes, resultado da não diferença de desempenhos dos animais independente da dieta. A quantidade de nutrientes que saem na forma de carne depende de fatores como o tamanho e desempenho dos animais (NRC, 2000). No balanço carne a quantidade de fósforo disponível na forma de produto foi de 2,86 e 2,97 $\mathrm{kg}$ de $\mathrm{P}$, para a dieta convencional e para a dieta com coprodutos, respectivamente. No balanço do potássio esses valores foram de 7,3 $\mathrm{kg}$ para a dieta convencional e 7,6 kg de $\mathrm{K}$ para a dieta com coprodutos. Esses nutrientes estão presentes na forma de tecidos e ossos dos animais. Segundo Kincaid (1988) os minerais são críticos para a vida animal, pois são participantes ativos das reações enzimáticas e constituem cerca de 5\% do PV dos animais.

$\mathrm{O} P$ dietético que excede as exigências do animal não é absorvido ou, se for, é excretado na urina, grandes quantidades de fósforo são recicladas via saliva (ARC, 1965). O N pode ser excretados, significativamente, via fezes e via urina. O potássio é eliminado preferencialmente na urina (HAYNES; WILLIANS, 1993). Em se tratando de balanço de nutrientes e avaliação de impactos ambientais, as perdas por potássio geralmente não são contabilizadas nas análises dos sistemas de produção animal (CELA et al., 2014).

$\mathrm{O}$ aproveitamento de coprodutos como ingredientes da dieta dos animais reduz os impactos ambientais das atividades agroindustriais, pois é menor necessidade de deposição de resíduos no ambiente e o uso dos coprodutos também permite ao produtor ter acesso a ingredientes com menor custo em períodos de escassez (OLIVEIRA et al., 2012). O uso de coprodutos na dieta promoveu impacto benéfico na eficiência de uso de fósforo e do potássio para o balanço carne e de nitrogênio e fósforo para o balanço carne+fezes. Isso significa, em valores absolutos, que a dieta com coprodutos proporcionou menor quantidade dos elementos na forma de produto e maior na forma de resíduos.

O balanço de nutrientes é sensível às variações de manejo, havendo relações entre as variáveis do rebanho e os excedentes de nutrientes produzidos. O desequilíbrio entre entradas e saídas de nutrientes define a magnitude do potencial de risco ambiental e fornece suporte a tomada de decisão sobre as causas subjacentes a estes desafios (COSTA JUNIOR et al., 2013). Segundo o NRC (2001), o excesso de nutrientes na dieta de bovinos, eleva não só o custo econômico, como também gera excessiva eliminação de nutrientes no ambiente. Os resultados dos balanços indicam 
que é possível reduzir as perdas absolutas de nutrientes e aumentar a eficiência de uso por meio da utilização de coprodutos na deita de bovinos em confinamento, mas ambas as dietas apresentaram balanços finais positivos e baixa eficiência de uso de nutrientes quando se considera no balanço apenas como produto a carne, ressaltando a necessidade de se internalizar o manejo ambiental nos sistema de produção de bovinos em confinamento a fim de promover os uso dos resíduos como um insumo a ser utilizado por outros sistemas produtivos. 


\section{CONCLUSÕES}

O tipo de dieta utilizada no confinamento de bovinos de corte impactou positivamente na eficiência do uso da água e não ocasionou impactos negativos nos índices de desempenho animal, sendo uma alternativa nutricional e hídrica viável. A dieta com substituição total dos ingredientes convencionais por coprodutos gerou menor valor de pegada hídrica total, devido ao menor consumo de água verde, apesar do consumo de água de dessedentação dos animais ter sido maior. Isso demonstra que a gestão dos recursos hídricos utilizados na produção do produto carne deve considerar os usos indiretos e diretos da água, tendo abordagens diferenciadas quanto cada um destes usos, seja na bacia hidrográfica onde se insere a unidade produtiva, seja no território de onde a água é exportada na forma de alimentos. Quanto ao balanço de nutrientes, os resultados demonstram que não houve uma dieta superior quanto à eficiência de uso de nutrientes. Portanto, a utilização de coprodutos na dieta de bovinos em confinamento proporcionou vantagens hídricas, mas diferenças, frente a dieta convencional, na capacidade dos animais aproveitarem os nutrientes. Com isso, estudos futuros devem continuar investigando as relações entre as eficiências hídrica e de uso de nutrientes a partir do manejo nutricional a fim de identificar e propor manejos e práticas produtivas que promovam impactos positivos em ambas dimensões.

Também são necessários estudos para indicar qual o melhor nível de substituição de coprodutos na dieta do ponto de vista econômico, pois conforme avaliado neste estudo a substituição total significou maior custo produtivo.

O cálculo da pegada hídrica é uma ferramenta eficiente e de caráter multifatorial para a gestão hídrica da propriedade rural e do complexo agroindustrial da carne. Com ela é possível o entendimento da utilização da água pelo sistema produtivo, além de proporcionar o conhecimento da inter-relação entre produto, produção e eficiência hídrica gerando dados para o fomento de ações, práticas, políticas que visem uma produção hidricamente correta e subsidie a sociedade nas suas escolhas. 


\section{REFERÊNCIAS}

ABDAlLA, A. L.; SILVA FILHO, J.C.; GODOI, A. R.; CARMO, C.A.; EDUARDO, J.L. P. Utilização de subprodutos da indústria de biodiesel na alimentação de ruminantes. Revista Brasileira de Zootecnia, v. 37, p. 260-268, 2008.

AGRICULTURAL RESEARCH COUNCIL. ARC. The Nutrient Requirements of Farm Livestock no. 2 Ruminants. 1. ed. London, UK: Agricultural Research Council, 1965. 264p.

ALI, S.; GOONEWARDENE, L.A; BASARAB, J.A. Estimating water-consuption and factors affecting intake in grazing cattle. Canadian Journal of Science, n. 74, p.551-554, 1994.

ANUÁRIO ESTATÍSTICO DA PECUÁRIA DE CORTE. ANUALPEC. São Paulo: FNP Consultoria e Comércio Ltda., 2012.

ANUÁRIO ESTATÍSTICO DA PECUÁRIA DE CORTE. ANUALPEC. São Paulo: FNP Consultoria e Comércio Ltda., 1999.

ARAÚJO, P.P.P.; COSTA, L.P. Impactos ambientais nas atividades de abate de bovinos: um estudo no matadouro público municipal de Caicó-RN. Rio Grande do Norte. Holos, v. 1, p. 1-20, 2014.

ARIAS, R.A.; MADER, T.L. Environmental factors affecting daily water intake on cattle finished in feedlots. Journal of Animal Science, v. 89, p. 245-25, 2011.

ASSOCIAÇÃO BRASILEIRA DE NORMAS TÉCNICAS. ABNT. NBR ISO 14040: Gestão ambiental- Avaliação do ciclo de vida- Princípios e estrutura. Rio de Janeiro: ABNT, 2009.

ASSOCIATION OF OFFICIAL ANALYTICAL CHEMISTS. AOAC. Official methods of analysis. 16. ed. Washington D.C: AOAC, 1995.1298p.

ATZORI, A.S.; CANALIS, C.; FRANCESCONI, A.H.D.; PULINA, G. A preliminary study on a new approach to estimate water resources allocation: the net water footprint applied to animal products. Agriculture and Agricultural Science Procedia, v.8, p. 50-57, 2016.

BECKETT, J.L.; OLTJEN, J.W. Estimation of the water requirement for beef production in the United States. Journal of Animal Science, v.71, p. 818-826, 1993.

BEKELE, L. D.; ZHANG, W.; LIU, Y.; DUNS, G. J.; YU, C.; JIN, L.; LI, X.; CHEN, J. Impact of cotton stalk biomass weathering on the mechanical and thermal properties of cotton stalk flour/linear low-density polyethylene (lldpe) composites. Journal of Biobased Materials and Bioenergy, v. 11, p. 27-33, 2017.

BELLAVER, C.; LUDKE J.V. Considerações sobre os alimentos alternativos para dietas de suínos. In: ENCONTRO INTERNACIONAL DOS NEGÓCIOS DA PECUÁRIA, Cuiabá, 2004. Anais... Cuiabá, 2004. 
BLÜMMEL, M.; HAILESLASSIE, A.; SAMIREDDYPALLE, A.; VADEZ, V.; NOTENBAERT, A. Livestock water productivity: feed resourcing, feeding and coupled feed-water resource data bases. Animal Production Science, v. 54, p. 1584-1593, 2014.

BOSIRE, C.K.; OGUTU, J. O.; SAID, M.Y.; KROL, M.S.; LEEUW, J de; HOEKSTRA, A.Y. Trends and spatial variation in water and land footprints of meat and milk production systems in Kenya. Agriculture, Ecosystems \& Environment, v. 205, p.36-47, 2015.

BRAGA, L.G.T.; RODRIGUES. F.L.; AZEVEDO, R.V.; CARVALHO, J.S.O.; RAMOS, A.P.S. Digestibilidade aparente da energia e nutrientes de coprodutos agroindustriais para tilápia do Nilo. Revista Brasileira de Saúde e Produção Animal, v. 11, n. 4, P. 1127-1136, 2010.

BRASIL. Ministério da Saúde. Instituto Brasileiro de Geografia e Estatística (IBGE). Pesquisa de orçamentos familiares 2008-2009: análise do consumo alimentar pessoal no Brasil. Rio de Janeiro: IBGE. 2011.

BREW, M.N.; MYER, R.O.; HERSOM, M.J.; CARTER, J.N.; ELZO, M.A.; HANSEN, G.R.; RILEY, D.G. Water intake and factors affecting water intake of growing beef cattle. M. Livestock Science, v. 140, p. 297-300, 2011.

BRUECK, H.; LAMMEL, J. Impact of fertilizer N application on the greywater footprint of winter wheat in a NW-European temperate climate. Water, v.8, p. 356, 2016.

BURGÜI, R. Confinamento estratégico. In: MATTOS, W.R.S. A produção animal na visão dos brasileiros. Piracicaba: Fealq, 2001. 927p.

CAMPOS, K.C. Análise da volatilidade de preços de produtos agropecuários no Brasil. Revista de Economia e Agronegócio, v.5, p. 303-328, 2007.

CAMPOS, R.T.; CAMPOS, K.C. Capacidade de pagamento pela água bruta na irrigação pública na bacia do Jaguaribe- Ceará. Revista de Economia e Agronegócio, v. 11, p. 357-380, 2014.

CARRERA, R.A.B.; VELOSO, C.M.; KNUPP, L.S.; SOUZA, A.H. de; DETMANN, E.; LANA, $\mathrm{R}$. de P. Protein co-products and by-products of the biodiesel industry for ruminants feeding. Revista Brasileira de Zootecnia, v.41, p.1202-1211, 2012.

CELA, S.; KETTERINGS, Q. M.; CZYMMEK, K.; SOBERON, M.; RASMUSSEN, C. Characterization of nitrogen, phosphorus, and potassium mass balances of dairy farms in New York State. Journal of Dairy Science, v. 97, p. 7614-7632, 2014.

CERVIERI, R.C; CARVALHO, J.C.F. Manejo alimentar em confinamentos: importância dos subprodutos da Agroindústria. In: SIMPÓSIO DE BOVINO DE CORTE, Lavras, 2009. Anais... Lavras: UFLA/NEPEC, 2009. p. 103-129.

CHASE, L.E. Nitrogen utilization in dairy cows: what are the limits of efficiency? In: CORNELL 
COLE, N.A.; TODD, R.W. Nitrogen and phosphorus balance of beef cattle feedyards. In: PROCEEDINGS OF THE TEXAS ANIMAL MANURE MANAGEMENT ISSUES CONFERENCE, Texas, 2009. Proceedings... Texas, 2009, p. 17-24.

CHAPAGAIN, A.K., HOEKSTRA, A.Y. Virtual Water Flows Between Nations in Relation to Trade in Livestock and Livestock Products. Value of Water Research Report Series 13. UNESCO-IHE, Delft, The Netherlands, 2003.

COMPANHIA NACIONAL DE ABASTECIMENTO (CONAB). Custos de produção agrícola: a metodologia da Conab. Brasília: CONAB, 2010. 59p.

COMPANHIA DE TECNOLOGIA DE SANEAMENTO AMBIENTAL. CETESB. Informações de empresa do setor de abate do estado de São Paulo. São Paulo: CETESB, 2004.

CONTE, I. I.; BOFF, L. A. As crises mundiais e a produção de alimentos no Brasil. Acta Scientiarum: Human and Social Sciences, v.35, p.49-59, 2013.

PACHECO, J.W.; YAMANAKA, H.T. Guia técnico ambiental de abates (bovino e suíno). São Paulo: CETESB, 2006. 98p.

CONSELHO NACIONAL DO MEIO AMBIENTE. CONAMA. 2005. Resolução Conama $\mathbf{n}^{\mathbf{0}}$ 357. Disponível em: http://www.mma.conama.gov.br/conama. Acesso em: 15 de novembro de 2017.

COUNCIL FOR AGRICULTURAL SCIENCE AND TECHNOLOGY. CAST. Water and Land Issues Associated with Animal Agriculture: A U.S. Perspective. Issue Paper, v. 50, p. 1-24, 2012.

COSTA JUNIOR, C.; GOULART, R.S.; ALBERTINI, T.Z.; FEIGL, B.J.; CERRI, C.E.P.; VASCONCELOS, J.T.; BERNOUX, M.; LANNA, D.P.D.; CERRI, C.C. Brazilian beef cattle feedlot manure management: A country survey. Journal of Animal Science, v. 91, p. 1811-1818, 2013.

CSIRO. Nutrient requirements of domesticated ruminants. Melbourne: CSIRO Publishing, 2007. 270p.

CURRAN, T.P.; UPTON, J. Water footprinting of dairy farming in Ireland. Journal of Cleaner Production, v. 140, p. 547-555, 2017.

DE BOER, I.J.M.; HOVING, I.E.; VELLINGA, T.V.; VEN, G.W.J.V.de.; LEFFELAAR, P.A.; GERBER, P.J. Assessing environmental impacts associated with freshwater consumption along the life cycle of animal products: the case of Dutch milk production in Noord-Brabant. International Journal of Life Cycle Assessment, v. 18, p. 193 - 203, 2013.

DEUTSCH, L., FALKENMARK, M., GORDON, L., ROCKSTRÖM, J., FOLKE, C. Water mediated ecological consequences of intensification and expansion of livestock production. In: Steinfeld, H., Mooney, H.A., Schneider, F., Neville, L.E., Livestock in a Changing Landscape. Island Press, London, pp. 97 e 110, 2010. 
DOOLE, G. J. Cost-effective policies for improving water quality by reducing nitrate emissions from diverse dairy farms: An abatement-cost perspective. Agricultural Water Management, v. 104, p. 10-20, 2012.

DOORENBOS, J.; KASSAM, A. H. Efeito da água no rendimento das culturas. Campina Grande: UFPB, 1994. 306p. (FAO. Estudos FAO. Irrigação e Drenagem, 33).

DRASTIG, K.; PALHARES, J.C.P.; KARBACH, K.; PROCHNOW, A. Farm water productivity in broiler production: case studies in Brazil. Journal of Cleaner Production, v. 135, p. 9-19, 2016.

EZEQUIEL, J.M.B.; GALATI, R.L.; MENDES, A.R.; FATURI, C. Desempenho e características de carcaça de bovinos Nelore em confinamento alimentados com bagaço de cana-de-açúcar e diferentes fontes energéticas. Revista Brasileira de Zootecnia, v. 35, p. 2050-2057, 2006.

FABRINI, F.F.; AVELINO, K.V.; MARIM, R.A.; CARDOSO, B.K.; COLAUTO, G.A.L.; COLAUTO, J.S. V. Produção de lacase de Pycnoporus sanguineus em meio de cultivo à base de melaço soja. Arquivos de Ciências Veterinárias e Zoologia da UNIPAR, v. 19, p. 159-164, 2017.

FENG, K.; CHAPAGAIN, A.; SUH, S.; PFISTER, S.; HUBACEK, K. Comparison of bottom-up and top-down approaches to calculating the water footprint of nations. Economic Systems Research, v. 23, p. 371-385, 2011.

FOOD AND AGRICULTURE ORGANIZATION OF THE UNITED NATIONS. FAO. Technical conversion factor for agriculture commodities. Roma: FAO. 2013. 782p.

FOOD AND AGRICULTURE ORGANIZATION. FAO. Livestock's long shadow: environmental issues and options. Roma: FAO, 2006. 390 p.

FRANKE, N.A., BOYACIOGLU, H. AND HOEKSTRA, A.Y. Grey water footprint accounting: Tier 1 supporting guidelines, Value of Water Research Report Series No. 65. Delft: UNESCO, 2013. 64p.

FRONZA, N. Estudos das potencialidades do reúso de água em uma Indústria frigorífica. 2004. 82p. Dissertação (Mestrado em Engenharia de alimentos) -Universidade Federal de Santa Catarina. Florianópolis: s.n., 2004.

FUQUAY, J.W. Heat stress as it affects animal production. Journal Animal Science, v. 32, p. 164-174, 1981.

FURLAN, M.; PALHARES, J.C.P. Monitoramento da pegada hídrica cinza de um abatedouro bovino. In: V SIMPÓSIO INTERNACIONAL SOBRE GERENCIAMENTO DE RESÍDUOS AGROPECUÁRIOS E AGROINDUSTRIAIS, Foz do Iguaçu, 2017. Anais... Foz do Iguaçu, 2017.

GERBENS-LEENES, P.W.; NONHEBEL, A.S.; KROL, B.M.S. Food consumption patterns and economic growth: increasing affluence and the use of natural resources. Appetite, v.55, p.597-608, 2010. 
GERON, L.J.V.; MOURA, D.C.; RODRIGUES, D.N.; JUNIOR, E.; PAULA, H.; TRAUTMANNMACHADO, R.J.; GARCIA, J.; SCHUMANN, A.M.; SILVA, D.A. Economic viability of bulls finished in feedlot fed with different levels of cottonseed in diets prepared with agro-industrial byproducts. Ciências Agrárias, v. 35, p. 2673-2684, 2014.

GERON, L.J.V.; ZEOULA, L.M.; DE PAULA, E.J.H; RUPPIN, R.F.; RODRIGUES, D.N.; MOURA, D.C. Inclusão do caroço de algodão em rações de alto concentrado constituído de coprodutos agroindustriais sobre o desempenho animal em tourinhos confinados. Archives of Veterinary Science, v. 16, p. 14-24, 2011.

GIRARD, C.L. Reducing the impact of animal production on the water supply: Increasing knowledge is the only solution. Animal Frontiers, v.2, p.1-2, 2012.

GOES, R.H.T.B.; TRAMONTINI, R.C.M.; ALMEIDA, G.D. Degradabilidade ruminal da matéria seca e proteína bruta de diferentes subprodutos agroindustriais utilizados na alimentação de bovinos. Revista Brasileira de Saúde e Produção Animal, v.9, n.3, p. 715-725, 2008.

GOMES, M.R. Confinamento de gado de corte. Rio de Janeiro: Secretaria da Agricultura e Abastecimento, 1975. 29p.

GOMEZ-LIMON, J.; BERBEL, J. A. The impact of water pricing in Spain: An analysis of three irrigated areas. Agricultural Water Management, v. 43, p. 219-238, 1999.

GUNDUZ, O. Water quality perspectives in a changing world. Water Quality, Exposure and Health, v. 7, p. 1-3, 2015.

HASHIMOTO, J. H.; ALCALDE, C.R.; ZAMBOM, M. A.; SILVA, K.T.; MACEDO, F.A.F.; MARTINS, E.N.; RAMOS, C.E.C.O.; PASSIANOTO, G.O. Desempenho e digestibilidade aparente em cabritos Boer x Saanen em confinamento recebendo rações com casca do grão de soja em substituição ao milho. Revista Brasileira de Zootecnia, v. 36, p. 174-182, 2007.

HAYNES, R.J.; WILLIAMS, P.H. Nutrient cycling and fertility in the grazed pasture ecosystem. Advances in Agronomy, v. 49, p. 119-199, 1993.

HENRIQUE, W.; SAMPAIO, A.A.M.; LEME, P.R.; LANNA, D.P.D.; ALLEONI, G.F.; COUTINHO FILHO, J.L.V. Desempenho e características da carcaça de tourinhos Santa Gertrudes confinados, recebendo dietas com alto concentrado e níveis crescentes de polpa cítrica peletizada. Revista Brasileira de Zootecnia, v.33, p.463-470, 2004.

HICKS, R.B.; OWENS, F.N.; GILL, D.R.; MARTIN, J.J.; STRASIA, C.A. Water intake by feedlot steers. Animal Science Report, v. 12, p. 125-208, 1988.

HOANG, V.N.; NGUYEN, T.T. Analysis of environmental efficiency variations: A nutrient balance approach. Ecological Economics, v. 86, p. 37-46, 2013.

HOEKSTRA, A.Y. The hidden water resource use behind meat and dairy. Animal Frontiers, v.2, n. 2, p. 3-8, 2012. 
HOEKSTRA, A.Y. Virtual water trade. In: INTERNATIONAL EXPERT MEETING ON VIRTUAL WATER TRADE, Delft, Netherlands, 2003. Proceedings...Delf, 2003.

HOEKSTRA, A.Y.; CHAPAGAIN, A.K. Water footprints of nations: water use by people as a function of their consumption pattern. Water Resource Management, v. 21, p. 35-48, 2007.

HOEKSTRA, A.Y., CHAPAGAIN, A.K., ALDAYA, M.M., MEKONNEN, M.M. Water Footprint Manual State of the Art 2009. Enschede: Water Footprint Network. 2009. 127p.

HOEKSTRA, A.Y.; CHAPAGAIN, A.K.; ALDAYA, M.M.; MEKONNEN, M.M. The water footprint assessment manual: setting the global standard. 1. ed. London, UK: Earthscan, 2011. $80 \mathrm{p}$.

HUANG, J., XU, C.C., RIDOUTT, B.G., LIU, J.J., ZHANG, H.L., CHEN, F., LI, Y. Water availability footprint of milk and milk products from large-scale dairy production systems in Northeast China. Journal of Cleaner Production, v.79, p. 91-97, 2014.

JALAVA, M.; KUMMU, M.; PORKKA, M.; SIEBERT, S.; VARIS, O. Diet change- a solution to reduce water use? Environmental Research Letters, v.9, p. 1-14, 2014.

KADZERE, C.T.; MURPHY, M.R.; SILANIKOVE, N.; MALTZ, E. Heat stress in lactating dairy cows: a review. Livestock Production Science, v. 77, p. 59-91, 2002.

KELMAN, J.; RAMOS, M. Custo, valor e preço da água utilizada na agricultura. Revista de gestão de água da américa latina, v.2, p. 39-48, 2005.

KINCAID, R. Macro elements for ruminants. In: CHURCH, D.C. The ruminant animal. digestive physiology and nutrition. Englewood Cliffs: Prentice Hall International. 1988, p. 326341.

KNOWLTON, K.; RAY, P. Water-related Issues in sustainability: Nitrogen and phosphorus management. Sustainable Animal Agriculture, v. 1, p. 113-123, 2013.

KUBIAK, K.I. Proposta de um Sistema de Custos para uma fazenda de confinamento de gado. 2006. 76P. Monografia (Trabalho de conclusão de curso de Ciências Contábeis) - Universidade Federal de Santa Catarina, Florianópolis, 2006.

LEGESSE, G.; CORDEIRO, M.R.C.; OMINSKI, K.H.; BEAUCHEMIN, K.A.; KROEBEL, R.; McGEOUGH,E.J.; POGUE, S.; McALLISTER, T.A. Water use intensity of Canadian beef production in 1981 as compared to 2011. Science of the Total Environment, v. 619-620, p. 10301039, 2018.

LONERAGAN, G.H.; WAGNER, J.J.; GOULD, D.H.; GARRY, F.B.; THOREN, M.A. Effects of water sulfate concentration on performance, water intake, and carcass characteristics of feedlot steers. J. Journal of Animal Science, v. 79, p. 2941-2948, 2001. 
LOPES, M.A.; CARVALHO, F.M. Custo de produção do gado de corte. Lavras: UFLA, 2002. 47p. (Boletim Agropecuário, 47).

LOPES, M.A.; MAGALHÃES, G.P. Análise da rentabilidade na terminação de bovinos de corte em confinamento: um estudo de caso. Arquivo Brasileiro de Medicina Veterinária e Zootecnia, v. 57, p. 374-379, 2005.

MALAFAIA P.A.; VALADARES FILHO M.S.C.; VIEIRA R.A.M.; SILVA J.F.C.; PEREIRA J.C. Determinação das frações que constituem os carboidratos totais e da cinética ruminal da Fibra em detergente neutro de alguns alimentos para ruminantes. Revista Brasileira de Zootecnia, v. 27, p.790-796, 1998.

MARION, J.C.; SEGATTI, S. Contabilidade da Pecuária: Atualizada pelas leis n 11.368/07 e 11.941/09. 10. ed. Paulo: Editora Atlas, 2010. 216p.

MARTIN, L.C.T. Instalações para bovinos de corte sob sistemas de confinamento. In: Confinamento de bovinos de corte. 1 ed. São Paulo: Nobel, 1987.

MEDEIROS, S. R.; 2014. Como o boi funciona: Terminação em pasto ou confinamento. Disponível em: http://sites.beefpoint.com.br/sergioraposo/2014/05/09/como-o-boi-funcionaterminacao-em-pasto-ou-confinamento. Acesso em: 20 de dezembro de 2016.

MEKONNEN, M. M.; HOEKSTRA, A. Y. A Global Assessment of the Water Footprint of Farm Animal Products. Ecosystems, v.15, p. 401-415, 2012.

MEKONNEN, M. M.; HOEKSTRA, A. Y. The green, blue and grey water footprint of farm animals and animal products. 1.ed. Delft: UNESCO-IHE, 2010. 43p.

MELO, A.A.S.; FERREIRA, M.A.; VÉRAS, A.S.C.; LIRA, M.A.; LIMA, L.E.; PESSOA, R.A.S.; BISPO, S.V.; CABRAL, A.M.D.; AZEVEDO, M. Desempenho leiteiro de vacas alimentadas com caroço de algodão em dieta à base de palma forrageira. Pesquisa Agropecuária Brasileira, v.41, p.1165-1171, 2006.

MERTENS, D.R. Regulation of forage intake. In: FAHEY JR GC. Forage quality, evaluation and utilization. Madison: American Society of Agronomy; 1994. 967p.

MEYER, U.; STAHL, W.; FLACHOWSKY, G. Investigations on the water intake of growing bulls. Livestock Science, v.103, p. 186-191, 2006.

MILLEN, D.D.; PACHECO, R.D.L.; ARRIGONE, M.D.B.; GALYEAN, M.L.; VASCONCELOS, J. T. A snapshot of management practices and nutritional recommendations used by feedlot nutritionists in Brazil. Journal of Animal Science, v.87, p. 3427-3439, 2014.

MIODUSZEWSKI, W. Water for agriculture and natural environment. Journal of Water Land Development, v. 13, p. 3-16, 2009.

MORIN, E. A Via para o futuro da humanidade. Rio de Janeiro: Bertrand Brasil, 2013. 392p. 
MORALES, M.M. Avaliação dos resíduos sólidos e líquidos num sistema de abate de bovinos. 2006. 84p. Dissertação (Mestrado em Agronomia) - Faculdade de Ciências Agronômicas, Universidade Estadual Paulista, Botucatu, 2006.

MORAN, E. F., RINDFUSS, R.R., SKOLE, D., TURNER II, B.L., VOGEL, C. Land-Use and Land-Cover Change Implementation Strategy. IGBP Report n. 48/IHDP Report n.10, IGBP, Stockholm, 1999. 125p.

MOREIRA, S.A; THOMÉ, K.M; FERREIRA, P.S.; BOTELHO FILHO, F.B. Análise econômica da terminação de gado de corte em confinamento dentro da dinâmica de uma propriedade agrícola. Custos e Agronegócio online, v. 5, p. 132 -152, 2009.

MOREIRA, T.S.; OLIVEIRA, M.N.N.F.; VILLELA, S.D.J.; BARBOSA, F.A.; MOURTHE, M.H.F.; DINIZ, F.B. Desempenho produtivo e econômico de três grupos genéticos de bovinos recriados a pasto com suplementação e terminados em confinamento. Arquivo Brasileiro Medicina Veterinária e Zootecnia, v.67, p.140-148, 2015.

MORELLI, M. Eficiência de utilização de alimentos em machos Nelore classificados para consumo alimentar residual. 2015. 66p. Dissertação (Mestrado em Produção Animal Sustentável) - Instituto de Zootecnia, Nova Odessa, 2015.

MORELLI, M.; PALHARES, J.C.P. Balanço de nutrientes de sistema de confinamento de bovinos de corte. IN: IV SIMPÓSIO DE SUSTENTABILIDADE \& CIÊNCIA ANIMAL, Niterói, 2015. ANAIS... Niterói, 2015b.

MORELLI, M.; PALHARES, J.C.P. Custo da água em sistemas de produção de bovinos confinados. IN: IX SIMPÓSIO DE PÓS-GRADUAÇÃO E PESQUISA EM NUTRIÇÃO E PRODUÇÃO ANIMAL-VNP, Pirassununga, 2015. Anais... Pirassununga, 2015a.

MULLER, G. T. Emprego da pegada hídrica e da análise de ciclo de vida para a avaliação do uso da água na cadeia produtiva do biodiesel de soja. 2012. 188p. Dissertação (Mestrado em Recursos Hídricos e Saneamento Ambiental) - Universidade Federal do Rio Grande do Sul, Porto Alegre, 2012.

MURPHY, E.; DE BOER, I.J.M.; VAN MIDDELAAR, C.E.; HOLDEN, N.M.; SHALLOO, L.; NASCIMENTO, T.P.A.; SANTO, M.L.; DOS SANTOS, V.O.; CASTRO, W.S.; DOS SANTOS, J.A. Tratamento e reaproveitamento de efluentes provenientes da dessedentação de animais em frigoríficos e abatedouros de pequeno porte. In: II CONGRESSO BRASILEIRO DE GESTÃO AMBIENTAL, Londrina, 2011. Anais.... Londrina, 2011.

NATIONAL RESEARCH COUNCIL. NRC. Effect of environment on nutrient requirements of domestic animals. Washington D.C.: National Academy Press, 1981. 152p.

NATIONAL RESEARCH COUNCIL. NRC. Nutrient requirements of dairy cattle. 7.ed. Washington, DC: National Academy Press, 2001. 381p. 
NATIONAL RESEARCH COUNCIL. NRC. Requirements of Beef Cattle.7. ed. Washington, DC: National Academy Press, 2000. 242p.

NEETESON, J.J. Nitrogen and phosphorus management on Dutch dairy farms: legislation and strategies employed to meet the regulations. Biology and Fertility of Soils, v. 30, p. 566-572, 2000.

NEIVA, J. N.M, NUNES, F.C.S.; CÂNDIDO, M.J.D.; RODRIGUEZ, N.M.; LÔBO, R.N.B. Digestibilidade aparente dos nutrientes de silagem de capim elefante contendo níveis crescentes de subproduto de maracujá em ovinos. In: REUNIÃO ANUAL DA SOCIEDADE BRASILEIRA DE ZOOTECNIA, Goiânia, 2005. Anais... Goiânia, 2005.

NEPA/ UNICAMP. TABELA BRASILEIRA DE COMPOSIÇÃO DE ALIMENTOS. NEPA - UNICAMP.4. ed. rev. e ampl.. -- Campinas: NEPA- UNICAMP. 2011. 161p.

NOVELLI, T.I. Impacto de intervenções nutricionais no valor de pegada hídrica do produto leite bovino. 2017. 114p. Dissertação (Mestrado em Ciências) - Faculdade de Medicina Veterinária e Zootecnia, Pirassununga, 2016.

NUTRITION CONFERENCE FOR FEED MANUFACTURES, 2003, Syracuse, NY. Proceedings... Ithaca, NY: Cornell University, 2003, p. 233 - 245.

ORGANIZAÇÃO PARA A COOPERAÇÃO E O DESENVOLVIMENTO ECONÔMICOS. OCDE. Agricultural Water Pricing in OECD Countries. Paris: OECD. 1998. 72 p.

OENEMA, O.; JANSSEN, B.H.; SMALLING, E.; HOFFLAND, E. Nutrient management in tropical agroecosystems. Agriculture, Ecosystems \& Environment, v. 116, p.1-3, 2006.

OIAGEN, R.O.; BARCELlOS, J.O.J.; CHRISTOFARI, L.F.; CASTRO, E.E.C.; CANOZZI, M.E.A. Custo de produção em terneiros de corte: uma revisão. Revista Veterinária em Foco, Canoas, v. 3, p. 169-180, 2006.

OLEGÁRIO, J. Análise econômica probabilística do confinamento de novilhos com diferentes peses iniciais. 2017. 61p. Dissertação (mestrado em Zootecnia) - Universidade federal de Santa Maria, Santa Maria, 2017.

OLIVEIRA, R.L.; CÂNDIDO, E.P.; LEÃO, A.G. A nutrição de ruminantes no Brasil. In: TÓPICOS ESPECIAIS EM CIÊNCIA ANIMAL, 1., 2012, Espirito Santo. Coletânea da I jornada científica da pós-graduação. Espirito Santo: Universidade federal do Espirito Santo, 2012. 169p.

OLIVEIRA, R.L.; LEÃO, L.L; ABREU. L.L.de; TEIXEIRA, S.; SILVA, T.M. Alimentos Alternativos na Dieta de Ruminantes. Revista Científica de Produção Animal, v.15, p.141-160, 2013.

OLKOWSKI, A. A. Livestock water quality: A field guide for cattle, horses, poultry and swine. Agriculture and Agri-Food Canada, v.157, p. 2009. 
OPHEIM, T.L.; CAMPANILI, P.R.B.; LEMOS, B.J.M.; OVINGE, L.A.; BAGGERMAN, J.O.; MCCUISTION, K.C.; GALYEAN, M.L.; SARTURI, J.O; TROJAN, S.J. Biofuel feedstock and blended coproducts compared with deoiled corn distillers grains in feedlot diets: Effects on cattle growth performance, apparent total tract nutrient digestibility, and carcass characteristics. Journal of Animal Science, n. 94, p. 227-239, 2016.

ORGANIZATION FOR ECONOMIC COOPERATION AND DEVELOPMENT. OECD. Developing OECD Agri-Environmental Indicators. Paris: OECD, 1996.

ORNAGHI, M.G.; EIRA, C.E.; BARRADO, A.G.; TORRECILHAS, J.A.; PASSETTI, R.A.C.; MOTTIN, C.; PRADO, I.N. Glicerina como substituto do milho na nutrição de bovinos e influência na composição de ácidos graxos da carne: Revisão. Pubvet, v. 10, p. 271-355, 2016.

OWUSU-SEKYERE, E.; SCHEEPERS, M.E.; JORDAAN, H. Water footprint of milk produced and processed in South Africa: implications for policy-makers and stakeholders along the dairy value chain. Water, v. 8, p. 322, 2016.

PACHECO, J.W.; YAMANAKA, H.T. Guia técnico ambiental de abate (bovino e suíno). São Paulo: CETESB, 2008. 95p.

PACHECO, P.S.; FABRICIO, E.A.; CAMERA, A. Análise conjunta de indicadores financeiros na viabilidade econômica do confinamento de bovinos no Rio Grande do Sul em diferentes épocas do ano. Agropampa, v. 1, p. 86-99, 2016.

PACHECO, P.S.; SILVA, R.M.; PADUA, J.T.; RESTLE, J.; TAVEIRA, R.Z.; VAZ, F.N.; PASCOAL, L.L.; OLEGARIO, J.L.; MENEZES, F.R. Análise econômica da terminação de novilhos em confinamento recebendo diferentes proporções de cana-de-açúcar e concentrado. Ciências Agrárias, v. 35, p. 999-1012, 2014.

PALHARES, J. C. P. Eficiência de uso do nitrogênio e do fósforo em um sistema de produção de leite. In: SIMPÓSIO INTERNACIONAL SOBRE GERENCIAMENTO DE RESÍDUOS AGROPECUÁRIOS E AGROINDUSTRIAIS, 3., 2013, Concórdia. Anais... Concórdia :Sbera, 2013.

PALHARES, J. C. P.; MORELLI, M.; COSTA JUNIOR, C. Impact of roughage-concentrate ratio on the water footprints of beef feedlots. Agricultural Systems, v. 155, p. 126-135, 2017.

PALHARES, J. C. P.; PEZZOPANE, J. R. M. Water footprint accounting and scarcity indicators of conventional and organic dairy production systems. Journal of Cleaner Production, v. 93, p. 299-307, 2015.

PALHARES, J.C.; A. AFONSO, E.R.; GAMEIRO, A.H. Reducing the water cost in livestock eith adoption of best pratices. Environment, Development and Sustainability. https://doi.org/10.1007/s10668-018-0117-z. 2018.

PALHARES, J.C.; MORELLI, M.; COSTA JUNIOR, C. Impact of roughage-concentrate ratio on the water footprints of beef feedlots. Agricultural Systems, n.155, p. 126-135, 2017. 
PASSOS, C.R.M.; NOGGAMI, O. Teoria dos custos. In: . Princípios de economia. $5^{\mathrm{a}}$ ed., São Paulo: Cengage Learning, 2008, p. 239-282.

PATIENCE, J.F. The importance of water in pork production. Animal Frontiers, v.2, p.28-35, 2012.

PEIXOTO, A.M.; MOURA, J.C.; DE FARIA, V.P. Bovinocultura de corte: fundamentos da exploração racional. Piracicaba: FEALQ, 1986. 345p.

PEREIRA, A. R.; ANGELOCCI, L. R.; SENTELHAS, P. C. Agrometeorologia: fundamentos e aplicações práticas. Cuiabá: Agropecuária, 2002. 487p.

PEREIRA, E.M.; SANTOS, F.A.P.; BITTAR, C.M.M.; RAMALHO, T.R.; COSTA D.F.A.; MARTINEZ, J.C. Substituição do milho por farelo de trigo ou farelo de glúten de milho na ração de bovinos de corte em terminação. Acta Scientiarum. Animal Sciences, v. 29, p. 49-55, 2007.

PETERS, G.; WIEDEMANN, S.; ROWLEY, H.; TUCKER, R. Accounting for water use in Australian red meat production. International Journal Life Cycle Assess, v. 15, p. 311- 320, 2010.

PIMENTEL, D., HOUSER, J., PREISS, E., WHITE, O., FANG, H., MESNICK, L., BARSKY, T., TARICHE, S., SCHRECK, J., ALPERT, S. Water resources: agriculture, the environment, and society. Bioscience, v. 47, p. 97-106, 1997.

POWELL, J.M.; GOURLEY, C.J.P.; COSTA, L.P. Nitrogen use efficiency: A potential performance indicator and policy tool for dairy farms. Environmental Science \& Policy, v.13, p. 217-228, 2010.

POWERS, T.L. Breakeven analysis with semifixed costs. Industrial Marketing Management, v.16, p.35-41, 1987.

PRADO, I.N.; MOREIRA, F.B.; PRADO, R.M.; ROTTA, P.P. Alimentos usados para suplementação de bovinos de corte. In: PRADO, I. N. Produção de bovinos de corte e qualidade da carne. 1. ed. Maringá: Eduem, 2010. 242p.

PRADO, I.N.; ZEVIANI, A.L.; MARQUES, J.A.; NASCIMENTO, W.G. Avaliação produtiva e econômica da substituição do milho por subprodutos industriais da mandioca na terminação de novilhas. Campo digital, v.1, p.37-47, 2006.

QUEIROZ, M.A.A.; SUSIN, I.; VAZ PIRES, A.; MENDES, C.Q.; GENTIL, R.S.; ALMEIDA, O.C.; AMARAL, R.C. do; MOURÃO, G.B. Desempenho de cordeiros e estimativa da digestibilidade do amido de dietas com diferentes fontes proteicas. Pesquisa Agropecuária Brasileira, v.43, p.1193-1200, 2008.

QUINTELLA, C.M.; TEIXEIRA, L.S.G.; KORN, M.G.A.; COSTA NETO, P.R.; TORRES, E.A.; CASTRO, M.P.; JESUS, C.A. Cadeia do biodiesel da bancada à indústria: uma visão geral com prospecção da tarefas e oportunidades para P\&D\&I. Química Nova, v.32, p.793-808, 2009. 
OLIVEIRA, R.L.; LEÃO, A.G.; ABREU, L.L.; TEIXEIRA, S.; SILVA, T.M. Alimentos Alternativos na Dieta de Ruminantes. Revista Científica de Produção Animal, v. 15, p. 141-160, 2013.

RABOBANK. Agricultural water. Rabobank industry note 534. Disponível em: http://www.agriw orlds a.com/article-archi ve/natur al-resou rces/71834 4_Rabob ank_IN534 Agricultural-Water Crowd er_Feb20 16.pdf. Acessso em: 18 fevereiro 2016.

RAN, Y., LANNERSTAD, M., HERRERO, M., VAN MIDDELAAR, C.E., DE BOER, I.J.M. Assessing water resource use in livestock production: A review of methods. Livestock Science, v.187, p. 68-79, 2016.

RENAULT, D., WALLENDER, W.W. Nutritional water productivity and diets. Agric. Water Management, v. 45, p. 275-296, 2000.

RIBEIRO, E.L. de A.; SOUSA, C.L. de; PAIVA, F.H.P. Desempenho de cordeiros alimentados com diferentes níveis de torta de nabo forrageiro em substituição ao farelo de soja. In: CONGRESSO BRASILEIRO DE ZOOTECNIA, 27, 2007. Londrina. Anais... Universidade Estadual de Londrina, 2007.

RIDOUTT, B.G.; SANGUANSRI, P.; NOLAN, M.; MARKS, N. Meat consumption and water scarity: beware of generalizations. Journal of Cleaner Production, v. 28, p. 127-133, 2012.

RIDOUTT, B.G.; SANGUANSRI, P.; HARPER, G.S. Comparing Carbon and Water Footprints for Beef Cattle Production in Southern Australia. Sustainability, v.3, p .2443-2455, 2011.

RIDOUTT, B.G.; PFISTER, S. A revised approach to water footprinting to make transparent the impacts of consumption and production on global freshwater scarcity. Global Environmental Change, v.20, p. 13-120, 2010.

RIDOUTT, B.G.; PAGE, G.; OPIE, K.; HUANG, J.; BELLOTTI, W. Carbon, water and land use footprints of beef cattle production systems in southern Australia. Journal of cleaner production, v.73, p. 24-30, 2014.

RIJSBERMAN, F. R. Water scarcity: fact or fiction? Agricultural Water Management, v.80, p. 5- 22, 2006.

ROCKSTROM, J.; LANNERSTAD, M.; FALKENMARK, M. Assessing the water challenge of new green revolution in developing countries. Proceedings of the National Academy of Sciences, v.104, p. 6253- 6260, 2007.

ROMAGUERA, M.; HOEKSTRA, A. Y.; SU, Z.; KROL, M. S.; SALAMA, M. S. Potencial of using remote sensing techniques for global assessment of water footprint of crops. Journal Remote Sensing, v.2, p.1177-1196, 2010. 
RODRIGUES, G.H.; SUSIN, I.; VAZ PIRES, A.; MENDES, C.Q.; URANO, F.S.; CASTILHO, C.J.C. Polpa cítrica em rações para cordeiros em confinamento: características da carcaça e qualidade da carne. Revista Brasileira de Zootecnia, v.37, n.10, p.1869-1875, 2008.

SAINZ, R.D. Otimização do confinamento para garantir a qualidade das carcaças e maximizar os lucros. In: SIMPÓSIO INTERNACIONAL DE NUTRIÇÃO DE RUMINANTES, 2., 2009, Botucatu. Anais... Botucatu: UNESP, 2009. p. 140- 155.

SARTORELLO, G.L. Desenvolvimento de modelo de cálculo e de indicador de custos de produção para bovinos de corte em confinamento. 2016. 190p. Dissertação (Mestrado em Ciências) - Faculdade de Medicina Veterinária e Zootecnia, Pirassununga, 2016.

SCARASSATI, D.; CARVALHO, R.F.; DELGADO, V.L.; CONEGLIAN, C.M.R.; BRITO, N.N.; TONSO, S.; DRAGONI SOBRINHO, G.; PELEGRINE, R. Tratamento de efluentes de matadouros e frigoríficos. In: III FÓRUM DE ESTUDOS CONTÁBEIS, Rio Claro, 2003. Anais... Rio Claro, 2003.

SCHNEIDER, V.E.; CARRA, S.H.Z. Pegada hídrica dos suínos abatidos na região do Corede Serra, RS, Brasil. Ambiente \& Água, v. 11, p. 211-224, 2016.

SENAI. Princípios básicos de produção mais limpa em matadouros frigoríficos. Série Manuais de Produção Mais Limpa. Centro Nacional de Tecnologias Limpas, Porto Alegre, 2003.

SHI, R.; UKAEW, S.; ARCHER, D.W.; LEE, J.H.; PEARLSON, M.; LEWIS, K.C.; SHONNARD, D. Life Cycle Water Footprint Analysis for Rapeseed Derived Jet Fuel in North Dakota. ACS Sustainable Chemistry \& Engineering, v. 5, p. 3845-3854, 2017

SILVA, A.N. Manejo de resíduos sólidos industriais: frigorífico de Araguaína/TO. 2011. 58p. Monografia (Trabalho de conclusão de curso em Administração) - Faculdade de Economia, Administração e Contabilidade, Universidade de Brasília, Palmas, 2011.

SILVA, V de P.R. da; ALEIXO, D de O.; DANTAS NETO, J; MARACAJÁ, K.F.B.; ARAUJO, L.E. de. Uma medida de sustentabilidade ambiental: Pegada Hídrica. Revista Brasileira de Engenharia Agrícola e Ambiental, v.17, p.100-105, 2013.

SILVA, W.M. da; SOUZA, F.P.; RODRIGUES, J.C.W.; SILVA, V.V. da; BORDINHON, A.M. Aproveitamento de coprodutos regionais na alimentação de animais domésticos na agricultura familiar. Cadernos de Agroecologia, v. 10, 2016.

SILVEIRA, R.N.; BERCHIELLI, T.T.; CANESIN, R.C.; MESSANA, J.D.; FERNANDES, J.J.R.; VAZ PIRES, A. Influência do nitrogênio degradável no rúmen sobre a degradabilidade in situ, os parâmetros ruminais e a eficiência de síntese microbiana em novilhos alimentados com cana-deaçúcar. Revista Brasileira de Zootecnia, v. 38, p. 570-579, 2009.

SIPP, A.M. Análise de viabilidade econômica de bovinos de corte em uma propriedade rural. 2011. 57f. Monografia (Trabalho de conclusão de curso de Ciência Contábeis) - Universidade Tecnológica Federal do Paraná, Pato Branco, 2011. 
SOBERON, M.A.; KETTERINGS, Q.M.; RASMUSSEN, C.N.; CZYMMEK, K.J. Whole farm nutrient balance calculator for New York Dairy Farms. Natural Sciences Education, v. 42, p. 5767, 2013.

STELZLENI, A.M.; SEGERS, J.R.; STEWART JR, R.L. Long-term use of corn coproducts as a source of protein in beef finishing diets and the effects on carcass characteristics and round muscle quality. Journal of Animal Science, v. 94, p. 227-239, 2016.

TILMAN, D.; CASSMAN, K.G.; MATSON, P.A.; NAYLOR, R.; POLASKY, S. Agricultural sustainability and intensive production practices. Nature, v.418, p. 671-677, 2002.

TOM, M.S.; FISCHBECK, P.S.; HENDRICKSON, C.T. Energy use, blue water footprint, and greenhouse gas emissions for current food consumption patterns and dietary recommendations in the US. Environment Systems and Decisions, v. 36, p. 92-103, 2016.

UNITED NATIONS ENVIRONMENT PROGRAMME. UNEP. DEPA - DANISH ENVIRONMENTAL PROTECTION AGENCY; COWI Consulting Engineers and Planners AS, Denmark. Cleaner production assessment in meat processing. Paris: UNEP, 2000.

UNITED STATES DEPARTMENT OF AGRICULTURE. USDA. Agricultural Projections to 2025. Office of the Chief Economist, World Agricultural Outlook Board, U.S. Department of Agriculture. Prepared by the Interagency Agricultural Projections Committee. Long-term Projections Report OCE-2016-1. 2016. 99 p.

UTLEY, P.R.; BRADLEY, N.W.; BOLING, J.A. Effect of restricted water intake on feed intake nutrient digestibility and nitrogen metabolism in steers. Journal of Animal Science, v. 31, p. 130$135,1970$.

VALADARES FILHO, S.C.; MACHADO, P.A.S.; CHIZZOTTI, M.L. et al. CQBAL 3.0. Tabelas Brasileiras de Composição de Alimentos para Bovinos. Disponível em www.ufv.br/cqbal. Acesso em 18 de outubro de 2017.

VALENÇA, R.L.; FERREIRA, A.C.D.; DO SANTOS, A.C.P.; DA SILVA, B.C.D.; OLIVEIRA, V.S.; SANTANA NETO, J.A.; LIMA, J.U.N.; OLIVEIRA, E.S. Orange peel silage pre-dried and their use in ruminant feed - Review. Revista de Ciências Agroveterinárias, v.15, p.68-73, 2016.

VALENTE, E.; CHIZZOTTI, M. L.; DE OLIVEIRA, C. V. R.; GALVÃO, M. C.; DOMINGUES, S. S.; RODRIGUES, A. D. C.; LADEIRA, M. M. Intake, physiological parameters and behavior of Angus and Nellore bulls subjected to heat stress. Ciências Agrárias, v.36, p. 4565-4574, 2015.

VAN CLEEF, E.H.; D’ÁUREA, A.P.; FÁVARO, V.R.; VAN CLEEF, F.O.S.; BARDUCCI, R.S.; ALMEIDA, M.T.C.; MACHADO NETO, O.R.; EZEQUIEL, J.M.B. Effects of dietary inclusion of high concentrations of crude glycerin on meat quality and fatty acid profile of feedlot fed Nellore bulls. PLoS One, v. 12, 2017.

VANHAM, D.; BIDOGLIO, G. A review on the indicator water footprint for the EU28. Ecological Indicators, v.26, p.61-75, 2013. 
VARIAN, H. Microeconomia- Princípios Básicos- Uma abordagem moderna. 6 ed. Rio de Janeiro: Campus Elsevier, 2003.

WALLACE, J. Increasing agricultural water use efficiency to meet future food production. Agriculture, Ecosystems \& Environment, v.82, p.105-119, 2000.

WILKINSON, J.M. Re-defining efficiency of feed use by livestock. Animal, v.5, p. 1014-1022, 2011.

WILLERS, C.D.; FERRAZ, S.P.; CRAVALHO, L.S.; SI, L.B. Determination of indirect water consumption and suggestions for cleaner production initiatives for the milk-producing sector in a Brazilian middle-sized dairy farming. Journal of Cleaner Production, v.72, p. 146-152, 2014.

WILLIAMS, C.M. Influence of winter conditions on the feed and water intake of feedlot steers. Journal of Animal Science, v. 18, p. 1177 - 1178, 1959.

WINCHESTER, C. F.; MORRIS, M. J. Water intake rates of cattle. Journal of Animal Science, v. 15 , p. $722-740,1956$.

WORLD BANK. Pollution Prevention and Abatement Handbook: Toward Cleaner Production. Washington, DC: World Bank, 1998. 457p.

ZANETTI, D. Mineral release from different feeds, mineral balance for Nellore young bulls, and prediction of water intake by beef cattle. 2017.39f. Tese (Doutorado em Zootecnia) Universidade Federal de Viçosa, Viçosa, 2017.

ZHAO, X.; CHEN, B.; YANG, Z. F. National water footprint in an input-output framework-A case study of China 2002. Ecological Modeling, v.220, p.245-253, 2009.

ZILIOTTO, M.R.; SILVEIRA, C.; CAMARGO, M.E.; MOTTA, M.E.V.; FILHO, W.P. Comparação do Custo de Produção de Bovinocultura de Corte: Pasto versus Confinamento. In: VII SIMPÓSIO DE EXCELÊNCIA EM GESTÃO E TECNOLOGIA, Resende, 2010. Anais... Resende, 2010.

ZONDERLAND-THOMASSEN, M.A.; LIEFFERING, M.; LEDGARD. S.F. Water footprint of beef cattle and sheep produced in New Zealand: water scarity and eutrophication impacts. Journal of cleaner production, v. 73, p. 253-262, 2014. 


\section{Apêndices}

Apêndice A- Formulário eletrônico enviado aos responsáveis pelas fazendas.

\section{DIAGNÓSTICO CONFINAMENTOS}

PROJETO PEGADA HÍDRICA

DATA:

ENTREVISTADOR:

Dados do Produtor

Nome:

2. Dados da Propriedade

Área total da propriedade (considerando o confinamento e as outras áreas):

Área ocupada pelo o confinamento: ha

3. Dados da Produção

Quais as principais atividades que desenvolve na propriedade?

\section{Confinamento Bovino - (Referente ao último ciclo de confinamento)}

Atividade principal ( ) Sim ( ) Não

Plantel (capacidade de instalação)

Período do último confinamento- dia/mês a dia/mês

Peso de Entrada dos Animais-

Peso de Saída dos Animais-

Raças dos Animais Confinados

Quem elaborou a dieta dos animais? ( ) Técnico ( ) Agroindústria ( ) Produtor

Qual a ingestão de matéria seca dos animais ao longo do confinamento?

Período dias / Kg de MS por cabeça

Período dias / Kg de MS por cabeça

Período dias / Kg de MS por cabeça

Período dias / Kg de MS por cabeça

Relação Volumoso/Concentrado da dieta (\%):

\section{ALIMENTOS UTILIZADOS NA DIETA}

\begin{tabular}{|l|l|l|l|}
\hline Alimento & $\begin{array}{l}\text { \% na } \\
\text { Dieta }\end{array}$ & $\begin{array}{l}\text { Produz na Propriedade } \\
\text { (Se sim, qual porcentagem } \\
\text { do consumido) }\end{array}$ & $\begin{array}{l}\text { Da parte que compra fora, } \\
\text { qual a procedência } \\
\text { (Cidade/estado) }\end{array}$ \\
\hline & & & \\
\hline & & & \\
\hline
\end{tabular}

Qual o consumo de água por animal por dia- (litros)

( ) Não Sei 
Como é feito o manejo do esterco.

Qual o destino do esterco: ( ) Pastagem ( ) Lavoura ( ) Outro:

No uso do esterco como fertilizante:

Já fez alguma análise para saber as concentrações de NPK ( ) Sim ( ) Não

Qual a frequiência de utilização do esterco (dias, semanas, mês)

Qual a quantidade aplicada? (Ton/ha)

É feito o cálculo de adubação para o uso do esterco? ( ) Sim ( ) Não

Uso adubo químico na mesma área que recebe o esterco? ( ) Sim ( ) Não. Se sim, qual a

fórmula e a recomendação em Ton/ha

Outra Atividade Animal - Qual:

Atividade principal ( ) Sim ( ) Não

Sistema de criação ( ) Confinado ( ) Semi-Confinado( ) Pastejo

Plantel:

Quem elabora a ração dos animais? ( ) Técnico ( ) Agroindústria ( ) Produtor

Plantel

N. de vacas:

gestação:

lactação:

N. de bezerros:

N. de touros:

N. de machos:

N. de aves alojadas: $\mathrm{N}$ de suínos:

PRODUÇÃO AGRÍCOLA

Tipo de cultura área plantada (ha) prod. última safra

milho

soja

pastagem

cana

laranja

reflorestamento

Outros

4. Recursos Naturais

4.1. ÁGUA

Tem fonte de água superficial (nascente, rio etc.) na propriedade? ( ) Não ( ) Sim, quantas? Essa fonte é ( ) Permanente ( ) Anual ?

A água da fonte é usada para que?

Distribuição de água: ( ) Gravidade ( ) Bombeamento ( ) Outro:

Tem poço de água na propriedade? ( ) Não ( )Sim, quantos?

Qual a profundidade do poço? $\mathrm{m}$

A água do poço é usada para que?

Tem açudes na propriedade? ( ) Não ( ) Sim, quantos?

Qual o tamanho deste(s)? 
É realizada análises de água? ( ) Não ( ) Sim

Com que frequência?

Quem coleta a amostra?

Onde é feita a análise?

Existe algum Rio que passa na propriedade? ( ) Não ( )Sim, nome:

A propriedade tem outorga de uso da água- ( ) Sim ( ) Não

\subsection{SOLO}

Tipos de solo da propriedade (indicar a porcentagem de cada um)

Com que frequência faz análise de solo?

( ) Nunca fez ( ) Duas/ano ( ) Uma/ano ( ) Outra:

Quem faz a coleta de solo para análise? 
Apêndice B- Características das dietas utilizadas nos nove confinamentos comerciais.

\begin{tabular}{|c|c|c|c|}
\hline \multicolumn{4}{|c|}{ Fazendas } \\
\hline \multicolumn{2}{|c|}{1} & \multicolumn{2}{|c|}{2} \\
\hline Ingrediente & $\begin{array}{c}\text { Proporção na dieta } \\
(\%)\end{array}$ & Ingrediente & $\begin{array}{c}\text { Proporção na dieta } \\
(\%)\end{array}$ \\
\hline Milho & 32,7 & Bagaço de cana & 12,8 \\
\hline $\begin{array}{l}\text { Farelo de } \\
\text { amendoim }\end{array}$ & 9,8 & Silagem de milho & 4,5 \\
\hline Polpa cítrica & 7,1 & Torta de algodão & 4,3 \\
\hline Gérmen de milho & 34,9 & Farelo de soja & 6,4 \\
\hline Bagaço de cana & 11,6 & Ureia & 0,7 \\
\hline Núcleo & 2,9 & Calcário & 0,8 \\
\hline Ureia & 1,1 & Núcleo & 1,6 \\
\hline- & - & Milho floculado & 46,32 \\
\hline- & - & Gérmen de milho & 22,7 \\
\hline \multicolumn{2}{|c|}{3} & \multicolumn{2}{|r|}{4} \\
\hline Ingrediente & $\begin{array}{c}\text { Proporção na dieta } \\
(\%)\end{array}$ & Ingrediente & $\begin{array}{c}\text { Proporção na dieta } \\
(\%)\end{array}$ \\
\hline Água & 3,9 & Milho floculado & 54,0 \\
\hline Caroço de algodão & 8,2 & Silagem de milho & 6,0 \\
\hline Milho grão seco & 38,1 & Promil & 14,0 \\
\hline Núcleo & 4,7 & Melaço de soja & 15,0 \\
\hline Silagem de Milho & 25,2 & Bagaço de cana & 8,0 \\
\hline $\begin{array}{l}\text { Silagem de capim } \\
\text { (Mombaça) }\end{array}$ & 13 & Núcleo adaptação & 3,0 \\
\hline Silagem de sorgo & 3,7 & Núcleo terminação & 3,0 \\
\hline Farelo de soja & 3,2 & - & - \\
\hline
\end{tabular}

\begin{tabular}{cccc}
\hline \multicolumn{2}{c}{} & \multicolumn{6}{c}{$\mathbf{6}$} \\
\hline Ingrediente & $\begin{array}{c}\text { Proporção na dieta } \\
(\mathbf{\%})\end{array}$ & Ingrediente & $\begin{array}{c}\text { Proporção na dieta } \\
(\boldsymbol{\%})\end{array}$ \\
\hline Milho & 37,7 & Silagem de milho & 26,7 \\
Torta de algodão & 8,7 & Milho seco moído & 42,6 \\
Caroço de algodão & 8,3 & WDG & 24,7 \\
Melaço de soja & 13,0 & Proteína de milho & 1,2 \\
& 26,0 & e sorgo & 1,0 \\
Earlage & 6,3 & Bandinha de milho & 0,9 \\
Núcleo & - & e soja & 3,0 \\
- & & Convert H & Núcleo mineral \\
\hline
\end{tabular}

\begin{tabular}{cccc}
\multicolumn{2}{c}{} & \multicolumn{2}{c}{$\mathbf{8}$} \\
\hline Ingrediente & $\begin{array}{c}\text { Proporção na dieta } \\
(\boldsymbol{\%})\end{array}$ & Ingrediente & $\begin{array}{c}\text { Proporção na dieta } \\
(\boldsymbol{\%})\end{array}$ \\
\hline Silagem de milho & 27,2 & Silagem de milho & 13,0
\end{tabular}




\begin{tabular}{|c|c|c|c|}
\hline Sorgo & 26,6 & Casca de soja & 10,0 \\
\hline Caroço de algodão & 15,4 & Melaço de soja & 10,0 \\
\hline Milho & 8,0 & Milho grão & 55,0 \\
\hline Milheto & 6,9 & Torta de algodão & 4,0 \\
\hline Torta de algodão & 5,2 & Caroço de algodão & 4,0 \\
\hline Resíduo de soja & 0,4 & Ureia & 2,0 \\
\hline Bagaço de cana & 1,81 & Núcleo & 2,0 \\
\hline Resíduo de milho & 2,2 & - & - \\
\hline Núcleo & 2 & - & - \\
\hline Farelo de soja & 0,4 & - & - \\
\hline Ureia & 0,4 & - & - \\
\hline \multicolumn{4}{|c|}{9} \\
\hline \multicolumn{2}{|c|}{ Ingrediente } & \multicolumn{2}{|c|}{$\begin{array}{c}\text { Proporção na dieta } \\
(\%)\end{array}$} \\
\hline \multicolumn{2}{|c|}{ Silagem de milho } & \multicolumn{2}{|c|}{22,5} \\
\hline \multicolumn{2}{|c|}{ Sorgo } & \multicolumn{2}{|c|}{51,0} \\
\hline \multicolumn{2}{|c|}{ Capulho de algodão } & \multicolumn{2}{|c|}{5,3} \\
\hline \multicolumn{2}{|c|}{ Pré-mistura de minerais } & \multicolumn{2}{|c|}{6,2} \\
\hline
\end{tabular}

